University of Nebraska - Lincoln

DigitalCommons@University of Nebraska - Lincoln

U.S. National Park Service Publications and

Papers

National Park Service

$9-2020$

\title{
Agate Fossil Beds National Monument, Paleontological Resources Management Plan (Public Version)
}

\author{
Scott Kottkamp \\ United States National Park Service, Agate Fossil Beds National Monument \\ Vincent L. Santucci \\ United States National Park Service, Geologic Resources Division \\ Justin S. Tweet \\ United States National Park Service \\ Jessica De Smet \\ University of Oregon \\ Ellen Stark \\ United States National Park Service, Badlands National Park \\ Follow this and additional works at: https://digitalcommons.unl.edu/natlpark \\ Part of the Environmental Education Commons, Environmental Policy Commons, Environmental \\ Studies Commons, Fire Science and Firefighting Commons, Leisure Studies Commons, Natural Resource \\ Economics Commons, Natural Resources Management and Policy Commons, Nature and Society \\ Relations Commons, Other Environmental Sciences Commons, Other Life Sciences Commons, \\ Paleontology Commons, Physical and Environmental Geography Commons, Public Administration \\ Commons, and the Recreation, Parks and Tourism Administration Commons
}

Kottkamp, Scott; Santucci, Vincent L.; Tweet, Justin S.; De Smet, Jessica; and Stark, Ellen, "Agate Fossil Beds National Monument, Paleontological Resources Management Plan (Public Version)" (2020). U.S. National Park Service Publications and Papers. 238.

https://digitalcommons.unl.edu/natlpark/238

This Article is brought to you for free and open access by the National Park Service at DigitalCommons@University of Nebraska - Lincoln. It has been accepted for inclusion in U.S. National Park Service Publications and Papers by an authorized administrator of DigitalCommons@University of Nebraska - Lincoln. 
National Park Service

U.S. Department of the Interior

\section{Agate Fossil Beds National Monument}

\section{Paleontological Resources Management Plan}

(Public Version)

Natural Resource Report NPS/AGFO/NRR—2020/2172

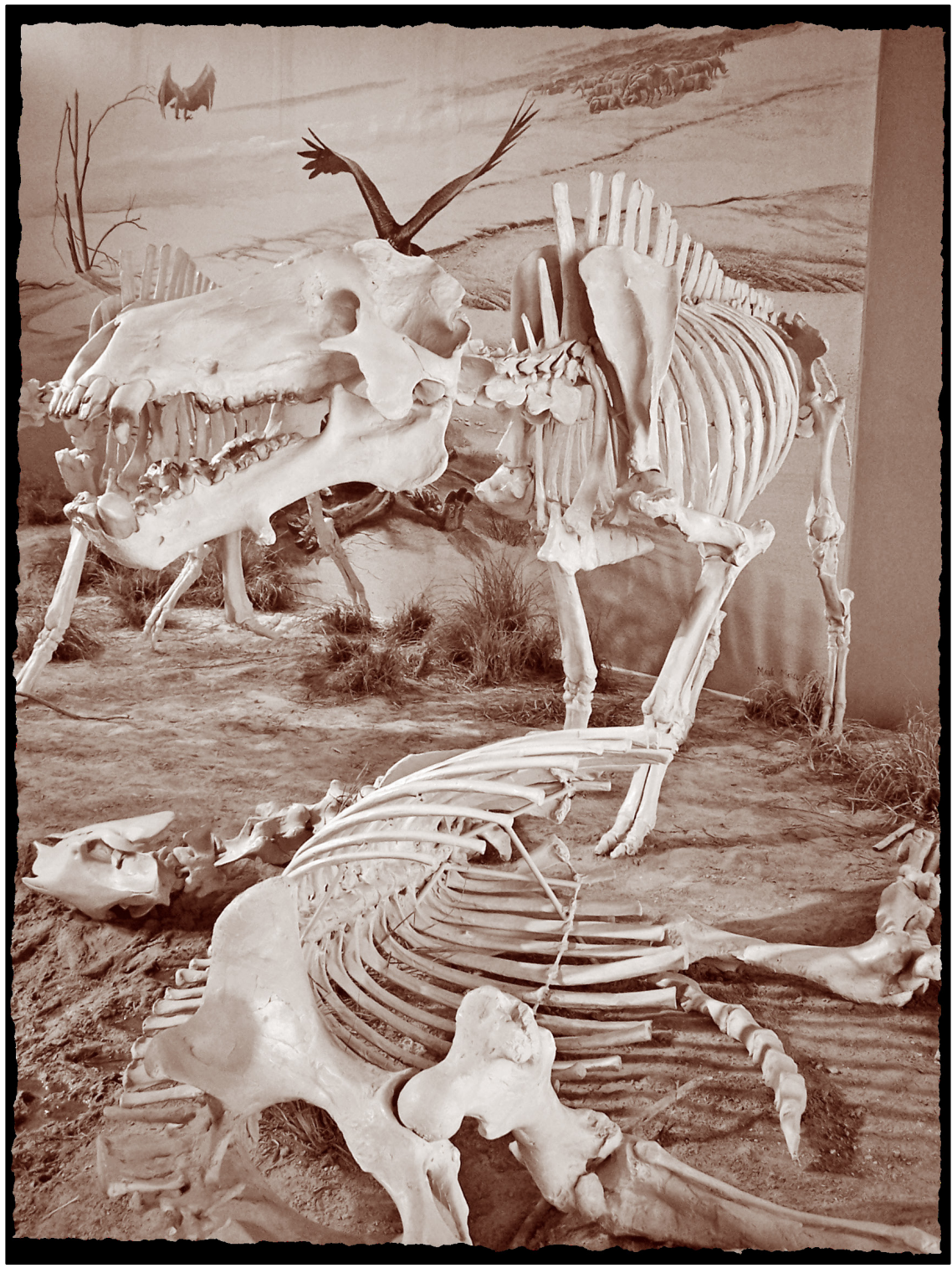




\section{ON THE COVER}

A cast skeleton of Daeodon, standing over a cast skeleton of Moropus, on display at the AGFO Visitor Center. NPS Photo. 


\section{Agate Fossil Beds National Monument}

\section{Paleontological Resources Management Plan (Public Version)}

Natural Resource Report NPS/AGFO/NRR—2020/2172

Scott Kottkamp ${ }^{1}$, Vincent L. Santucci ${ }^{2}$, Justin S. Tweet ${ }^{3}$, Jessica De Smet ${ }^{4}$, and Ellen Starck ${ }^{5}$

${ }^{1}$ Agate Fossil Beds National Monument

301 River Road

Harrison, Nebraska 69346

${ }^{2}$ National Park Service

Geologic Resources Division

1849 "C" Street, NW

Washington, D.C. 20240

${ }^{3}$ National Park Service

9149 79th St. S.

Cottage Grove, Minnesota 55016

${ }^{4}$ University of Oregon

Hopkins/Davis Lab

Eugene, Oregon 97403

${ }^{5}$ Badlands National Park

25216 Ben Reifel Road

Interior, South Dakota 57750

September 2020

U.S. Department of the Interior

National Park Service

Natural Resource Stewardship and Science

Fort Collins, Colorado 
The National Park Service, Natural Resource Stewardship and Science office in Fort Collins, Colorado, publishes a range of reports that address natural resource topics. These reports are of interest and applicability to a broad audience in the National Park Service and others in natural resource management, including scientists, conservation and environmental constituencies, and the public.

The Natural Resource Report Series is used to disseminate comprehensive information and analysis about natural resources and related topics concerning lands managed by the National Park Service. The series supports the advancement of science, informed decision-making, and the achievement of the National Park Service mission. The series also provides a forum for presenting more lengthy results that may not be accepted by publications with page limitations.

All manuscripts in the series receive the appropriate level of peer review to ensure that the information is scientifically credible, technically accurate, appropriately written for the intended audience, and designed and published in a professional manner.

This report received informal peer review by subject-matter experts who were not directly involved in the collection, analysis, or reporting of the data.

Views, statements, findings, conclusions, recommendations, and data in this report do not necessarily reflect views and policies of the National Park Service, U.S. Department of the Interior. Mention of trade names or commercial products does not constitute endorsement or recommendation for use by the U.S. Government.

This report is available in digital format from the Northern Great Plains Inventory \& Monitoring Network and the Natural Resource Publications Management website. If you have difficulty accessing information in this publication, particularly if using assistive technology, please email irma@,nps.gov.

Please cite this publication as:

Kottkamp, S., V. L. Santucci, J. S. Tweet, J. De Smet, and E. Starck. 2020. Agate Fossil Beds National Monument: Paleontological resources management plan (public version). Natural Resource Report NPS/AGFO/NRR—2020/2172. National Park Service, Fort Collins, Colorado. https://doi.org/10.36967/nrr-2278685.

NPS 165/173719, September 2020 


\section{Contents}

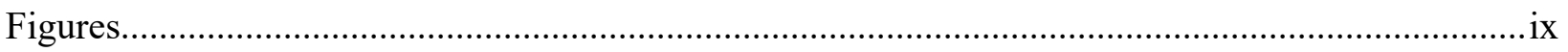

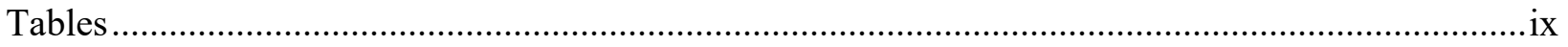

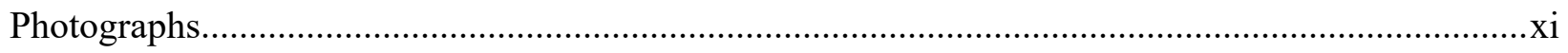

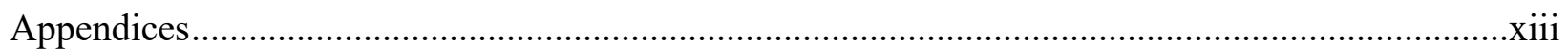

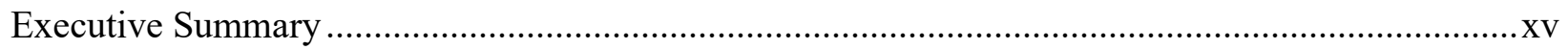

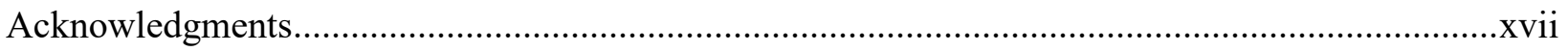

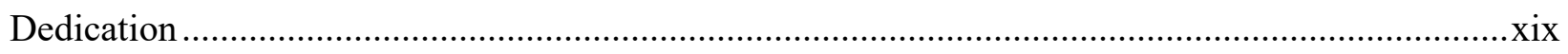

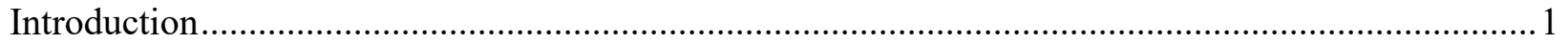

Significance of Paleontological Resources at AGFO ........................................................... 1

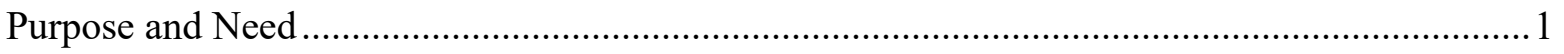

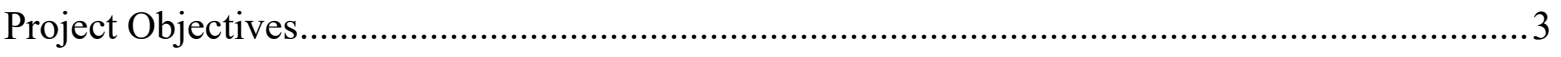

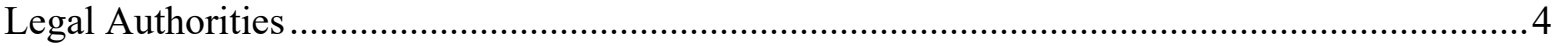

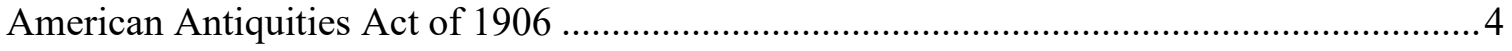

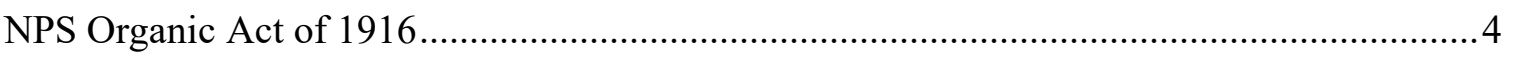

Archaeological Resources Protection Act (ARPA) of 1979 .............................................. 4

Federal Cave Resources Protection Act (FCRPA) of 1988 ................................................5

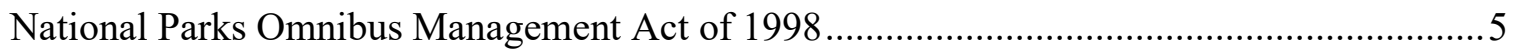

Assessment of Fossil Management on Federal and Indian Lands, A Report to Congress by the Secretary of the Interior (May 2000) ......................................................... 5

Omnibus Public Lands Act of 2009 (HR 146 \& PL 111-11): Subtitle D -

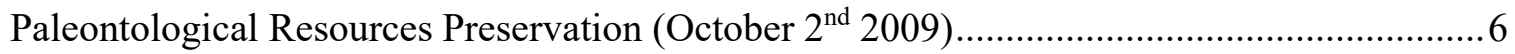

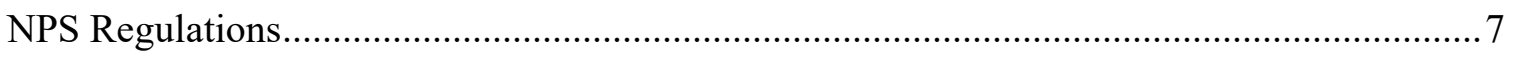

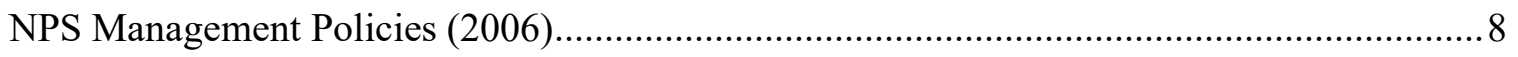

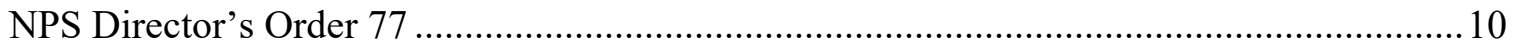

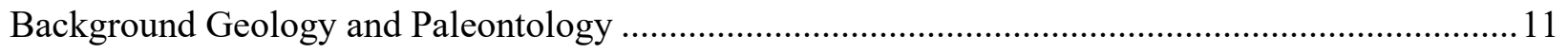

Overview of Paleontological Resources and Localities at AGFO ......................................... 11 


\section{Contents (continued)}

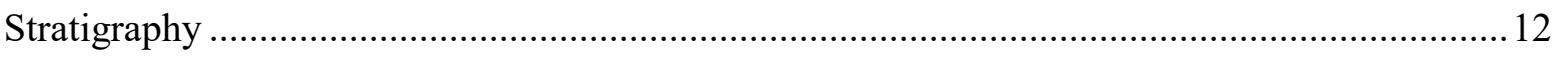

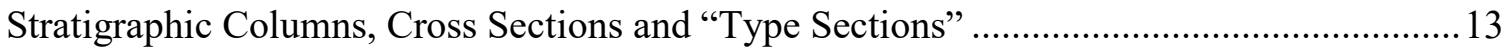

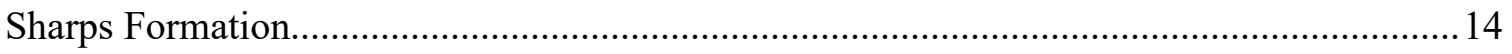

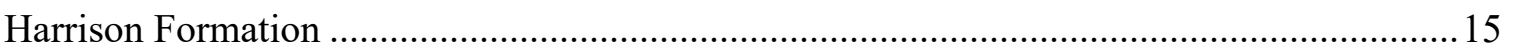

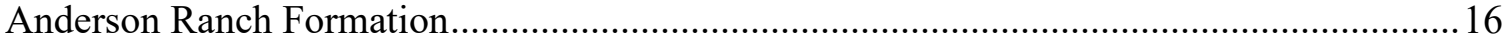

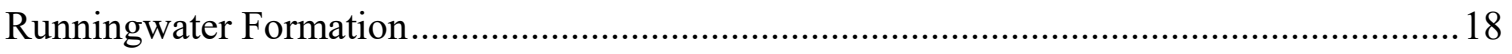

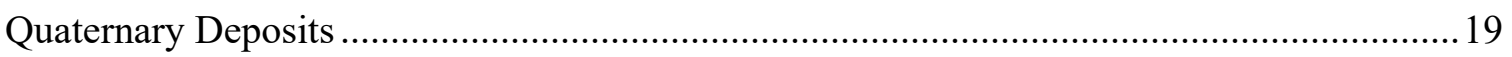

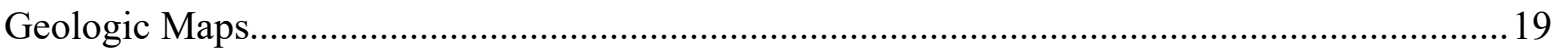

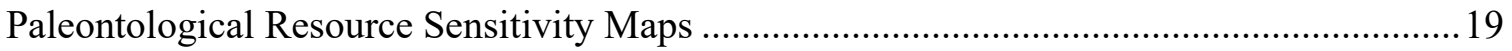

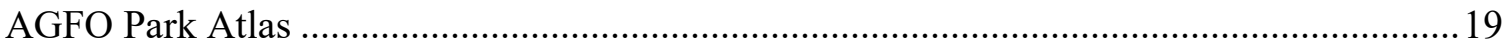

History of Paleontological Work at AGFO …................................................................... 21

Current Hypothesis on Origin of AGFO Bonebed ............................................................22

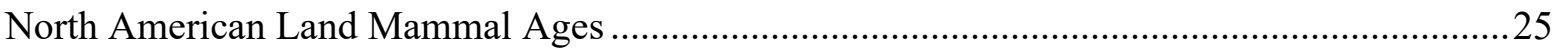

AGFO's Role in Defining the Arikareean NALMA and Miocene Epoch ............................22

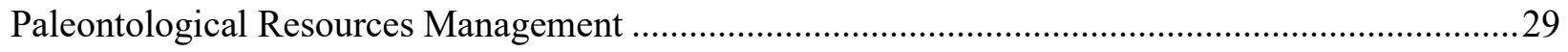

Strategic Goals Relating to Paleontological Resources........................................................29

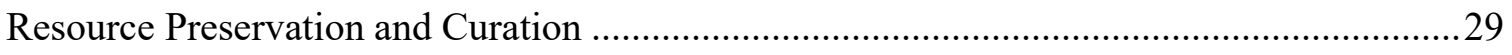

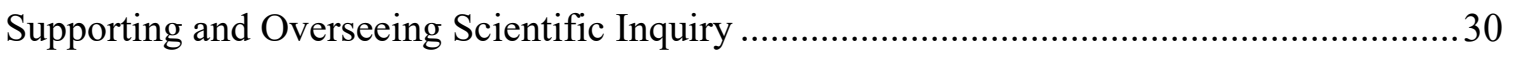

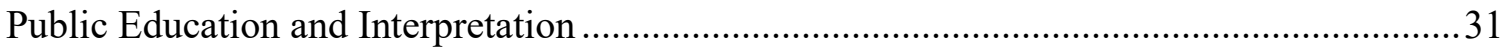

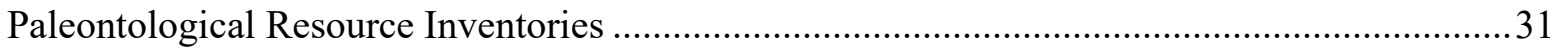

When Are Specimens Collected During Inventory? ........................................................ 33

Documenting and Numbering New Fossil Localities....................................................... 34

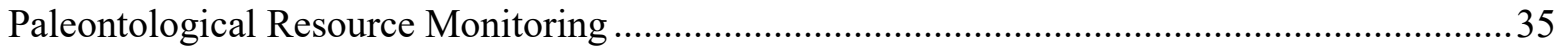

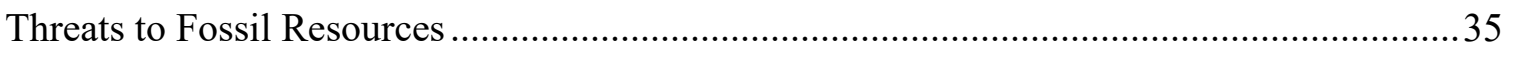

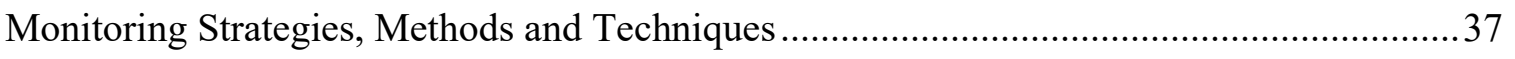

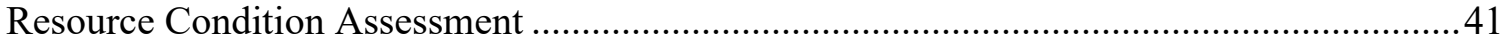




\section{Contents (continued)}

Disturbance and/or Recovery of Paleontological Resources During Other

Activities 42

Other Considerations Related to Paleontological Resources Monitoring .44

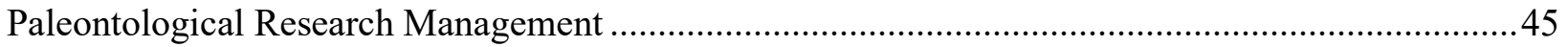

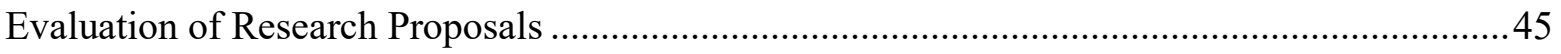

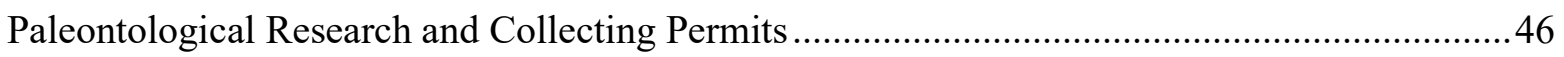

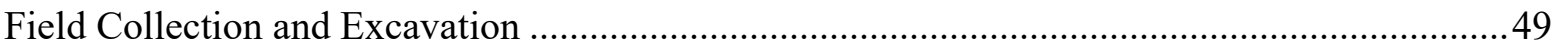

Special Considerations for the Stenomylus Quarry ........................................................5

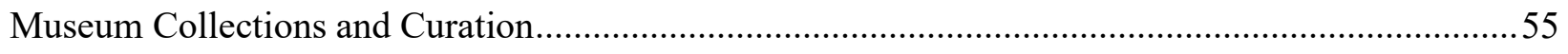

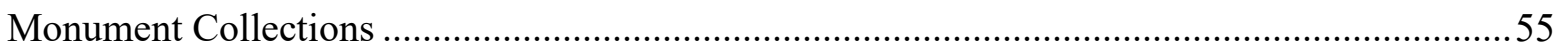

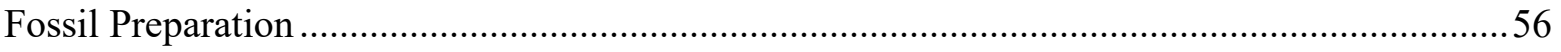

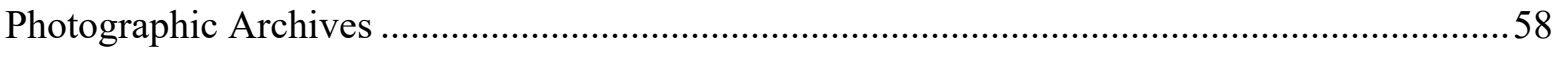

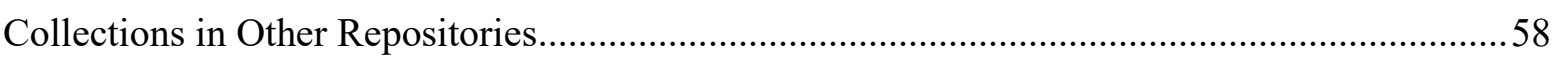

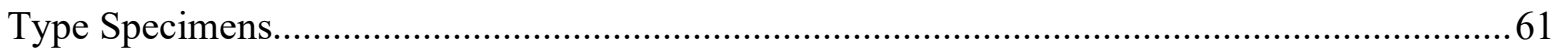

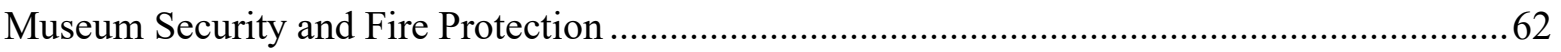

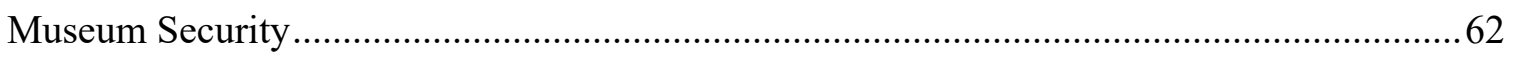

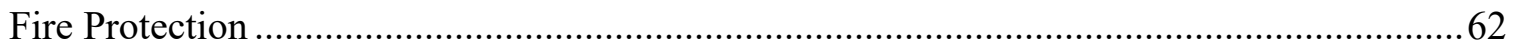

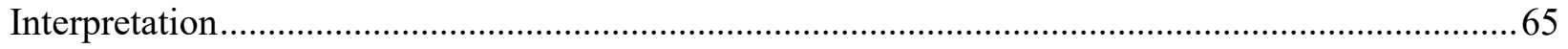

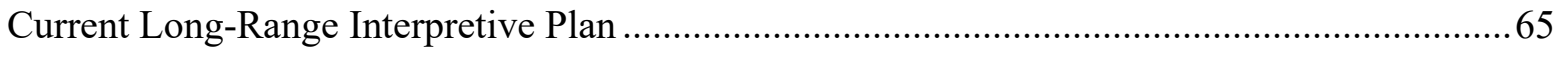

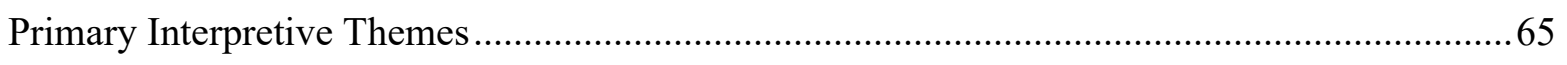

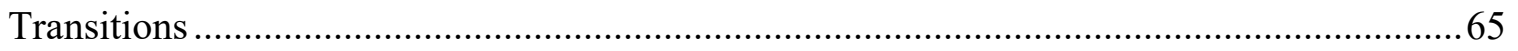

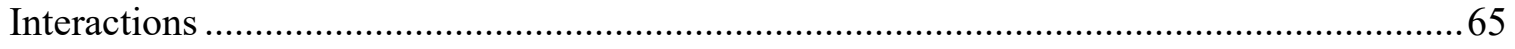

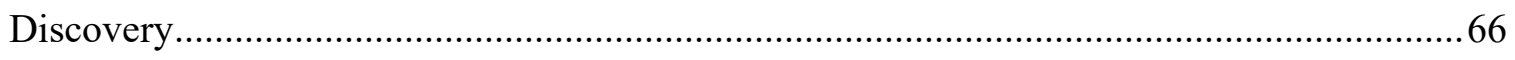

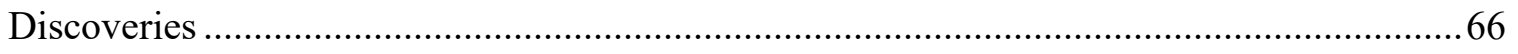

Interpretation Programs and Resources Related to Paleontological Resources ..........................66

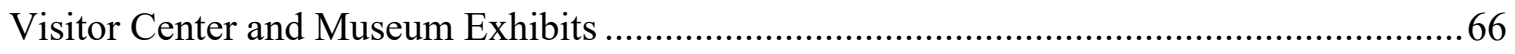




\section{Contents (continued)}

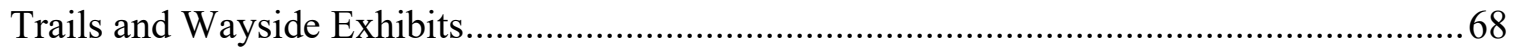

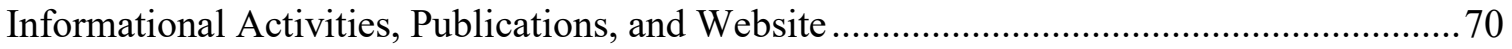

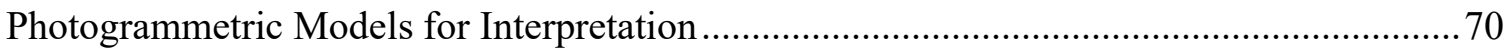

Staff Interaction with Guests and Special Events and Programs....................................... 71

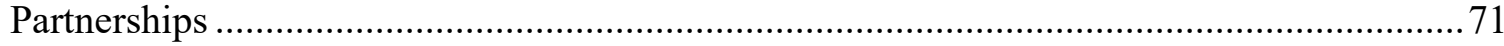

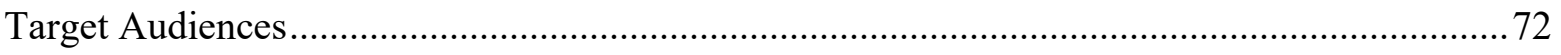

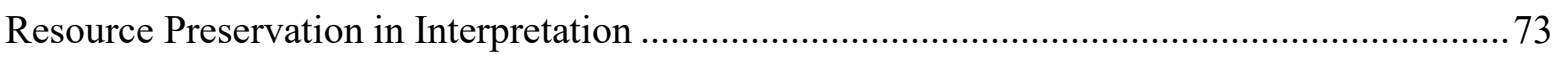

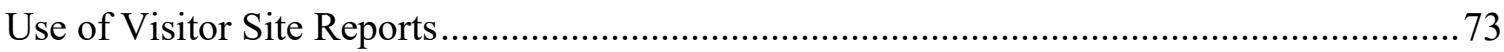

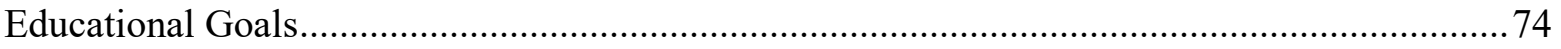

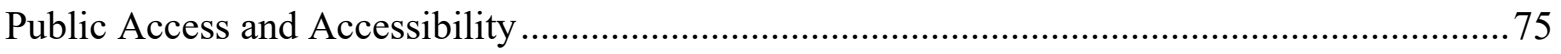

Relation of Paleontological Resources to Other AGFO Programs and Resources ............................77

Interactions of Park Divisions with Paleontological Resources ............................................... 77

Impact of Paleontological Resource Management on Other AGFO Resources......................... 79

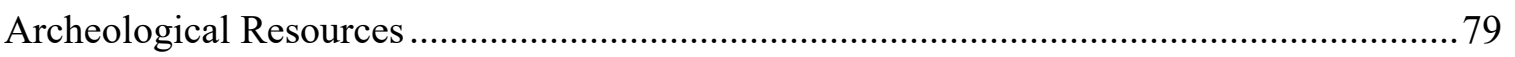

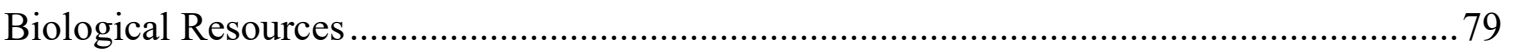

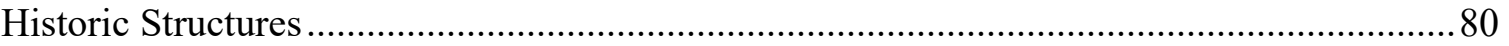

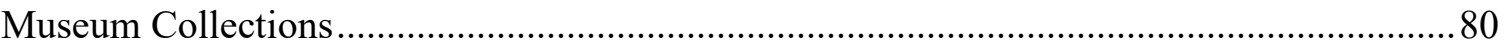

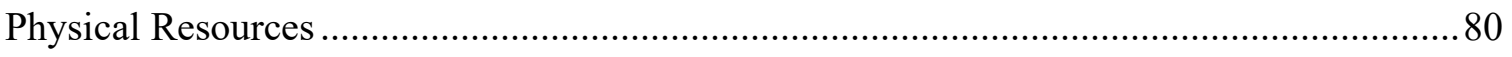

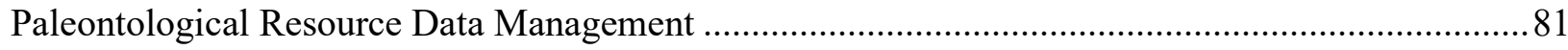

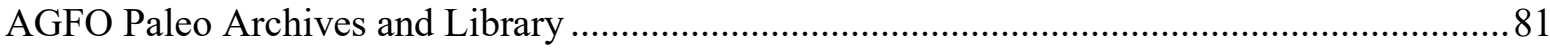

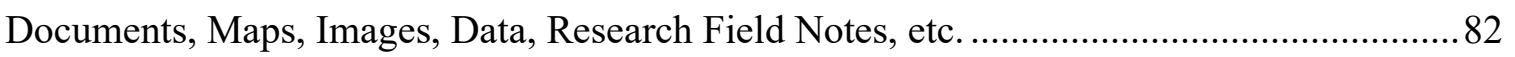

Historic Records, Letters and Correspondence .......................................................... 84

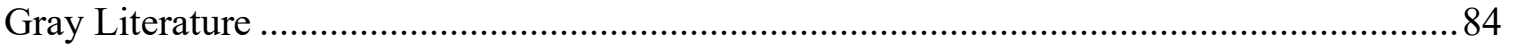

NPS Paleontology Program Archives and Library .............................................................. 84

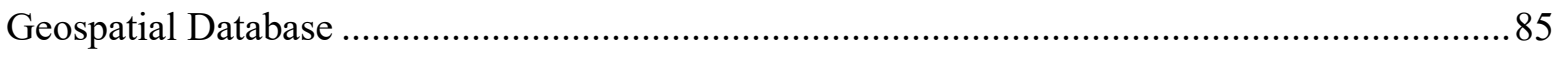

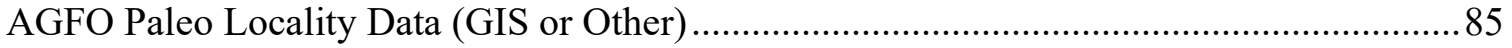




\section{Contents (continued)}

Confidentiality of Sensitive Paleontological Resource Information ..................................... 85

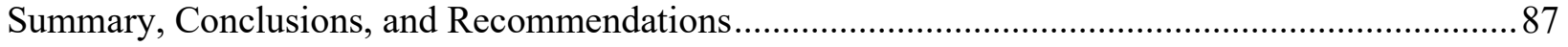

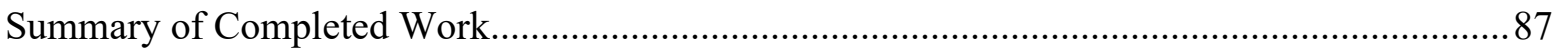

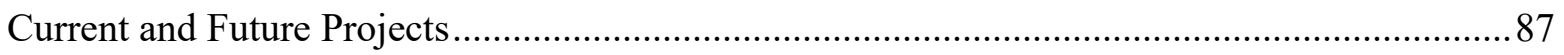

Inventory and Reorganization of AGFO Records, Archives, and Library …........................ 87

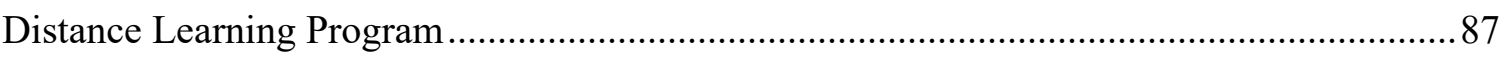

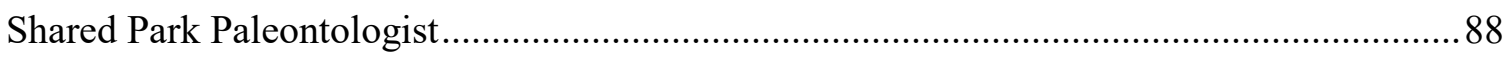

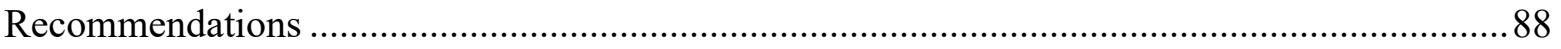

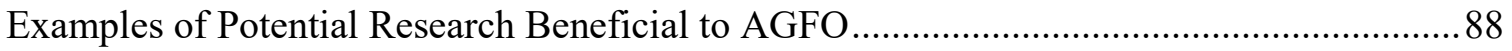

Examples of Potential Intern or Volunteer Projects ...................................................... 90

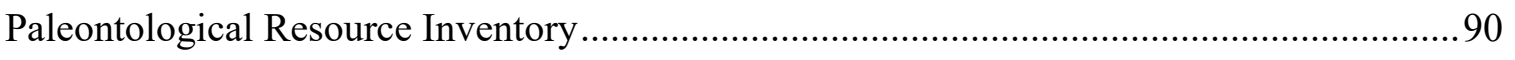

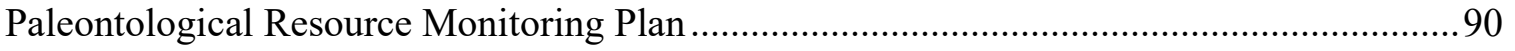

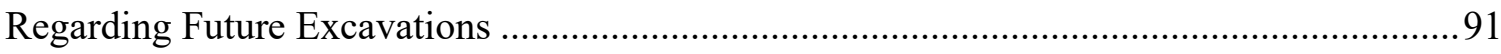

Potential Improvements and Recommendations for Interpretation ....................................91

Desired Future State of AGFO Archives and Recommendations ......................................92

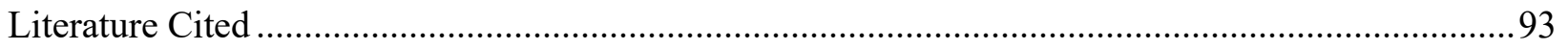





\section{Figures}

Page.

Figure 1. Map of AGFO, showing location of trails, Visitor Center, and nearby highways. .11

Figure 2 AGFO Print Park Atlas, Geology Layer.

Figure 3. Timeline adapted from Woodburne (2004) showing NALMA and NALMA

subdivisions, with a timeline for the entire Cenozoic for comparison.

Appendix A Figure 1. Map of the major excavation sites at Beardog Hill, Carnegie Hill, North Ridge, and University Hill, from Hunt (1984).

Appendix D Figure 1. The front side of the proposed AGFO Visitor Site Report form.

Appendix D Figure 2. The reverse side of the proposed AGFO Visitor Site Report form.

\section{Tables}

Page

Table 1. Stratigraphic units exposed at AGFO. 13

Table 2. Lithology, environmental interpretations, and biota from the Anderson Ranch and Harrison formations at AGFO.

Table 3. Fossil taxa named from specimens found within AGFO.

Appendix A Table 1. Summary of excavations at Agate Springs Ranch 1904-1923, adapted from Evans-Hatch (2008). 105

Appendix A Table 2. Chronology of University of Nebraska excavations, 1981-1986. 106 Appendix I Table 1. Descriptions of paleontological localities. 135 



\section{Photographs}

Photo 1. The Stenomylus Quarry, displaying cross-bedded and poorly indurated sandstone layers, characteristic of this portion of the Harrison Formation. 16

Photo 2. Photograph of Carnegie Hill Southwest Quarry.

Photo 3. Historical photograph of workers excavating a slab at the Agate Springs in the early $20^{\text {th }}$ century. 22

Photo 4. Dr. Robert Hunt, Jr. carefully extracting a jacketed specimen from the surrounding rock.

Photo 5. An aerial photo of University Hill and Carnegie Hill.

Photo 6. The Visitor Center hosts a fossil display showing mounted casts of Daeodon, Moropus, and Daphoenodon, and a bonebed of mixed material. 26

Photo 7. Dr. Darrin Pagnac conducting a survey with his field paleontology class.

Photo 8. NPS paleontologist Ellen Starck, Bureau of Land Management paleontologist Greg McDonald, and others preparing to remove a field-jacketed Stenomylus specimen collected as salvage at AGFO in 2013.

Photo 9. Photographs illustrating fossil preparation.

Photo 10. Bonebed slab from AGFO exhibited at the South Dakota School of Mines and Technology Museum of Geology. .59

Photo 11. Visitors observing the exhibits and replica skeletons within the AGFO Visitor Center.

Photo 12. Example of an interpretive wayside exhibit at Beardog Hill along the Fossil Hills Trail.

Photo 13. Scott Kottkamp gives a presentation about beardogs, paleoecology, and the importance of context as scientific data to a school group at Beardog Hill.

Photo 14. Alvis Mar gives a lecture on AGFO to a remote classroom via distance learning.

Photo 15. Historical photograph of Carnegie Hill, with written on annotations recording the sites of different quarries at the hill for the year 1908 .

Photo 16. Dr. Darrin Pagnac holding a microfossil fragment. 



\section{Appendices}

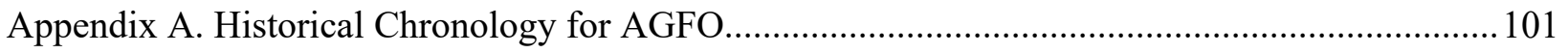

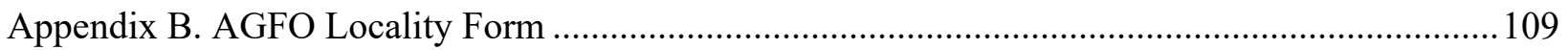

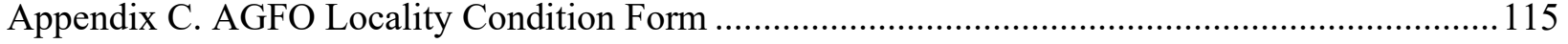

Appendix D. AGFO Visitor Site Report Form .................................................................... 119

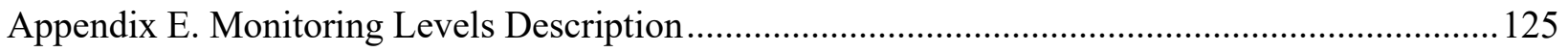

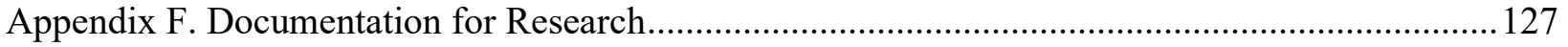

Appendix G. Conditions for Research Permits .......................................................................... 129

Appendix H. Site Disclosure Policy/Leave No Trace Guideline ................................................. 133

Appendix I. Descriptions of Paleontological Localities of Management Concern............................ 135

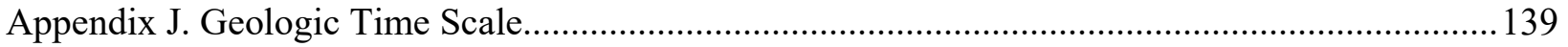





\section{Executive Summary}

Since Agate Springs Ranch was founded by James H. Cook in 1887, exquisite examples of transitional Miocene mammalian fauna have been found along this stretch of the Niobrara River valley. Collectively these paleontological discoveries, along with the existing archeological and historical Native American collection, were the basis for establishing Agate Fossil Beds National Monument (AGFO) as a unit of the National Park System (NPS). The fossil remains from the Harrison and Anderson Ranch formations span a short, but important, time period within the Miocene Epoch. AGFO has provided science with an intimate look into North American mammalian evolution of the time that is matched nowhere else, with body fossils and trace fossils (burrows) of many mammals in excellent condition. Investigation of the paleontological resources at AGFO has been very limited since its establishment, but the opportunities for research and discovery are still substantial.

Public and academic interest in the Monument's paleontological resources are considerable. Although there are existing legal authorities, policies and guidelines regarding the management of paleontological resources, at both the departmental and agency levels, more specific guidance would be helpful for the management of AGFO's non-renewable fossils. This document has been prepared to provide more specific guidance and recommendations for paleontological resources management at AGFO.

The Introduction outlines the significance of AGFO's paleontological resources and defines the purpose, need, and objectives for the Agate Fossil Beds National Monument Paleontological Resources Management Plan (PRMP). This plan also identifies the legal authorities, requirements, and mandates underpinning AGFO's mission as a unit of the NPS, with special attention to authorities that address managing and preserving paleontological resources.

Background Geology and Paleontology provides a basic park geologic description, discusses the scope of AGFO's paleontological resources, and summarizes past paleontological work performed at the Monument. This information includes historical information from periods both before and after authorization of the Monument as a unit of the NPS. This section also presents the paleontological significance of AGFO and its specimens, such as how AGFO's taxa are cornerstones of North American geochronology and biostratigraphy.

Paleontological Resources Management begins by listing in greater detail the strategic objectives related to paleontological resources within the NPS and at AGFO. This section then proceeds to discuss the specific considerations related to paleontological resource inventories and monitoring along with management requirements (from policy and guidelines) specific to AGFO. This section discusses what a paleontology inventory is and why, when and how to conduct one; fundamentals of paleontological resource monitoring; the various types of threats to paleontological resources and how to mitigate them; and resource condition assessment and site monitoring protocols. It also addresses how to handle paleontological resources discovered or recovered during other park activities. 
Paleontological Research Management presents NPS and AGFO research goals, how to evaluate the scientific significance of research, and how to weigh the significance of research against other park mandates, operations, and goals. The section also includes a description of the permitting process, recommended park-specific permit conditions, and rules for overseeing collection and excavation.

Museum Collections and Curation documents AGFO's current paleontological collections, collections management and curation policies, AGFO's photographic archives, collections from AGFO in external repositories, type specimens from AGFO, and Monument compliance with museum security policies.

Interpretation discusses goals and current implementation for how AGFO interprets its paleontological resources for the public. This includes: the primary themes for interpretation; the exhibits, tools and programs used by AGFO to interpret fossil resources; the target audiences for the interpretive programs; teaching good stewardship of paleontological resources; and a discussion of public accessibility to AGFO, its interpretive materials, and the paleontological resources.

Relation of Paleontological Resources to Other Park Programs provides an overview of how each park division may interact with paleontological resources and have their duties cross over with paleontological resource management related actions. It also discusses the potential impacts of paleontological resource management on other types of AGFO resources (archeological, biological, historical, and physical).

Paleontological Resource Data Management discusses various paleontological resource records, datasets, and other archives. AGFO's paleontological archives and library, as well as their current status, are discussed along with an overview of the type of contents stored within them. The NPS Paleontology Program Archives and Library, and how to exchange data and records between them and the AGFO archives, are also described. This section also reviews geospatial data available to AGFO and issues of sensitivity and confidentially related to paleontological resource data and information.

Finally, the Summary, Conclusions, and Recommendations summarizes the work done on the AGFO PRMP, discusses ongoing and planned projects which assist in implementing the instructions and goals set out in this PRMP, and makes a variety of recommendations for future paleontological resource management at AGFO. 


\section{Acknowledgments}

NPS staff at AGFO were crucial to the development of this plan, both through direct feedback on the document and by providing support to the authors. Specific individuals and their contributions include: James Hill (former Superintendent of AGFO, now at Guilford Courthouse National Military Park) first supported the development of the AGFO PRMP, gave feedback on section drafts and provided detailed information about AGFO's past operations, needs, and logistical limitations; AJ Legault (Park Ranger) supervised the interns, provided information on law enforcement essential to a few sections of the PRMP, and assisted in trips to localities and into the collections; Jedediah Wannarka was a source of information and feedback regarding data management at AGFO and also helped the primary author find documents and records; Alvis Mar provided IT support and feedback about the interpretation section, and was a great sounding board for ideas about visitor education and staff training at AGFO; Anne Wilson provided suggestions and information about AGFO's partnerships for the interpretation section; Dan Kaiser provided suggestions for the interpretation section. Dan Morford, superintendent of SCBL and acting superintendent of AGFO, reviewed and provided feedback on the PRMP draft.

This plan could not have been completed without the gracious support of other NPS staff, who often offered critical insights into current NPS policy and supplied access to various data and records essential to the plan. Ann Hitchcock and John Dennis provided critical feedback and up-to-date NPS policy for the Research Management section, especially emphasizing the critical place of assessing scientific merit when reviewing permit applications among other contributions. Matthew Colwin provided access to park atlas datasets. Tim Connors provided access to geologic map datasets for AGFO and the associated records of the geologic scoping session. Heather Young, museum program manager for NPS Midwest, offered advice utilized in the museum collections and curation section of the plan while on a visit to AGFO. Keely Rennie-Tucker, Karin Roberts, and Chris Mather provided the most recent copy of the Collections Management Report for AGFO, which included the total number of paleontological specimens in the AGFO collections. Rachel Benton, former Paleontologist at BADL, wrote a list of recommendations for AGFO that was used in part during the development of the PRMP.

Individuals who assisted in reviewing the document include: Mike Antonioni of National Capitol Parks East (NACE); Erin Eichenberg of Tule Springs Fossil Beds National Monument (TUSK); Emmett Evanoff, Assistant Professor of Geology at the University of Northern Colorado; ReBecca Hunt-Foster of Dinosaur National Monument (DINO); Kari Prassack of Hagerman Fossil Beds National Monument (HAFO); Ed Welsh (BADL); and Lindsey Yann of Waco Mammoth National Monument (WACO).

Finally, the writing of the PRMP was greatly assisted by several individuals outside of the National Park Service. Robert Hunt, Jr., Professor Emeritus at University of Nebraska Lincoln, has a long history of paleontological work at AGFO. Dr. Hunt provided several lists of recommendations for AGFO over the years, some of which were utilized in the writing of the PRMP. Dr. Hunt also provided a detailed and up-to-date history of age dates for AGFO stratigraphic units for the PRMP. 
Toni Culver created the AGFO Fossil Locality Database and its associated maps and tables in 2003, which were referred to, or directly utilized, throughout the PRMP. Daniel Traub updated the AGFO Fossil Locality Database in 2014. Spencer Lynch was the Stewards Program Coordinator for the primary author, and ensured the internship ran smoothly. Darrin Pagnac, Professor of Geology at South Dakota School of Mines and Technology, was responsible for the primary author's paleontological education and has provided continued support since then. Dr. Pagnac has a history of paleontological work at AGFO that has supported resource management efforts, and provided opinions on several proposed management actions recommended in this PRMP. Sally Shelton was also a teacher to the main author, specifically in the field of paleontological resource management critical to writing this document. 


\section{Dedication}

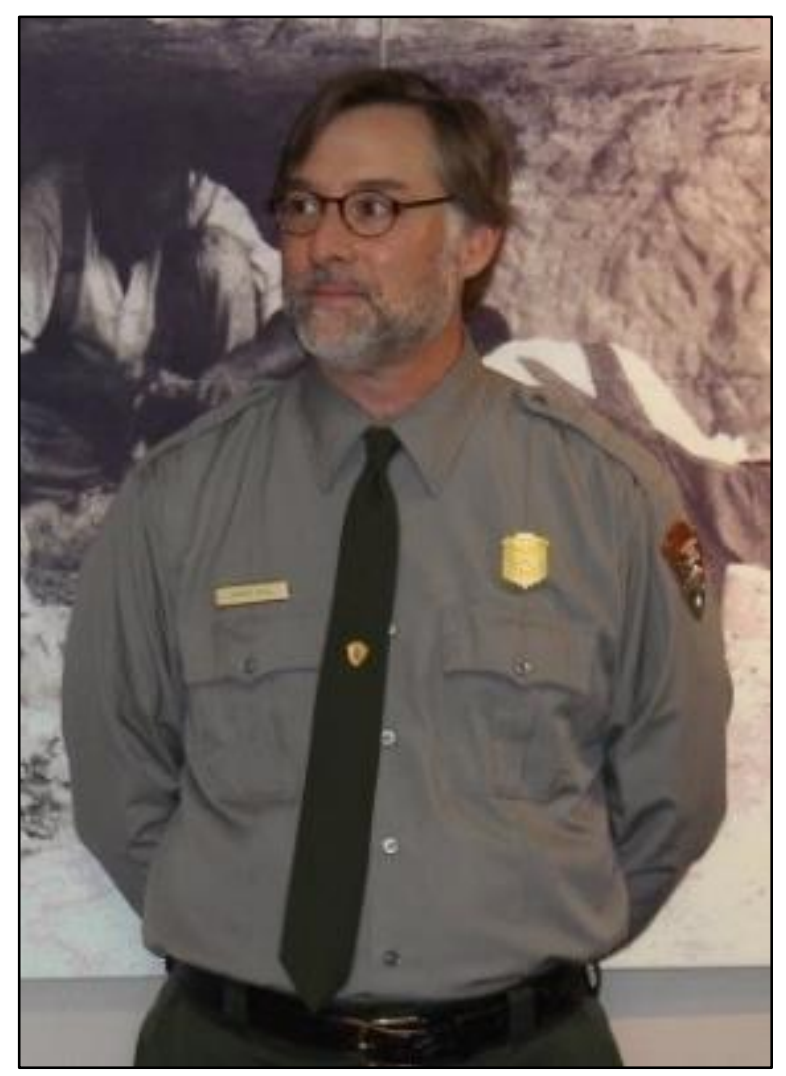

Photo of James Hill (NPS)

We dedicate the Agate Fossil Beds National Monument Paleontological Resource Management Plan to James Hill. James served as the superintendent at Agate Fossil Beds National Monument between June 2009 and August 2019. During his tenure, James made significant contributions to the management, protection, education and stewardship of the Monument's world-renowned fossils. James was instrumental in hiring the first permanent paleontologist at the Monument, through a shared position with Badlands National Park. Additionally, James piloted a long-distance learning program for paleontology to enhance educational opportunities in rural Nebraska. Through the leadership and vision of James Hill, this paleontological resource management plan will help to benefit future managers at Agate Fossil Beds National Monument for many decades into the future. 



\section{Introduction}

\section{Significance of Paleontological Resources at AGFO}

Agate Fossil Beds National Monument (AGFO) owes its existence as an NPS unit primarily due to its significant paleontological resources. As defined in the 2012 Foundation Document (NPS 2012) and the significance statements listed therein, fossils at AGFO bear significance because:

- "The Great Bone Bed at Agate is world-renowned as one of the earliest discoveries that helped define the Miocene epoch (23 to 5.3 million years ago). The thousands of densely packed bones deposited into an ancient watering hole are well known for their quality of preservation and completeness."

- "The discovery of beardog dens in the 1980s showed the earliest known denning behavior of carnivorans. This and other important discoveries at AGFO include animals new to science, as well as traces of the actual environments they lived in."

- 'Daemonelix, 'Devil's corkscrews,' enormous sandstone spirals - sometimes up to 10 feet tall - fascinated and confounded the early researchers, who developed several theories to explain their origin. It was later determined that these deposits were natural casts of rodent burrows, which provided valuable insight on the burrowing habits of early beavers and their adaptations to the open grassland environment."

- "The Stenomylus Quarry is unique because it contains multiple skeletons of the tiny camelid (gazelle-like camel), one of the smallest of the North American camels. Other occurrences of Stenomylus in the region are limited to isolated specimens. Many of the skeletons are fully articulated and are preserved in detail. The site is thought to represent a mass death assemblage."

- "The history of research at Agate Fossil Beds National Monument provides important data needed to better understand the climate and ancient mammals that lived during the Miocene epoch. The scientific history includes important examples of cooperation, competition, near misses, rediscovery, and detailed problem solving, all significant components of scientific understanding."

To this list of significances from the AGFO Foundation Document, this plan adds:

- AGFO fossils contribute to the biochronological definition of the latest Arikareean North American Land Mammal Age (NALMA).

\section{Purpose and Need}

The NPS is required to manage its lands and resources in accordance with federal laws, regulations, management policies, guidelines, and scientific principles. Authorities and guidance directly applicable to paleontological resources are cited below. Paleontological resource inventories have been developed by the NPS to compile information regarding the scope, significance, distribution, and management issues associated with fossil resources present within parks. This information is intended to increase awareness of park fossils and paleontological issues in order to facilitate informed management decisions and actions that comply with these laws, directives, and policies. 
On June 5, 1965, Agate Fossil Beds National Monument was established under Public Law 89-33, 79 Stat. 123. The Act specifically states:

"SEC. 1. To provide for the establishment of the Agate Fossil Beds National Monument in the State of Nebraska, and for other purposes. Be it enacted by the Senate and House of Representatives of the United States of America in Congress assembled, That in order to preserve for the benefit and enjoyment of present and future generations the outstanding paleontological sites known as the Agate Springs Fossil Quarries, and nearby related geological phenomena, to provide a center for continuing paleontological research and for the display and interpretation of the scientific specimens uncovered at such sites, and to facilitate the protection and exhibition of a valuable collection of Indian artifacts and relics that are representative of an important phase of Indian history, the Secretary of the Interior is authorized to acquire by donation, or by purchase with donated or appropriated funds, or otherwise, title or a lesser interest in not more than three thousand one hundred and fifty acres of land in township 28 north, range 55 west, sixth principal meridian, Sioux County, Nebraska, for inclusion in the Agate Fossil Beds National Monument in accordance with the boundary designation made pursuant to section 2 hereof, which boundary may include such right-ofway as is needed for a road between the Stenomylus Quarry site and the monument lands lying in section 3 or 10 of the said township and range.

SEC. 2. Within the acreage limitation of section 1, the Secretary may designate and adjust the boundaries of Agate Fossil Beds National Monument. When the Secretary finds that lands constituting an initially administrable unit are in Federal ownership, he shall establish such national monument by publication of notice thereof in the Federal Register, and any subsequent adjustment of its boundaries shall be effectuated in the same manner.

SEC. 3. The Agate Fossil Beds National Monument shall be administered by the Secretary of the Interior pursuant to the Act entitled "An Act to establish a National Park Service, and for other purposes”, approved August 25, 1916 (39 Stat. 535; 16 U. S. C. 1 et seq.), as amended and supplemented.

SEC. 4. There are hereby authorized to be appropriated the sums of not more than $\$ 301,150$ for acquisition of lands and interests in land and not more than \$1,842,000 for development in connection with the Agate Fossil Beds National Monument under this Act."

This AGFO Paleontological Resources Management Plan (PRMP) is designed to synthesize NPS law, policies, scientific principles, resource management practices and other information to provide guidance for future management of the Monument's non-renewable paleontological resources. This PRMP is intended as a guiding document to outline "best practices" in the management of the Monument's fossils and significant sites.

The public version of this report has been redacted to remove sensitive information pertaining to localities and certain management procedures; qualified NPS staff may request access to the sensitive version. 


\section{Project Objectives}

This PRMP was created with several goals in mind. While individual recommendations can be quite specific and are elaborated on in sections dedicated to each topic of the PRMP, all of the PRMP's objectives fall under four broad categories.

The first is to assist staff in planning. This document provides staff with: up-to-date authorities and policies regarding paleontological resources managed by the NPS and DOI; the status of AGFO paleontological resources and management activities related to them; recommendations about future resource management policies and best practices; and essential background about AGFO's history, geology, and paleontology necessary for AGFO staff to make informed decisions about the resources. This plan is largely intended as a guide, a set of suggestions, or the best practices to be aimed for - it is not a strict set of orders, and AGFO should amend the implementation of this plan according to their logistical limits and needs.

The second is to ensure the highest level of preservation of paleontological resources. Paleontological resources are referenced in AGFO's authorizing legislation and their preservation for public benefit is a core mandate of the Monument. Paleontological resources are non-renewable, and thus any damage to or loss of these resources cannot be restored or recovered. At the same time, fossil resources are under constant threat from both natural and anthropogenic sources. Rigorous and well-maintained programs involving paleontological resource management are intended to mitigate and/or prevent degradation of these resources. Paleontological resource management activities inform about the state of the resource (inventory), check if the resource has degraded since it was last observed and assess if further mitigation is necessary (monitoring), reduce risk factors (e.g., law enforcement and erosion controls), curate fossils that have been removed from their original context, and record and preserve information about the fossil resources and their management activities (e.g., archives and data management). This plan outlines suggestions for modifying or implementing each type of management action at AGFO in order to best prevent the degradation of paleontological resources, and preserve the benefits they provide to science, education, and public enjoyment.

The third is to facilitate research related to fossil resources, including in paleontology, paleoecology, and other geoscience specialties (paleosols, tephrastrat, etc.). AGFO's founding mandate requires it to continue serving as a center for paleontological research, and NPS policy dictates that parks are to be run according to the best available science and scientific principles. More immediately, up-to-date research informs management about the nature of the paleontological resources within a park and helps determine how best to manage and preserve the resources. This plan lays out for resource managers the goals for research at AGFO, guidelines for assessing the scientific merit of research permit proposals, suggestions for park-specific permit conditions, and rules regarding collection and excavation of fossils, and provides an overview of museum collections and curation policies in the context of paleontological resources.

The fourth is to promote public outreach and education. Through four primary interpretive themes, AGFO teaches about the Miocene fauna and landscape preserved in the fossil record, the history and maturation of paleontology, and encourages critical thinking about the relevance of AGFO's paleontological resources and story to modern issues. In the interest of reaching as many people as 
possible, AGFO has strived to maintain a high level of accessibility in its interpretive program. All trails were designed to be wheelchair accessible; the Visitor Center provides a video walking tour of the trails to those that cannot walk them, the AGFO website is regularly updated, and the rangers run distance learning programs to educate those who cannot visit the Monument. This document provides AGFO staff with an overview of the Monument's interpretive themes and resources in the context of paleontology, and also makes recommendations about how the interpretive program could be improved to foster further visitor understanding of the paleontological resources at AGFO.

\section{Legal Authorities}

\section{American Antiquities Act of 1906}

This law began the system of scientific use through permitting. Paleontological resources collected from public lands in the early $20^{\text {th }}$ century may have been permitted under this law. That is not the case at AGFO, which was established much later, but the law is included here for the benefit of other parks with paleontological resources.

\section{NPS Organic Act of 1916}

The National Park Service Organic Act of 1916 states that the NPS

“... shall promote and regulate the use of the Federal areas known as national parks, parks, and reservations hereinafter specified... by such means and measures as conform to the fundamental purpose of the said parks, parks, and reservations, which purpose is to conserve the scenery and the natural and historic objects and the wild life therein and to provide for the enjoyment of the same in such manner and by such means as will leave them unimpaired for the enjoyment of future generations. [Emphasis added]."

Congress reaffirmed this mandate in 1978 when it directed that:

"The authorization of activities shall be construed and the protection, management, and administration of these areas shall be conducted in light of the high public value and integrity of the National Park System and shall not be exercised in derogation of the values and purposes for which these various areas have been established, except as may have been or shall be directly and specifically provided by Congress."

In addition to avoiding impairment, NPS managers must always seek ways to avoid, or to minimize to the greatest degree practicable, adverse impacts on park resources and values. However, the NPS has management discretion to allow certain impacts to park resources and values when necessary and appropriate to fulfill the purposes of a park, so long as the impact does not constitute impairment of the affected resources and values.

\section{Archaeological Resources Protection Act (ARPA) of 1979}

When paleontological resources occur in an archeological context, the fossils fall under the enhanced guardianship of ARPA. Section 3 of that Act, as amended, specifically excludes non-fossilized and fossilized paleontological specimens from the Act's authorities, unless those specimens are found in an archeological context. This exclusion is reaffirmed in section -.3(a) (4) of the Act's uniform 
regulations (43 CFR 7; 36 CFR 296, 18 CFR 1312; 32 CFR 229), which states that paleontological remains "shall not be considered of archaeological interest, and shall not be considered to be archaeological resources...unless found in a direct physical relationship with archeological resources..." Archeological resources are defined in section -.3(a) of the uniform regulations to mean "any material remains of human life or activities which are at least 100 years of age, and which are of archaeological interest."

\section{Federal Cave Resources Protection Act (FCRPA) of 1988}

Paleontological resources are referenced in the Federal Cave Resources Protection Act of 1988 (16 U.S.C. 4301 through 4309). Section 3 of the Act defines the term "cave resource" as "any material or substance occurring naturally in caves on Federal lands, such as animal life, plant life, paleontological deposits, sediments, minerals, speleogens, and speleothems." Therefore, every reference to "cave resource" in the law applies to "paleontological resources."

\section{National Parks Omnibus Management Act of 1998}

Section 207, 16 U.S.C. $\S 5937$, authorizes the NPS to protect the confidentiality of the nature and specific location of paleontological objects from a Freedom of Information Act request made by a member of the public, unless the agency determines that:

(1) disclosure of the information would further the purposes of the unit of the National Park System in which the resource or object is located and would not create an unreasonable risk of harm, theft, or destruction of the resource or object, including individual organic or inorganic specimens; and

(2) disclosure of locality information is consistent with other applicable laws protecting the resource or object.

See also Appendix $\mathrm{H}$ of this document for more discussion of disclosure of site information.

Assessment of Fossil Management on Federal and Indian Lands, A Report to Congress by the Secretary of the Interior (May 2000)

This report was prepared in response to Congress's request for an assessment of the need for a unified federal policy on collection, storage and preservation of fossils and for standards that would maximize the availability of fossils for scientific study.

This report (Department of the Interior 2000) makes the following seven recommendations for further action:

Principle 1: Fossils on Federal Lands are part of America's heritage.

Principle 2: Most vertebrate fossils are rare.

Principle 3: Some invertebrate and plant fossils are rare.

Principle 4: Penalties for fossil theft should be strengthened.

Principle 5: Effective stewardship requires accurate information.

Principle 6: Federal fossils should be preserved and available for research and public education. 
Principle 7: Federal fossil management should emphasize opportunities for public involvement.

\section{Omnibus Public Lands Act of 2009 (HR 146 \& PL 111-11): Subtitle D - Paleontological Resources Preservation (October $2^{\text {nd }}$ 2009)}

Section 6302 - Management

Directs the Secretary of the Interior or the Secretary of Agriculture, as appropriate, to: (1) manage and protect paleontological resources on federal land, using scientific principles and expertise; and (2) develop plans for inventorying, monitoring, and deriving the scientific and educational use of such resources.

Section 6303 - Public Awareness \& Education

Directs the Secretary to establish a program to increase public awareness about such resources.

Section 6304 - Collection of Paleontological Resources

Prohibits a person from collecting a paleontological resource from federal land without a permit issued under this subtitle. Requires the Secretary to allow casual collecting of a reasonable amount of common invertebrate and plant paleontological resources for non-commercial personal uses without a permit on certain non-NPS federal lands. Recognizes as valid permits issued before enactment of this Act. Sets forth criteria by which the Secretary may issue permits for paleontological resources. Requires that any paleontological resource and associated records collected under a permit be deposited in an approved repository. Allows the Secretary to modify, suspend, or revoke a permit under specified circumstances. Revokes a permit if any person working under the authority of the permit is convicted of a criminal offense under this section 6306 or assessed a civil penalty under this section 6307. Specifies that locality data will not be released without Secretary permission.

Section 6305 - Curation

Permits the Secretary to enter into agreements with non-federal repositories regarding the curation of paleontological resources, data, and records.

Section 6306 - Prohibited Acts

Prohibits: (1) evacuating, removing, or altering a paleontological resource located on federal lands, except in accordance with this subtitle; (2) exchanging or receiving a paleontological resource, or selling or purchasing a paleontological resource, if the person knew or should have known such resource was illegally removed from federal lands; or (3) making or submitting false records, accounts, or identification of any paleontological resource excavated or removed from federal lands. Imposes criminal penalties for violating this section. 


\section{Section 6307 - Civil Penalties}

Sets forth requirements for the assessment of civil penalties by the Secretary for violations of any prohibitions contained in regulations or permits issued under this subtitle. Requires any recovered amounts to be available for use: (1) to protect, restore, or repair paleontological resources and sites which were the subject of the action, and to protect, monitor, and study the resources and sites; (2) to provide educational materials to the public about paleontological resources and sites; and (3) as a reward.

\section{Section 6308 - Rewards \& Forfeiture}

Allows the Secretary to pay a reward from penalties collected under section 6306 or 6307 to any person who furnishes information leading to the finding of a civil or criminal violation with respect to which the penalty was paid. Subjects to civil or criminal forfeiture all paleontological resources with respect to which a violation occurred and which are in the possession of any person. Allows the Secretary to transfer administration of seized paleontological resources to educational institutions for scientific or educational purposes.

Section 6309 - Confidentiality

Requires information on the nature and specific location of a paleontological resource to be withheld from the public, including under the Freedom of Information Act, except under specified conditions.

Section 6310 - Regulations

Directs the Secretary to issue such regulations as are appropriate to carry out this subtitle.

$\underline{\text { Section } 6312 \text { - Appropriations }}$ Authorizes appropriations.

\section{NPS Regulations}

The NPS governs activities in paleontological parks through the general NPS regulations, found at $\underline{36}$ Code of Federal Regulations (CFR) Chapter I. These regulations apply to federally owned lands and waters administered by the NPS within park boundaries and also to some non-federal lands and waters within park boundaries (36 CFR $\S 1.2$ ). The regulations directly related to paleontology questions in parks include:

§2.1 Preservation of natural, cultural and archeological resources.

(a) Except as otherwise provided in this chapter, the following is prohibited:

(1) Possessing, destroying, injuring, defacing, removing, digging, or disturbing from its natural state: 
(iii) Non-fossilized and fossilized paleontological specimens, cultural or archeological resources, or the parts thereof.

(iv) A mineral resource or cave formation or the parts thereof.

\section{$\S 2.5$ Research Specimens}

(a) Taking plants, fish, wildlife, rocks or minerals except in accordance with other regulations of this chapter or pursuant to the terms and conditions of a specimen collection permit, is prohibited.

(b) A specimen collection permit may be issued only to an official representative of a reputable scientific or educational institution or State or Federal agency for the purpose of research, baseline inventories, monitoring, impact analysis, group study, or museum display when the superintendent determines that the collection is necessary to the stated scientific or resource management goals of the institution or agency and that all applicable Federal and State permits have been acquired, and that the intended use of the specimens and their final disposal is in accordance with applicable law and Federal administrative policies. A permit shall not be issued if removal of the specimen would result in damage to other natural or cultural resources, affect adversely environmental or scenic views, or if the specimen is readily available outside of the park area.

(g) Specimen collection permits shall contain the following conditions:

(1) Specimens placed in displays or collections will bear official National Park Service museum labels and their catalog numbers will be registered in the National Park Service National Catalog.

(2) Specimens and data derived from consumed specimens will be made available to the public and reports and publications resulting from a research specimen collection permit shall be filed with the superintendent.

(h) Violation of the terms and conditions of a permit issued in accordance with this section is prohibited and may result in the suspension or revocation of a permit.

The Paleontological Resources Preservation Act (PRPA) rulemaking process is currently underway for the development of a Department of Interior-level regulation. The proposed PRPA rule was published in the Federal Register on Wednesday, December 7, 2016 and was available for public review and comment until Monday, February 6, 2017. The proposed PRPA regulations resulted in 1611 public comments which were considered in the development of the final PRPA regulations. Once approved the final DOI regulation for PRPA will be available on the Federal Register website at: https://www.federalregister.gov/ and will be published in 43 CFR.

\section{NPS Management Policies (2006)}

Section 4.8.2, which addresses all NPS geologic features, requires the NPS to protect these features (such as paleontological resources) from adverse effects of human activity. See https://www.nps.gov/orgs/1548/upload/ManagementPolicies2006.pdf 
Protection of paleontological resources is specifically addressed at Section 4.8.2.1:

"Paleontological resources, including both organic and mineralized remains in body or trace form, will be protected, preserved, and managed for public education, interpretation, and scientific research. The Service will study and manage paleontological resources in their paleoecological context (that is, in terms of the geologic data associated with a particular fossil that provides information about the ancient environment)."

NPS Management Policy defines the objectives of paleontological resource management specifically at 4.8.2.2

"Superintendents will establish programs to inventory paleontological resources and systematically monitor for newly exposed fossils, especially in areas of rapid erosion. Scientifically significant resources will be protected by collection or by on-site protection and stabilization. The Service will encourage and help the academic community to conduct paleontological field research in accordance with the terms of a scientific research and collecting permit. Fossil localities and associated geologic data will be adequately documented when specimens are collected. Paleontological resources found in an archeological context are also subject to the policies for archeological resources. Paleontological specimens that are to be retained permanently are subject to the policies for museum objects."

"The Service will take appropriate action to prevent damage to, and unauthorized collection of, fossils. To protect paleontological resources from harm, theft, or destruction, the Service will ensure, where necessary, that information about the nature and specific location of these resources remains confidential, in accordance with the National Parks Omnibus Management Act of 1998.”

Directives with regard to collection and duration:

"Parks will exchange fossil specimens only with other museums and public institutions dedicated to the preservation and interpretation of natural heritage and qualified to manage museum collections. Fossils to be de-accessioned in an exchange must fall outside of the park's scope of collection statement. Exchanges must follow de-accession procedures in the Museum Handbook, Part II, chapter 6."

"The sale of original paleontological specimens is prohibited in parks."

"The Service generally will avoid purchasing fossil specimens. Casts or replicas should be acquired instead. A park may purchase fossil specimens for the park museum collection only after making a written determination that:

- The specimens are scientifically significant, and are accompanied by detailed locality data and pertinent contextual data;

- The specimens were legally removed from their site of origin, and all transfers of ownership have been legal; 
- The preparation of the specimens meets professional standards;

- The alternatives for making these specimens available to science and the public are unlikely; and

- Acquisition is consistent with the park's enabling legislation and Scope of Collection Statement, and will ensure the specimens' availability in perpetuity for public education and scientific research."

Specific directives with respect to facilities management:

"All National Park Service construction projects in areas with potential paleontological resources must be preceded by a preconstruction surface assessment prior to disturbance. For any occurrences noted, or when the site may yield paleontological resources, the site will be avoided, or the resources will, if necessary, be collected and properly cared for prior to the initiation of the construction disturbance. Areas with potential paleontological resources must also be monitored during construction projects."

Specific directives with respect to interpretation/education:

In some instances, issues of a paleontological focus can raise concerns with specific audiences with regards to disconnects between evolution and creationism; where this is the case, interpreters/educators need to be aware of language from 7.5.3 Resource Issue Interpretation and Education: "Acknowledging multiple points of view does not require interpretive and educational programs to provide equal time or disregard the weight of scientific or historical evidence." In effect, the park interprets to the highest degree of known information from a scientific perspective, but can include "other ways of knowing."

In order for the Interpretive Division to provide the highest degree of known information from a scientific perspective, relationships will be fostered between the various subject matter experts so "programs will be based on current scholarship and research about the history, science, and condition of park resources, and on research about the needs, expectations, and behaviors of visitors." (7.5.4 Research and Scholarship)

\section{NPS Director's Order 77}

Director's Order \#77 offers comprehensive guidance to NPS employees responsible for managing, conserving, and protecting the natural resources found in NPS units. The NPS Paleontological Resource Management guidelines in NPS DO 77 identify the nature of management actions available to managers; reasonable options that should be considered for intensive management; and roles and responsibilities of each park, each region, and the Washington Office. Accordingly, the park paleontology specialist (or park resource manager in consultation with professional paleontologists) on behalf of the superintendent has the primary responsibility for managing and protecting fossil resources. 


\section{Background Geology and Paleontology}

\section{Overview of Paleontological Resources and Localities at AGFO}

AGFO is located in Sioux County in northwestern Nebraska along the upper Niobrara River, $16 \mathrm{~km}$ (10 mi) east of Wyoming and approximately $145 \mathrm{~km}$ (90 mi) south of the Black Hills, South Dakota. The Monument was authorized in 1965 and established in 1967. AGFO received 16,657 visitors in calendar year 2019 .

Surrounded by private ranchlands, AGFO is located along the Niobrara floodplain bordered by fossiliferous hills and buttes. Of the 1,236 hectares (3,055 acres) of property on which AGFO is located, 919 hectares (2,270 acres) are fee-owned, 189 hectares (467 acres) are privately owned but under Federal easement, 119 hectares (293 acres) are privately owned without easement, and the remainder are publicly owned (Figure 1).

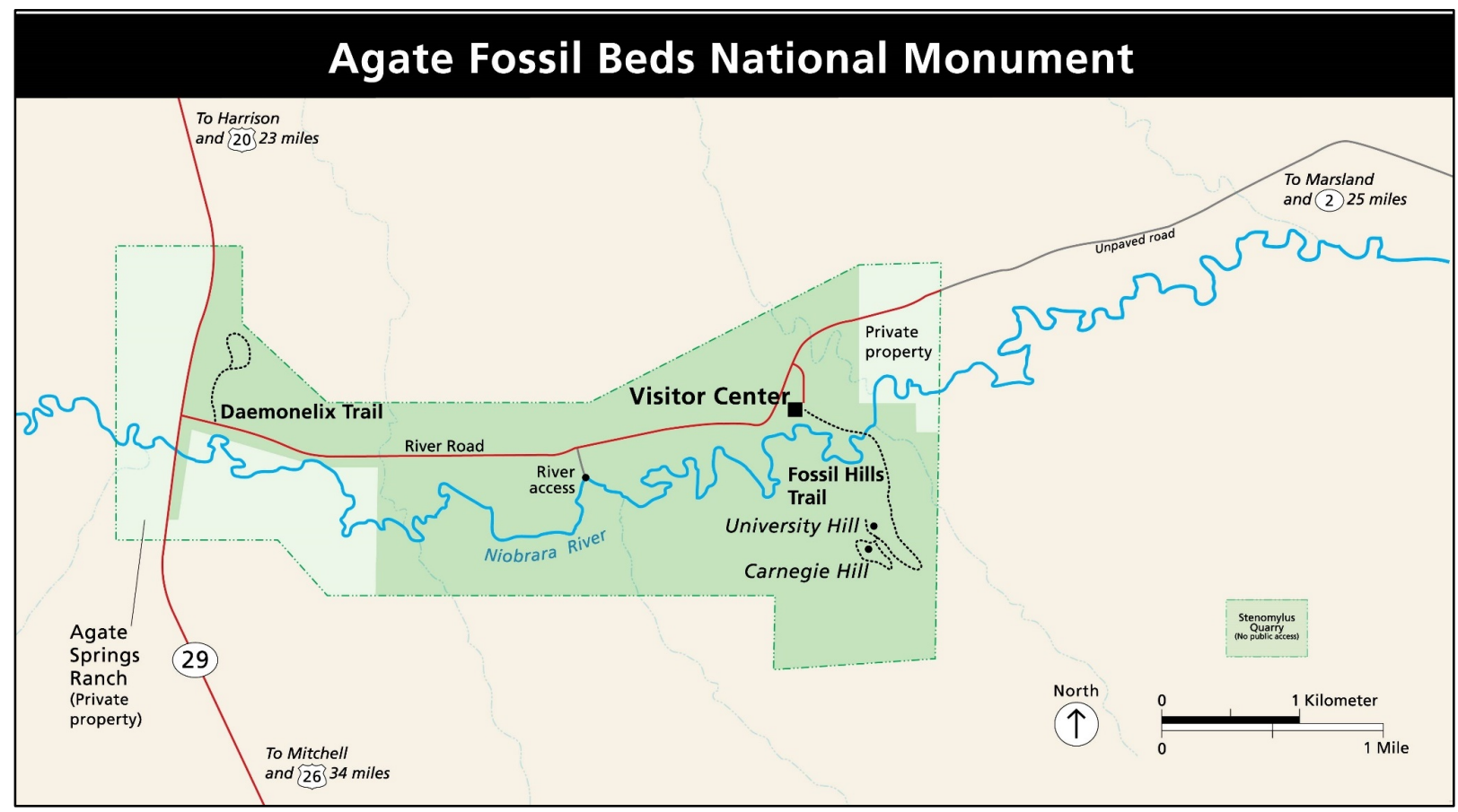

Figure 1. Map of AGFO, showing location of trails, Visitor Center, and nearby highways (NPS).

Overlooking the Niobrara River Valley from the south, four isolated hills contain some of the premier historic paleontological localities in North America: Carnegie Hill, University Hill, Beardog Hill, and the site known variously as Amherst Point, Quarry A, or North Ridge. In the early 1900s, these localities yielded thousands of bones of rhinoceros, horses, chalicotheres (extinct semi-bipedal ungulates), camels, oreodonts (extinct stocky pig-like or sheep-like ungulates), entelodonts (extinct omnivorous pig-like large ungulates), and beardogs (extinct carnivorans which, as the name suggests, had features resembling bears and dogs) (Hunt 1984). Some of the specimens were articulated and remain today as the most complete and best-preserved skeletons of their species. The localities were excavated by notable paleontologists from the American Museum of Natural History, Amherst 
College, the Carnegie Museum of Natural History, the Denver Museum of Nature and Science, University of Nebraska, and Yale University. The ongoing research of AGFO fossils has greatly contributed to the definition of the North American Land Mammal Ages (NALMAs) within the Early Miocene (Wood et al. 1941; Tedford et al. 2004).

The northwestern portion of AGFO contains burrow casts constructed by Palaeocastor sp., a small ancestral beaver. These casts are called Daemonelix or "Devil's Corkscrew" and are within the same horizon as several smaller rodent burrow casts, insect burrows and rhizoliths (root traces) (Martin and Bennett 1977). Two well-preserved burrow casts are displayed along the Daemonelix Trail (DTrail), encased in plexiglass for protection from the elements and potential vandalism.

Beautifully preserved and nearly complete remains of Stenomylus hitchcocki, a small gazelle-like camel, have been excavated from the Stenomylus Quarry. A complete, articulated skeleton of $S$. hitchcocki was found at this site and described as the holotype by F. B. Loomis (Loomis 1910). The

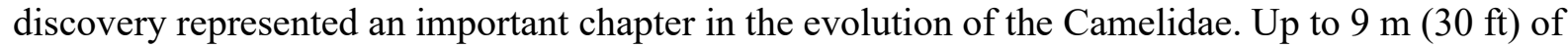
finely laminated, friable sandstone is exposed along the locality's west face, and along the northwest side up to $18 \mathrm{~m}$ (60 ft) of sandstone is exposed. The deposits represent two facies of the Harrison Formation ("Lower Harrison Formation" of Loomis 1911; Hunt 1990). In the lower facies at the Stenomylus Quarry, the fossil elements are disassociated, representing an allochthonous assemblage (remains transported from place of death), while the upper facies contain laterally continuous laminae that envelop both tracks and articulated fossil skeletons. These fossil features of the upper facies suggest sand accumulated relatively rapidly at the time they were buried. The entire locality is of geological importance; it is a place where the paleoenvironment and paleoclimate can be analyzed and the correlation of the geological formations in and around AGFO can be reviewed (Hunt 1990).

Interpretations on the depositional environment of the Stenomylus Quarry vary. Gandolfi's (2013) unpublished thesis hypothesizes a low-energy fluvial (river) environment based on fine scale laminations, subangular to subrounded sand grains, and the microfaunal assemblage. This assemblage includes: gastropods; bivalves; iguanid lizards; a lipotyphlan; several species of heteromyid and geomyid rodents; and sciurid rodents (Gandolfi 2013). Emmett Evanoff (University of Northern Colorado, pers. comm., May 2020) is skeptical of these conclusions, as the sedimentary features and most of the fossil taxa could also indicate an eolian environment (deposition of windblown sediment).

\section{Stratigraphy}

Many of the Cenozoic sedimentary units of the Great Plains are derived from an expansive blanket of sediment eroded from the Rocky Mountains and Black Hills following the Laramide Orogeny (Benton et al. 2015). Additionally, eruptions in the Great Basin and Colorado deposited a large amount of volcaniclastic sediment (derived from volcanic rocks) over the Great Plains during the Oligocene and Early Miocene (Hunt 1990) (see Appendix J for a geologic time scale). The remnants of this sedimentary blanket survive today in the central Great Plains as the topographically elevated Hartville and Cheyenne tablelands. AGFO is situated atop this blanket, which is comprised of multiple groups of formations. The oldest units exposed at AGFO (and all known fossiliferous units) belong to the Arikaree Group, while the youngest lithified unit belongs to the Ogallala Group. The 
Arikaree Group represents a combination of eolian deposits with a large volcaniclastic input and successional fluvial downcut and fill into older units (Hunt 1990), whereas the Ogallala Group is primarily composed of valley cuts-and-fills (Diffendal 1982; E. Evanoff, pers. comm., January 2020). Overall, this rock record traces the Late Oligocene through the Early Miocene, spanning a period of approximately 11-12 million years, from about 29-30 Ma (million years ago) to $18 \mathrm{Ma}$. The Arikaree Group does have unconformities that represent gaps in time.

The rock units at AGFO are comprised of mixed river valley sediments, sand and silt from the sediment wedge, and volcanic ash from eruptions to the west (Swinehart et al. 1985; Hunt 1990; McMillan et al. 2002). The sediments were worked and transported by low-gradient ephemeral streams, which left behind streambed and floodplain deposits in the vast and level interchannel plains (Hunt 1990). Shallow ponds, characterized by limestone deposits, lakes, and eolian sand sheets or dunes served as the other depositional environments in this region during the Miocene. Evidence derived from these sediments and ancient soil horizons suggest a warm semi-arid climate without a prolonged cold winter and probably a dry season interspersed with periods of intense rainfall (Hunt 1990). The climate is hypothesized to have been overall wetter than today.

Four formations are exposed at AGFO (Table 1). They are, in ascending order from oldest to youngest, the Sharps, Harrison, Anderson Ranch, and Runningwater formations (Tweet et al. 2011). Younger Pleistocene and Holocene surficial deposits mantle the formations and the channel zone of the Niobrara River (Swinehart et al. 1985; Tweet et al. 2011). To date, fossils have only been found in the Harrison and Anderson Ranch formations within AGFO. The other units are fossiliferous nearby and have been hypothesized as potentially fossiliferous at AGFO.

\section{Stratigraphic Columns, Cross Sections and "Type Sections"}

Tables 1 and 2 have been revised from Hunt (1990). Table 1 lists the ages and stratigraphic assignments of the various units exposed within AGFO. Table 2 lists the lithologies, lithological interpretations, and fossils represented in various sub-units of the Anderson Ranch and Harrison formations at AGFO.

Table 1. Stratigraphic units exposed at AGFO (revised from Hunt 1990). The Anderson Ranch and Harrison formations are the sources of the Monument's fossils.

\begin{tabular}{|l|l|l|l|}
\hline Era & Age & Group & Formation \\
\hline \multirow{4}{*}{ Cenozoic } & Quaternary & Not applicable & Unnamed surficial rocks and sediments \\
\cline { 2 - 4 } & Early Miocene & Ogallala Group & Runningwater Formation \\
\cline { 2 - 4 } & Early Miocene & Arikaree Group & Anderson Ranch Formation \\
\cline { 2 - 4 } & Early Miocene & Arikaree Group & Harrison Formation \\
\cline { 2 - 4 } & Late Oligocene & Arikaree Group & Sharps Formation \\
\hline
\end{tabular}


Table 2. Lithology, environmental interpretations, and biota from the Anderson Ranch and Harrison formations at AGFO (revised from Hunt 1990).

\begin{tabular}{|c|c|c|c|}
\hline Formation & Lithology & Lithology Interpretation & Major Biota at AGFO \\
\hline \multirow{4}{*}{$\begin{array}{l}\text { Anderson Ranch } \\
\text { Formation }\end{array}$} & Limestone and chert & Shallow lakes & Invertebrates and plants \\
\hline & $\begin{array}{l}\text { Massive, very fine-grained, silty } \\
\text { sandstone }\end{array}$ & $\begin{array}{l}\text { Eolian volcaniclastic loess } \\
\text { layered on flood plains and } \\
\text { paleosols }\end{array}$ & $\begin{array}{l}\text { Rhizoliths, small burrow } \\
\text { casts, oreodonts, and camels }\end{array}$ \\
\hline & $\begin{array}{l}\text { Thin cross-bedded and } \\
\text { horizontally laminated, very fine- } \\
\text { grained, tuffaceous sandstone }\end{array}$ & $\begin{array}{l}\text { Flood plain and stream } \\
\text { channel scour deposits }\end{array}$ & None specified \\
\hline & Tuffaceous sandstone & Waterholes & $\begin{array}{l}\text { Agate bonebeds, carnivores } \\
\text { and dens }\end{array}$ \\
\hline \multirow{3}{*}{$\begin{array}{l}\text { Harrison } \\
\text { Formation }\end{array}$} & $\begin{array}{l}\text { Fine-grained, cross-bedded } \\
\text { massive sandstone }\end{array}$ & $\begin{array}{l}\text { Stream and eolian deposits } \\
\text { and paleosols }\end{array}$ & $\begin{array}{l}\text { Rhizoliths, burrow casts of } \\
\text { Daemonelix, Palaeocastor } \\
\text { sp., disarticulated camels and } \\
\text { oreodonts, Stenomylus }\end{array}$ \\
\hline & $\begin{array}{l}\text { Agate Ash }(22.9 \pm 0.08 \text { million } \\
\text { years old })\end{array}$ & Volcanic ash & Not applicable \\
\hline & $\begin{array}{l}\text { Fine-grained, cross-bedded } \\
\text { massive sandstone }\end{array}$ & $\begin{array}{l}\text { Stream and eolian deposits } \\
\text { and paleosols }\end{array}$ & $\begin{array}{l}\text { Rhizoliths, burrow casts of } \\
\text { Daemonelix, Palaeocastor sp. }\end{array}$ \\
\hline
\end{tabular}

\section{Sharps Formation}

The oldest unit at AGFO is the Sharps Formation, formerly called the "unnamed lithic unit" at AGFO by Hunt (1988a), which is Late Oligocene in age and predates the fossil beds by several million years. It occurs in the southeast corner of the Monument. The current estimate for the age of the Sharps Formation at AGFO is 29-30 Ma, inferred from the lithologically similar "brown siltstone" also of the Sharps Formation on Wildcat Ridge south of Scottsbluff and Gering (Swinehart et al. 1985; R. Hunt, Jr., University of Nebraska-Lincoln emeritus, pers. comm., 2019). Another estimate of 28.7-28.1 Ma is based on geographic concordance with a similar deposit at Pine Ridge (Hayes 2007).

The Sharps Formation units exposed at AGFO are composed of light orange to light brown volcaniclastic sandstone and siltstone beds. It is of unknown thickness and limited exposure. Though the Sharps Formation is normally counted as part of the White River Group (Swinehart et al. 1985; Tedford et al. 2004), some researchers have proposed the uppermost part of the formation (which is what is found at AGFO) is actually its own unit and a basal formation of the Arikaree Group (Hayes 2007). The top of the Sharps Formation at AGFO is disconformable with the overlying Harrison Formation, indicating a period of Late Oligocene erosion.

The Sharps Formation is fossiliferous at both Badlands National Park (BADL) and in the Pine Ridge region of Nebraska. The well-documented outcrop at AGFO is potentially fossiliferous despite not having produced fossils (Hayes 2007). If the hypothesis about its correlation to Pine Ridge is correct, the assemblage should be similar to that found in the rest of the Arikaree Group or transitional between the Arikaree and White River groups (McConnell 1998). 


\section{Harrison Formation}

The oldest fossils known from AGFO are found in the Harrison Formation composed of tan, to gray, to dark gray fine-grained sandstone beds, usually massive (lacking bedding features), but locally featuring horizontal lamination or cross-bedding (lamination within beds angled with respect to the bedding plane) due to eolian (wind) or fluvial (river) processes (Photo 1). The rock contains high levels of volcanic ash and other pyroclastic elements (Hunt 1985, 1990). It is 40 to $50 \mathrm{~m}$ (130 to 160 $\mathrm{ft}$ ) thick throughout AGFO, though in many places it is partially buried underneath the overlying Anderson Ranch Formation (Tweet et al. 2011).

The ages of paleontological localities in the Harrison Formation and the overlying Anderson Ranch Formation have been approximated using four outcrops of the volcanic Agate Ash, a thinlylaminated, ponded white tuff diagenetically converted to nearly pure smectite. Each of the four ash outcrops possesses nearly identical mineralogy and trace element composition, and thus most likely represent a single unit (Izett 1968; Hunt 1984). A weighted mean (1 sigma) of these localities produced an age estimate of 22.9 $\pm 0.08 \mathrm{Ma}$ using argon-40/argon-39 dating on sanidine crystals (Izett and Obradovich 2001), updating the prior estimate of 21.3 Ma that used the potassium-argon method (Everden et al. 1964).

The deposits depict a seasonal, semi-arid paleoenvironment of ephemeral braided streams, shallow lakes, eolian deposits, and paleosols (ancient soils, usually with evidence of vegetation). The extensive paleosols and intermittent stream deposits indicate long periods of soil formation and shortlived watercourses during this time (Vicars and Breyer 1981). Erosion later modified the Harrison Formation surface into an incised paleoriver valley that became filled by disconformable fluvial and eolian sediments from the Anderson Ranch Formation (Hunt 2002a).

The Harrison Formation is fossiliferous throughout AGFO, displaying an extensive series of paleosols with root casts and occasional Daemonelix burrow casts. The Stenomylus Quarry (Photo 1) and Carnegie Quarry A fossil localities are within the Harrison Formation, as are the many Daemonelix showcased on the D-Trail in the western half of the Monument. Besides Stenomylus and Daemonelix, other fossils found in the Harrison Formation at AGFO include: hawks Buteo typhoius and Palaeastur atavus (Wetmore 1930; Ducey 1992; Chandler 1998); an amphicyonid (Hunt 2009); an entelodont, Daeodon hollandi (Loomis 1932); mammal tracks (Santucci et al. 2006); rhinocerotids Diceratherium niobrarense (more common at Quarry A than in the Anderson Ranch bonebed deposits) and Menoceras arikarense (less common than in the bonebeds); an oreodont; and a possible chalicothere. More information about the fossil taxa found in the Harrison Formation at AGFO, such as hypotheses about death and deposition, are summarized in Tweet et al. (2011).

There are also numerous fossils collected in the early $20^{\text {th }}$ century with uncertain Harrison Formation localities "near Agate," including the type specimens (specimens for which a species is named) of the horse species Kalobatippus agatensis, Parahippus nebrascensis and P. pawniensis (Osborn 1918; MacFadden 2001). Because the records for these specimens are vague about what is meant by "near Agate" (which could refer to the bonebeds, the ranch, or the post-office), it is unknown if they were found within the boundaries of AGFO. 


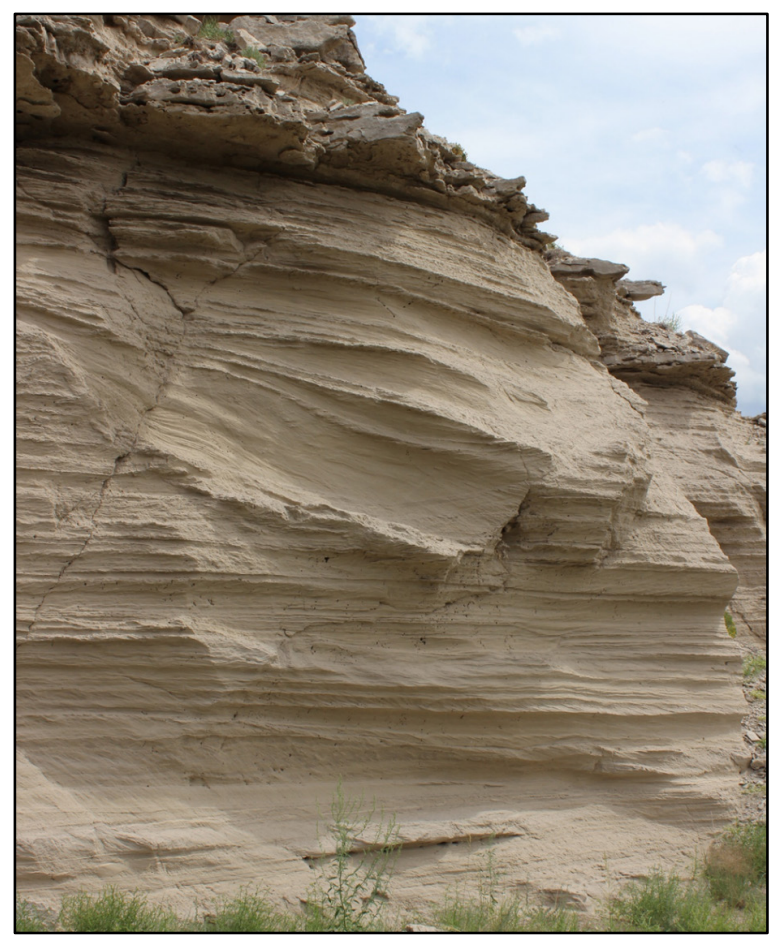

Photo 1. The Stenomylus Quarry, displaying cross-bedded and poorly indurated sandstone layers, characteristic of this portion of the Harrison Formation. Harder caprock is seen above (NPS).

\section{Anderson Ranch Formation}

Overlying the Harrison Formation is the Anderson Ranch Formation, formerly called the Upper Harrison beds (Hunt 1990, 2002a). The Anderson Ranch Formation includes some of the most important paleontological localities at AGFO, including the bonebeds at Carnegie Hill and University Hill and the carnivore den complex at Beardog Hill. The contact of the Anderson Ranch Formation with the underlying Harrison Formation is relatively close stratigraphically to one of the Agate Ash outcrops (also present at North Ridge), and thus is estimated to be between 23-22 Ma. Originally described and named as the Upper Harrison Beds by O. A. Peterson (1907, 1909), these rocks were renamed as the Anderson Ranch Formation by Hunt (2002a). The Anderson Ranch Formation is lithologically distinct from the Harrison Formation and their contact is an erosional unconformity. The sediments of the Anderson Ranch Formation were likely deposited in a broad fluvial paleovalley incised into older Harrison Formation material (Hunt 2002a). The term Marsland Formation, proposed by Schultz (1938) for rocks including not only the Anderson Ranch Formation, but also the overlying Runningwater Formation, has been abandoned.

The Anderson Ranch Formation is a light gray to brown, very fine-grained silty sandstone, approximately 30-54\% volcanic glass shards. Overall, the formation is indicative of more persistent streams and lakes than the underlying Harrison Formation (Hunt 1990; MacFadden and Hunt 1998). Lower strata tend to have distinct laminated bedding, whereas upper strata become massive. The Anderson Ranch Formation is notable for having several different depositional settings layered upon one another, each containing different types of fossils (Hunt 1990). These depositional settings include: fluvial deposits of several types, indicating rivers of different size and permanency; 
lacustrine deposits; eolian volcaniclastic sand sheets; and limestone deposits indicative of shallow ponds. All of these units can be seen in succession at University Hill and Carnegie Hill (Photo 2).

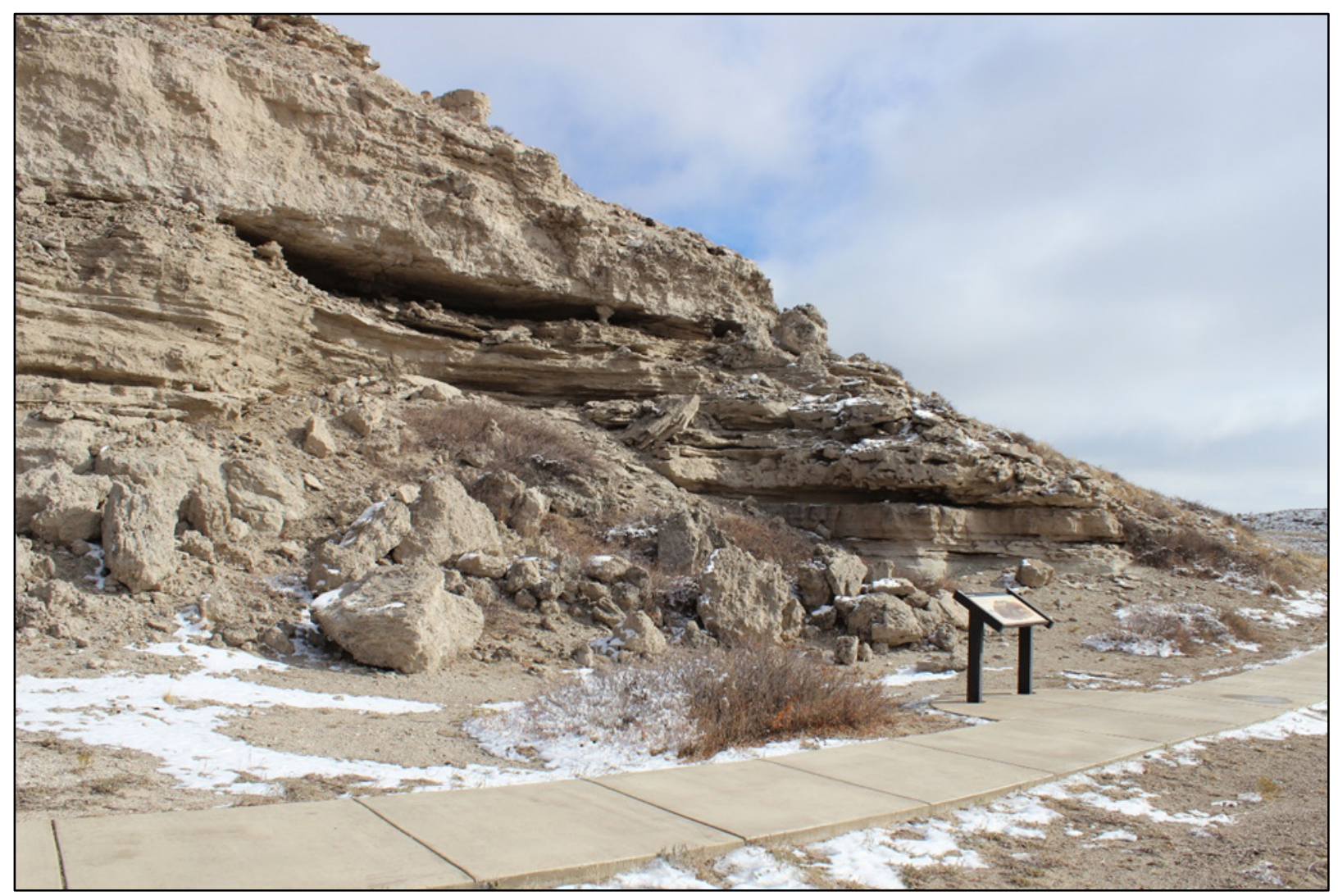

Photo 2. Photograph of Carnegie Hill Southwest Quarry. Carnegie Hill is an excellent example of the Anderson Ranch Formation, with most of the units characteristic of the formation visible at the outcrop (NPS).

The lowest deposits are the intertonguing tuffaceous (volcanic tuff) fine-grained sandstones that envelop the Agate fossil bonebeds at Carnegie Hill and University Hill. The bonebeds of Carnegie Hill and University Hill occur in this section of the Anderson Ranch Formation. The bonebeds are found in the base of a 100-m (30-ft) sequence of stream-deposited fine sands which overlie and incise a gray sandstone below. The bonebed deposit itself is a mixture of lime mud and fine-grained sandstone. The sediments in both Carnegie Hill and University Hill are nearly identical in vertical stratigraphic sequence. This similarity supports the theory that the sandstones now exposed on the two hills shared a common ephemeral stream system (Hunt 1990). The bonebeds are currently interpreted as a watering hole based on the sediments and fossils present. It is hypothesized that a regional drought killed most of the animals preserved within these strata. Similar to some modernday mass mortality events on the African savanna (Foster 1965; Schaller 1972; Backwell et al. 2018), entire herds laid down to die in the waterhole after having eaten all the surrounding vegetation within walking distance (Hunt 1988b, 1990, 2002b). 
Carnivoran bones and their dens are found in deposits stratigraphically lateral to, but topographically higher than, the bonebeds. The dens themselves are younger than the bonebeds, but older than the overlying strata, as they extend down from the paleosol that caps off the bonebed deposits (Hunt et al. 2018). Carnivore taxa found within, and around, the dens include: the amphicyonids Daphoenodon superbus and Delotrochanter oryktes, mustelids Megalictis and Promartes, and canids Phlaocyon and Cormocyon (Hunt et al. 1983; Hunt 1994; Hunt and Skolnick 1996; Hunt et al. 2018). Disassociated bones of herbivores (possibly prey or scavenge of the carnivores) are found within and above the carnivore dens and elsewhere within these strata. Taxa represented in these disassociated remains include Menoceras, the oreodont Merychyus, and camels (Hunt 1995).

Overlying the bonebeds are thin, cross-bedded or horizontally laminated very fine-grained sandstones of a floodplain and stream channel paleoenvironment. Still higher in the Anderson Ranch Formation, many disarticulated bones of camels and oreodonts are found. In areas where the stream deposits were less turbulent, horizontal laminations contain articulated skeletons of Stenomylus sp. Above the tuffaceous sandstone deposits are massive, very fine-grained silty sandstone deposits containing eolian volcaniclastic loess (windblown silt) mantled on a floodplain (Hunt 1990). These deposits contain small burrow casts, rhizoliths, oreodonts, and camels. Well-indurated benches with a high rhizolith concentration in the silty sandstone represent paleosol horizons (Hunt 1990; Retallack 2004). The terminal deposit of the Anderson Ranch Formation is a thin bed of white limestone, often pervaded by silica in the form of chert. The paleoenvironment for these limestones is one of shallow lakes in which invertebrate and plant fossils occur (Hunt 1990).

The Anderson Ranch Formation is fossiliferous throughout AGFO, not just at the Fossil Hills, though the quality and quantity of specimens is much reduced. Fossils found within the formation elsewhere in the Monument include root casts, invertebrate burrows, vertebrate burrows, and vertebrate bone fragments (Hunt 1990; MacFadden and Hunt 1998).

\section{Runningwater Formation}

The youngest formation at AGFO is the Runningwater Formation, deposited sometime between 18.8 and 18.0 Ma based on paleomagnetic data (MacFadden and Hunt 1998). At AGFO it occurs at two distinct exposures along the north border of the Monument. A disconformity separates this formation from the underlying Anderson Ranch Formation (Hunt 1988a). The Runningwater Formation particularly differs from all of the formations previously discussed by its much lower volcaniclastic content of less than 15\% (Strömberg 2002, 2004). It is a fluvial unit formed from the action of energetic streams in deep channels, and composed of buff to orange sandstone, with some lenses of gravel and silt (Hunt 1988a). Zones are locally cemented by carbonates, though not to the extent of forming distinct limestone caprock strata like in the uppermost Anderson Ranch Formation. The exact upper limit of these youngest rocks is uncertain because Runningwater Formation tuffs are vitric and datable crystals are rare (R. Hunt, Jr., pers. comm., 2019).

The Runningwater Formation is not known to be fossiliferous at AGFO, but fossils have been found within it at exposures near AGFO. These fossils include phytoliths (bits of silica secreted within plant tissues) from grasses (Strömberg 2002, 2004) and a large variety of mammals (Korth et al. 1990; MacFadden and Hunt 1998; Hunt 2004; Graham 2009). 


\section{Quaternary Deposits}

Alluvial and terrace sediments, including Quaternary sands, silts, and gravels, patchily blanket the

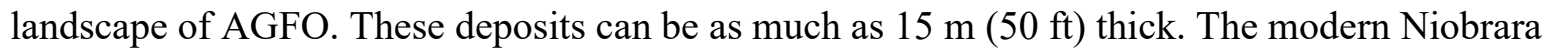
River deposited these sediments, and they are thickest around its current floodplain. Quaternary-age sand dunes can also be found on the lateral margins of the Niobrara floodplain; an example can be seen to the west-northwest of the D-Trail (E. Evanoff, pers. comm., January 2020). These units are not known to be fossiliferous at AGFO, but organic material has been confirmed to exist within them (Graham 2009). Furthermore, there are Pleistocene megafauna sites in the vicinity of AGFO, and a mammoth molar found in Niobrara River gravel as float in the area of the Cook ranch in 1906 (Cook 1914; Hay 1924) may have been found within the Monument's boundaries.

\section{Geologic Maps}

The Geologic Resources Inventory (GRI) program of the NPS has helped create new digital geologic maps for AGFO (Figure 2). The maps are comprised of GIS data layers, along with some associated GIS data tables and an ancillary file containing figures and tables. A related report summarizes the contents of the maps and makes management recommendations (Graham 2009). The maps were updated just as this PRMP was being finalized (July 2020).

Maps and related materials can all be found on the Data Store section of the Integrated Resource Management Applications (IRMA) website. Links to the scoping session summary (NPS 2003), geologic resources report (Graham 2009), and digital maps are provided below:

Scoping Summary: https://irma.nps.gov/DataStore/Reference/Profile/2250146

Report: https://irma.nps.gov/DataStore/Reference/Profile/661528

Maps: https://irma.nps.gov/DataStore/Reference/Profile/1047294

\section{Paleontological Resource Sensitivity Maps}

Sensitivity maps show the distribution of units within a park that have been documented as fossiliferous elsewhere. This provides an estimation of where undiscovered fossil localities may be found. Because AGFO is small, and the major units exposed within the Monument are already known to be extensively fossiliferous, these maps are of limited use for AGFO. Such a map could potentially have some utility in indicating the locations of Sharps Formation, Runningwater Formation, and Pleistocene sediment deposit exposures, which have not produced documented fossils at AGFO but are fossiliferous at nearby locations.

\section{AGFO Park Atlas}

Geological and paleontological data has been incorporated into the AGFO Park Atlas (Figure 2).

Figure 2 (Next Page). AGFO Print Park Atlas, Geology Layer (image modified to show only main map). Shows surface exposures of AGFO geologic units and marks historic paleontological quarries (but not other localities). Terms for geologic units are not current on this map. "Unnamed lithic unit" should be "Sharps Formation," and "Upper Harrison Beds" should be "Anderson Ranch Formation." The Stenomylus Quarry and Hickey Locality are not shown on this map and are located to the east. 


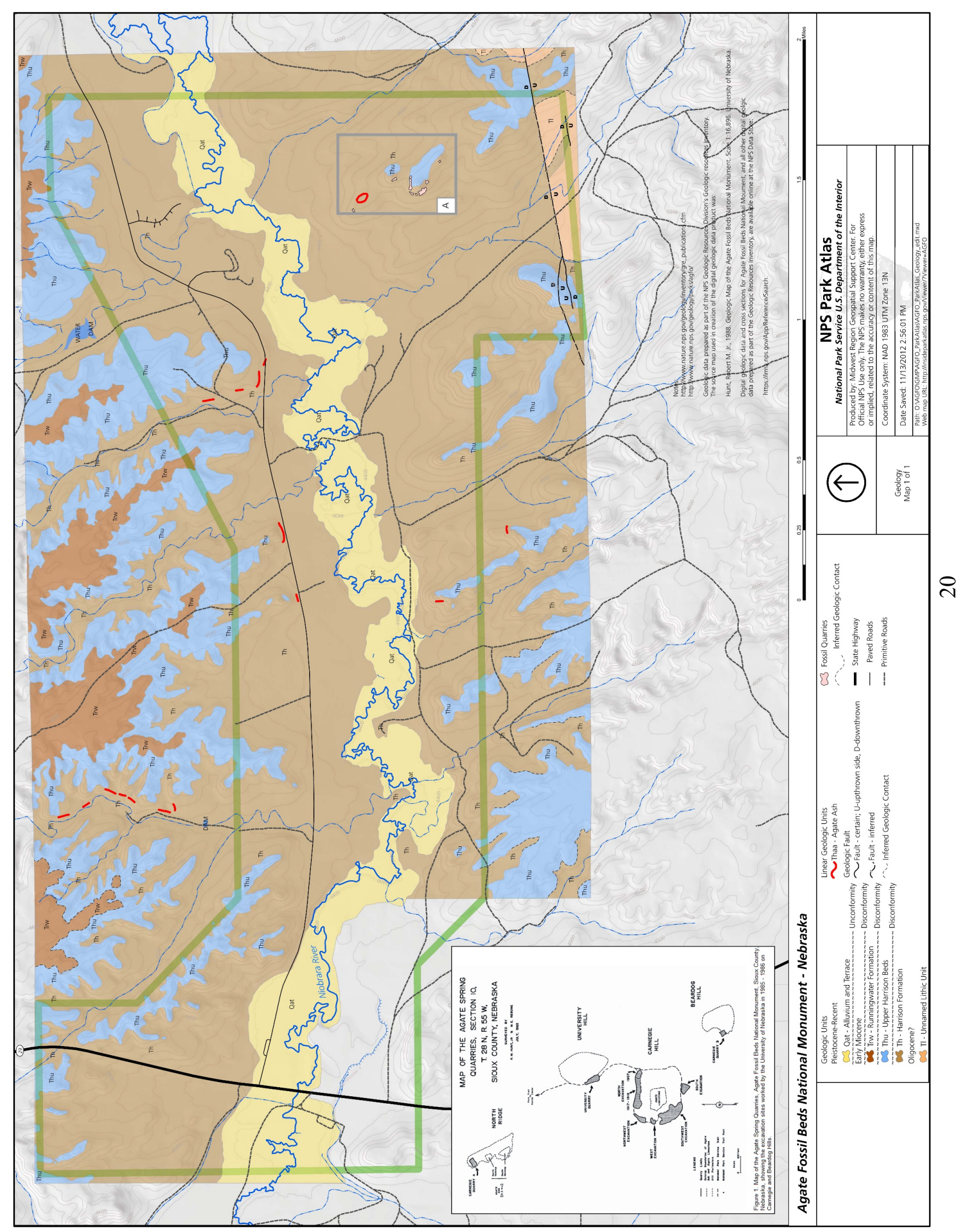




\section{History of Paleontological Work at AGFO}

Paleontologists have studied fossils from the area now administered as AGFO since 1891. Through the years scientists from many institutions have studied and worked at the site, primarily quarries at Carnegie Hill and University Hill and the Stenomylus Quarry. Some of the institutions represented include, but are not limited to: the American Museum of Natural History; Amherst College; the Carnegie Institute's Museum of Natural History; the Colorado Museum of Natural History (now the Denver Museum of Nature and Science); the Field Museum of Natural History; Princeton University; the Smithsonian Institution; the Universities of Chicago, Kansas, Michigan, and Nebraska; and Yale University (Hunt 1984; Graham 2009; Tweet et al. 2011). Some of the excavations here have uncovered the remains of animals previously unknown to science and have produced fossils for exhibit in museums throughout the world. Various names have been used for the AGFO area over the years and by different institutions, such as Agate, Agate Springs, Agate Springs Ranch, and Cook Ranch. A museum visitor who sees a specimen with any of those identifications is likely looking at material collected from what is now AGFO. Fossils with more general identifications, such as Sioux County, northwestern Nebraska, and western Nebraska, may also have come from AGFO.

Excavation began with the removal of approximately one ton of Daemonelix burrow casts in 1892 . With the discovery of bones in 1904, considerable competition began between major universities and museums for the opportunity to excavate at key sites (Photo 3). An excellent history of the excavations and paleontological field work is presented in Hunt (1984). By 1925 research interest in the Agate fossil hills had declined. This decline in interest was due to several factors, including the discovery of other paleontological sites and the saturation of museum needs for exhibit material. Institutions such as the Carnegie Museum of Pittsburgh, American Museum of Natural History in New York, the University of Nebraska, and Amherst College concluded the bulk of their field work at this time (Hunt 1984). Between 1930 and 1981 work was limited to preparation of excavated materials.

Most of the paleontological work within the Monument since 1981 has been conducted by Dr. Robert M. Hunt, Jr., Curator of Vertebrate Paleontology and Associate Professor of Geology, University of Nebraska-Lincoln (now emeritus) and his associates (Hunt 1988b; Graham 2009; Tweet et al. 2011). Most notably, during the 1980s Dr. Hunt's team discovered, excavated, and published papers on the earliest then-known large mammalian carnivore dens and the carnivoran skeletons found within (Hunt 1995). Dr. Hunt also studied the stratigraphy and depositional environments of AGFO, putting forth the current hypothesis that the bonebeds of AGFO were created by a mass mortality event around a watering hole caused by drought (Hunt 1992). Additional operations since 2012 have been conducted by H. Gregory McDonald (BLM), BADL staff, and South Dakota School of Mines and Technology (SDSMT) faculty and students (Pagnac 2015).

Most fossil collecting at AGFO today is undertaken for salvage reasons (Photo 4), though it is possible that new research excavations could occur pending sufficient scientific merit and the permit approval process. However, the Stenomylus Quarry has been under a moratorium on any future excavation and research since the 1980s; see "Research Management" for more details. 


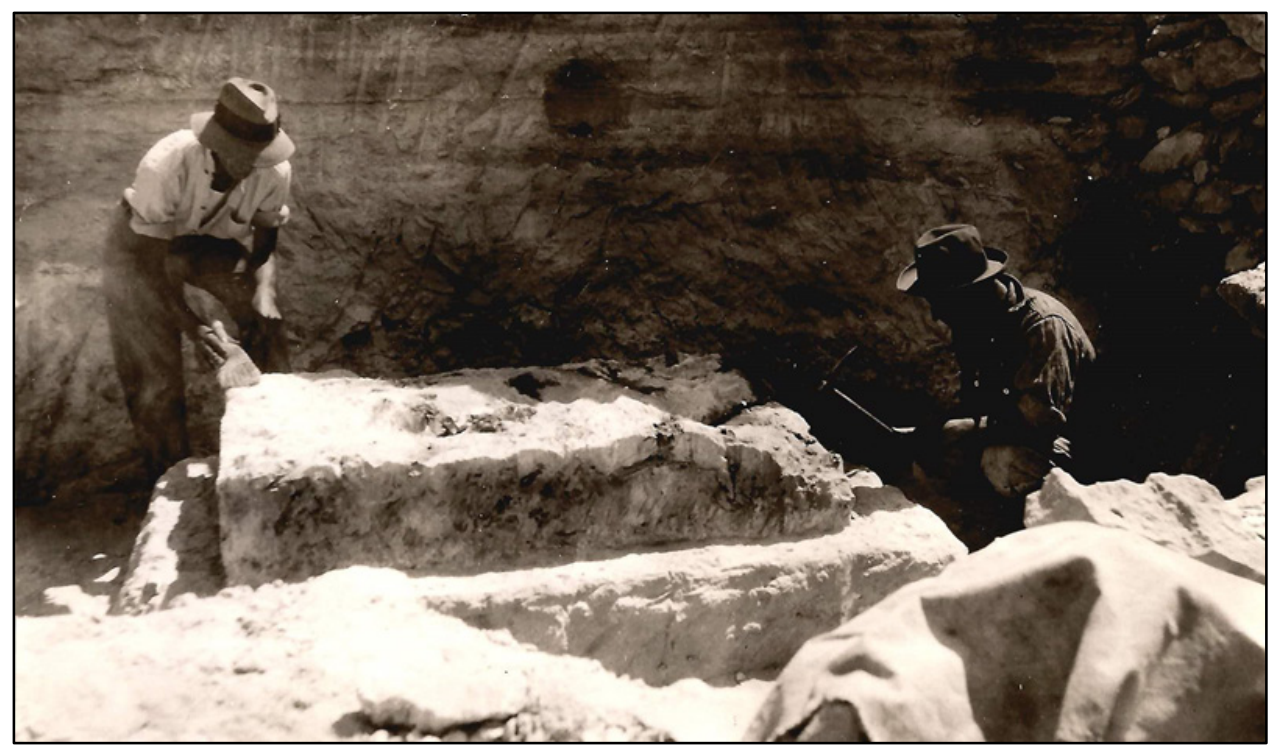

Photo 3. Historical photograph of workers excavating a slab at the Agate Springs in the early $20^{\text {th }}$ century (NPS). Early excavations at future AGFO were mostly done to obtain exhibit specimens.

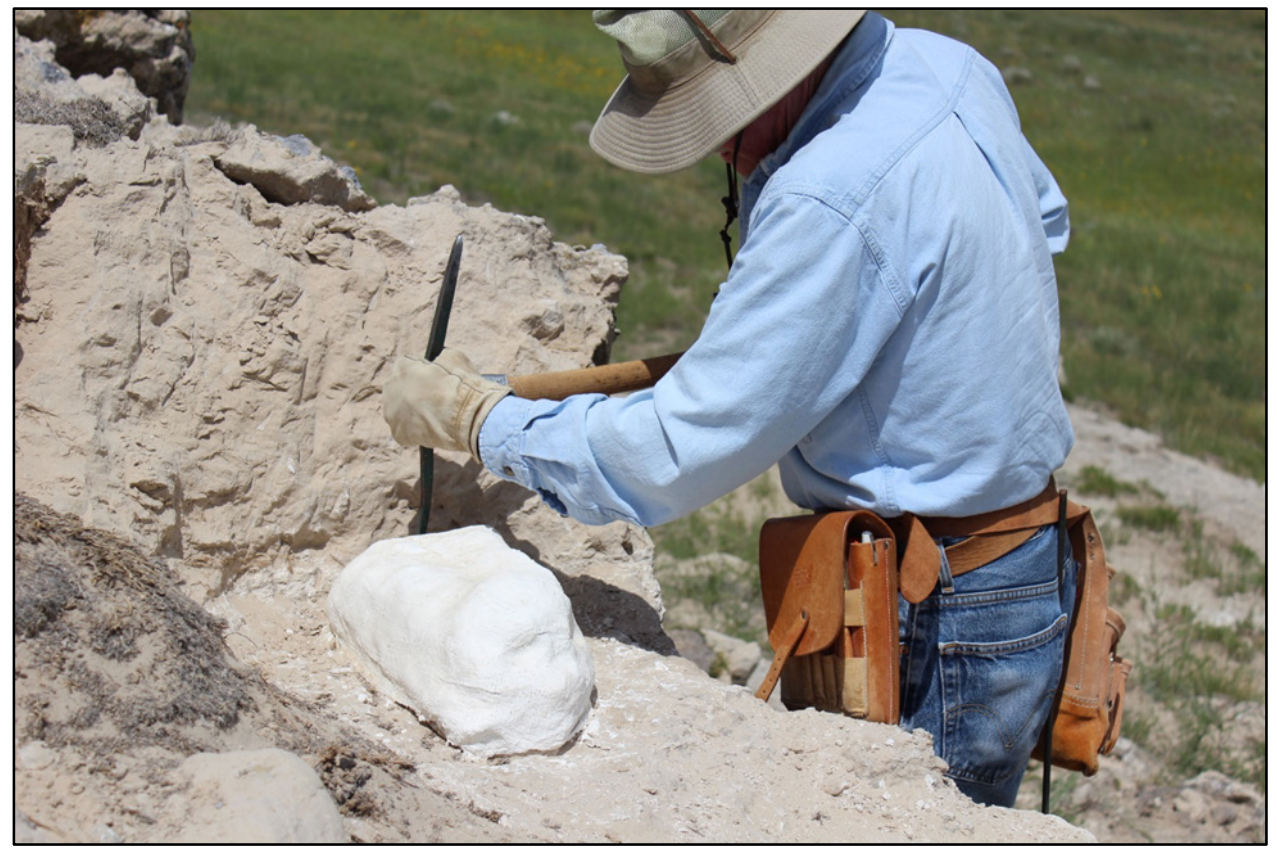

Photo 4. Dr. Robert Hunt, Jr. carefully extracting a jacketed specimen from the surrounding rock. This photograph is of a salvage collection undertaken in 2013, but Dr. Hunt has a long history of paleontological research and work at AGFO going back to the 1980s (NPS).

\section{Current Hypothesis on Origin of AGFO Bonebed}

The bonebed found within the Anderson Ranch Formation of Carnegie Hill and University Hill is the most famous fossil horizon at AGFO. This bonebed was the focus of most of the pre-authorization excavations at AGFO (Hunt 1984) and was also a major component of University of Nebraska research in the 1980s (Hunt 1988b). It has produced hundreds of museum specimens, including 
bonebed slabs of Menoceras, several entelodont skeletons, and the remains of an entire population of chalicotheres (Hunt 1984). Carnegie Hill today likely contains the remains of several hundred more animals (Hunt 1984). Over time, several hypotheses were put forth by researchers to explain the bonebed's origin. These included: lacustrine or floodplain accumulation over time (Peterson 1906; Holland and Peterson 1914); a mass drowning in a river crossing or flood (Schultz 1966); and a drought event (MacDonald and MacDonald 1980; Hunt 1984, 1992). Most of the hypotheses were eventually shown to be problematic, being unable to explain contradictory details about time, scale, or process; for example, the fossils being disarticulated, but often still near many associated bones, and non-random differences in preservation across the bonebed. Of these hypotheses, the currently favored hypothesis is a prolonged drought exacerbated by the animals eating all vegetation within walking distance of the waterhole that would become the bonebed, which would have been one of the sole sources of water during the drought (Hunt 1992).

During the earliest Miocene, the environment at what is now AGFO would have been similar to the modern African Serengeti savanna. Some herbivores would form massive herds, not unlike those seen in the African savanna today. While wetter than the modern Nebraska steppe, this semi-arid environment would still have been subject to occasional drought. When this occurs today, animals cluster around remnant watering holes. If the drought goes on for long enough, however, the herbivores gradually deplete the available vegetation near the water source. Eventually, the edible vegetation within walking distance of the waterhole is all consumed, and the herbivores begin to suffer malnutrition and/or starve. Many eventually lay down in the cool mud of the waterhole and die there in a mass death event. These deaths do not occur all at once, but by attrition over a period of months to years (still very rapid in terms of geologic time). This chain of events is the currently hypothesized origin for the waterhole bonebed (Hunt 1988b, 1992).

This hypothesis is supported by a variety of observations. First, the bonebed occurs in two continuous layers across Carnegie Hill and University Hill that were laid down at about the same time, separated by a thin layer of sediment and capped by a sandstone with transitions upward into paleosol (Hunt 1988b). At one time the space between the hills also would have included the bonebed layer, but it has since been eroded away (Photo 5). That each of the two bonebed layers has a consistent sedimentary makeup and sediment profile across both hills supports this. The bonebed layers are formed of mud with a carbonate component, indicative of a low energy, standing water environment. The dividing unit and the lower part of the uppermost unit are sandstones with slight fluvial sedimentary structures, which suggest fluvial input into the low energy pond (Hunt 1988b, 1990). The two different bonebed layers indicate multiple accumulation periods/events; in this case, multiple drought events (Hunt 1988b, 1990). The short period of time between deposition of these two layers is indicated by lack of a drying surface in the thin unit between them; rather, trackways, grooves, and other sedimentary structures at the contact between the lower bonebed and the dividing unit indicate that the sediment remained wet. In one corner of the bonebed, deposition of the intervening unit's fluvial sand either did not occur at all or the dividing unit was destroyed by bioturbation, as the bonebed layers are mixed there. This further suggests a short interval between deposition of the two bonebeds (Hunt 1988b). By contrast, the paleosol above the upper bonebed indicates a long period of drying and soil formation (Hunt 1988b). Taphonomic features such as 
differences in bone color, bone orientation, and skeletal disarticulation/disassociation reveal: differences in the topography of the waterhole, concurring with observed differences in unit thickness at different parts of the bonebeds; consistency with the depositional environment of a muddy, shallow, and low-energy pond disturbed by later animals; and similarities with modern mass death events caused by drought (Hunt 1988b).

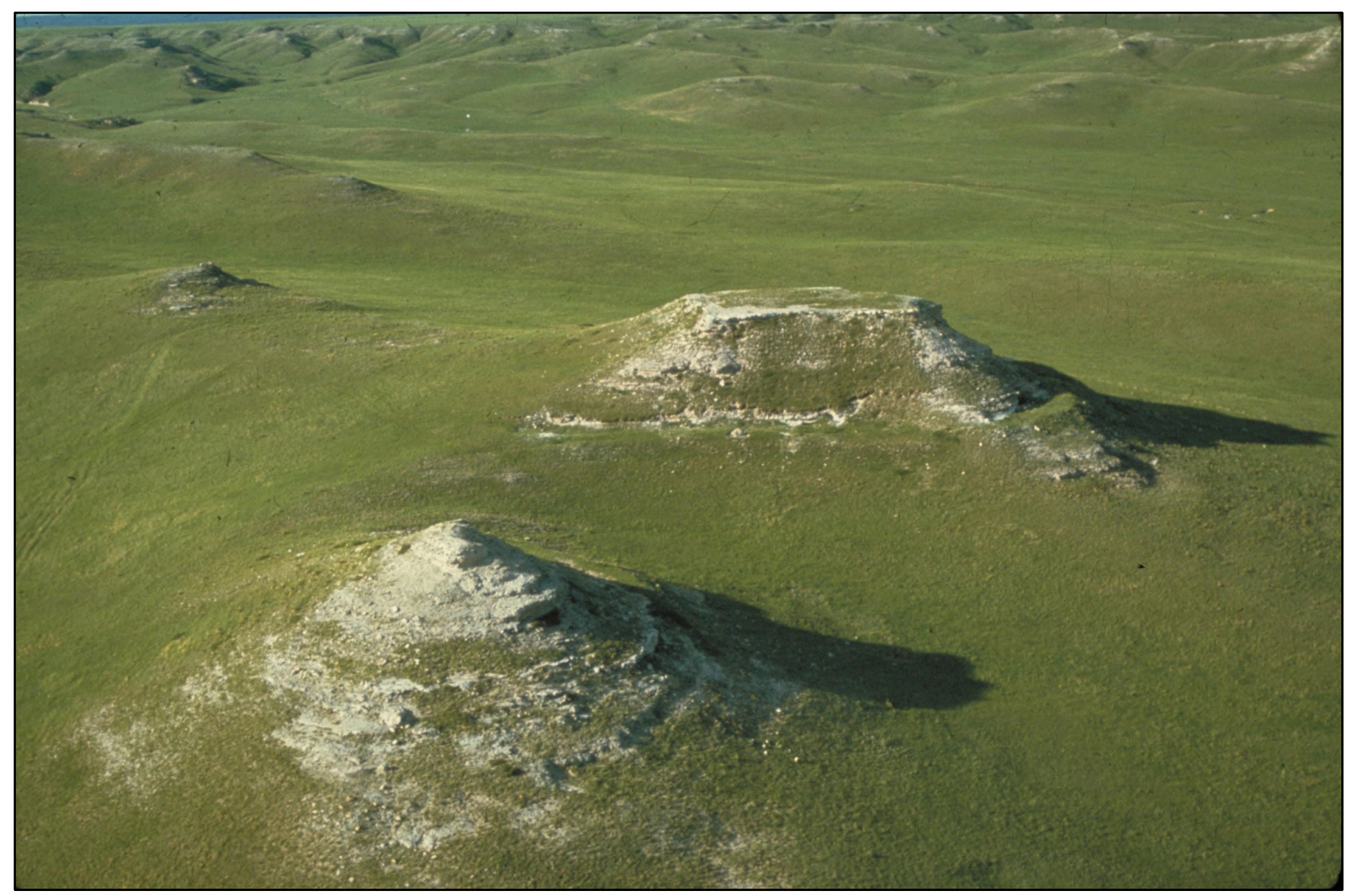

Photo 5. An aerial photo of University Hill (conical, lower left) and Carnegie Hill (flat-topped, center), taken from the northeast (NPS).

Based on the above geology and taphonomy, the events befalling the fossils post-mortem can also be hypothesized. Omnivores and carnivores scavenged parts of the carcasses, aiding the disarticulation of the skeletons, and left the rest to decay and sink into the mud (Hunt 1992). When significant precipitation finally returned, the waterhole refilled, and sediment, mostly sand and volcanic ash, was washed into it. This buried the bones still in the waterhole. In the next dry season(s), the process repeated on a smaller scale and created upper layers to the bonebed (Hunt 1988b). Bioturbation and other animal activity caused portions of various layers to become intermingled and further disarticulated skeletons, while also leaving trace fossils of this activity in the form of tracks (Hunt 1992). Eventually the sediment load added to the pond in the wet season filled it completely, leaving only dry ground upon which a soil eventually formed. This soil is the paleosol that directly overlies the bonebed (Hunt 1988b). 


\section{North American Land Mammal Ages}

The North American Land Mammal Ages (NALMAs) have been used as a biochronologic time scale in vertebrate paleontology since the 1940s. NALMAs describe the age and evolutionary succession of North American mammals and mammalian faunas (Wood et al. 1941). NALMAs are defined largely by the faunal assemblages found throughout the continent (at least three taxa define a given range of time, or chron) and associated correlative data. Abundant, widespread taxa tend to characterize a given NALMA, because their presence allows easier correlation of localities and faunas on a continent-wide scale. NALMA boundaries are further refined via correlation with radiometric dating, paleomagnetism, and other geologic data (Woodburne 2004).

The system delineates distinct biochrons in order to accommodate both a continent-wide understanding of faunal succession/evolution across the Cenozoic, and a limited generalized picture of the ecology during each NALMA. Transitions between NALMAs indicate major transitions in North American paleoecosystems. NALMAs also allow easier reference to broad bio- or chronostratigraphic intervals than more specific, short-lived intervals of biostratigraphy such as the stratigraphic range of an index taxon. However, subdivisions and Interval Zones within NALMAs are also defined based on more refined first appearances and index taxa. This system is so useful in the study of mammalian paleontology that it has been replicated on other continents and expanded into the Holocene (Barnosky et al. 2014) and Late Cretaceous (Woodburne 2004).

\section{AGFO's Role in Defining the Arikareean NALMA and Miocene Epoch}

The fossils found on the land that became AGFO were critical in defining the Miocene Epoch (and therefore the Paleogene-Neogene boundary) in North America, as well as part of the Arikareean NALMA. The bonebed assemblage at AGFO, containing Moropus, Menoceras, Dinohyus, and Daphoenodon among other taxa, differed distinctly from the mammalian assemblages of the White River Group (Photo 6). This assemblage was used to mark the beginning of the Miocene as well as a major subdivision of the Arikareean, making AGFO a foundation of North American biostratigraphy and geochronology (Wood et al. 1941; Tedford et al. 1987; MacFadden and Hunt 1998).

The Arikareean is an especially important NALMA because it represents a transitional fauna from the less modern taxa and assemblages of the Paleogene to those of the Neogene, which over time increasingly approach and resemble the recent in form, function, and ecology. The taxa of AGFO's bonebed are part of the type fauna that defines the fourth subdivision of the Arikareean (Ar4; Anderson Ranch, including the quarries, is also the type area), while the Daemonelix zone is representative of the third Arikareean subdivision (Tedford et al. 2004). Current estimations of the bonebed's age puts it between $22.9 \pm 0.08 \mathrm{Ma}$ (Izett and Obradovich 2001) and 19.2 $\pm 0.5 \mathrm{Ma}$ (Hunt et al. 1983) based on the Agate Ash and Eagle Crag ash layers, respectively. Current interpretation at the Monument, and by Hunt et al. (2018; R. Hunt, Jr., pers. comm., October 2019), places the bonebed (and thus the beginning of Ar4) closer to the older date than the younger date. This contrasts with the time scale depicted in Tedford et al. (2004) (Figure 3). Although it is beyond the scope of this document to resolve the biochronological implications of relatively old Anderson Ranch Formation bonebeds, further work on the ages of the major paleontological features at AGFO is recommended to ensure that the Arikareean subdivisions accurately reflect the ages of their faunas. 


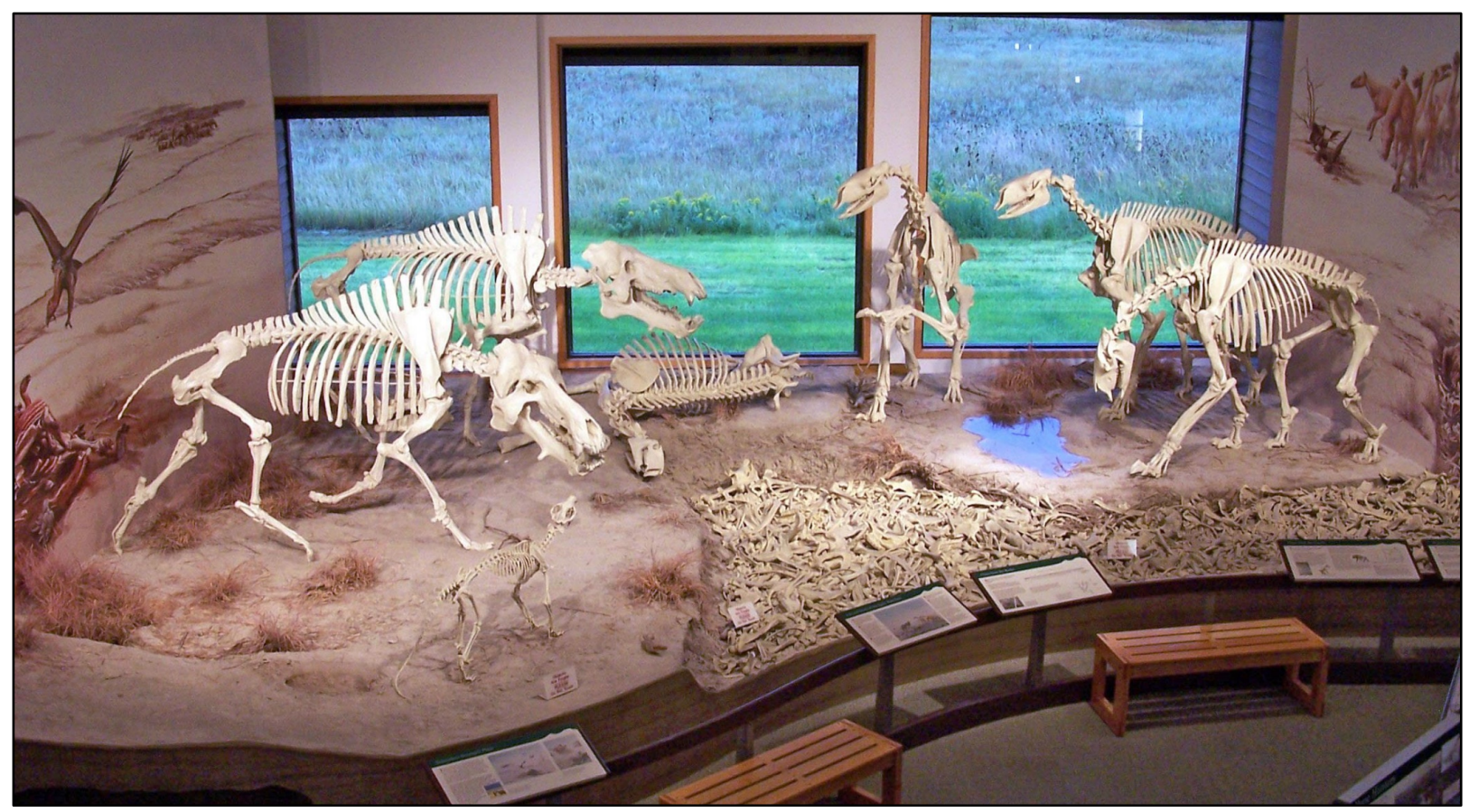

Photo 6. The Visitor Center hosts a fossil display showing mounted casts of Daeodon (two large skeletons on the left), Moropus (three standing skeletons on the right, and fallen skeleton), and Daphoenodon (small skeleton, left foreground), and a bonebed of mixed material (NPS). These AGFO taxa have been used to define the Early Miocene in North America. 


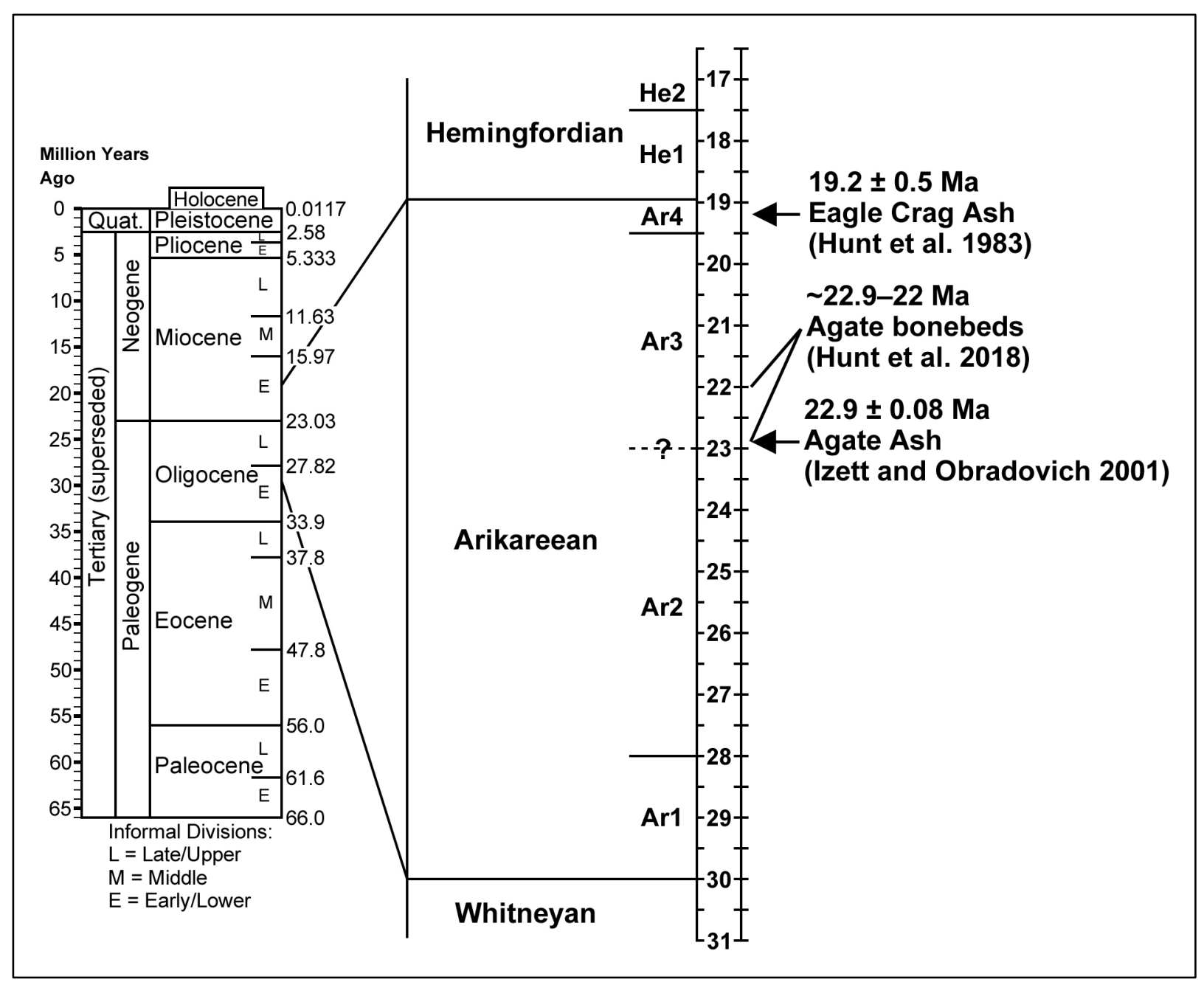

Figure 3. Timeline adapted from Woodburne (2004) showing NALMA and NALMA subdivisions, with a timeline for the entire Cenozoic for comparison. As NALMAs are based on biochrons (faunal assemblages) instead of geochrons (absolute dates), if the current estimate of $\sim 22-23$ Ma for the formation of the bonebeds is supported, the subdivisions of the Arikareean need to be reevaluated. 



\section{Paleontological Resources Management}

\section{Strategic Goals Relating to Paleontological Resources}

The management of paleontological resources is undertaken for various reasons, on behalf of several interests, and is mandated and guided by laws, policies and scientific principles. A comprehensive plan for the management of these resources thus needs to first consider the multifaceted nature of strategic management goals for non-renewable paleontological resources.

\section{Resource Preservation and Curation}

The preservation of natural resources, including paleontological resources, is a core value and mandate of the NPS embodied in the Organic Act of 1916. The Paleontological Resources Preservation Act of 2009 establishes specific requirements for the protection and use of paleontological resources on NPS and other specified federal lands. AGFO's enabling legislation (1965) sets aside the Monument in part to ensure that the fossils found therein remain available for the intellectual pursuits and enjoyment of future generations.

Resource preservation goals cover a wide range of activities, including but not limited to: inventory; monitoring; mitigation methods (e.g., stabilization, reburial); photogrammetry, collection; and curation. These activities are meant to prevent impairment or degradation of non-renewable paleontological resources, ensuring that they are available for future public education and enjoyment, and accessible for scientific study. Resource preservation covers not only fossils and their geologic/geographic context, but also the associated research and administrative history. Preservation and curation of archival records, including publications, field notes, photographs and other archives detailing administrative, resource management, interpretive, or other scientific activities are important aspects in long-term management of fossils. The following are critical tasks and goals to be undertaken in the interest of preserving paleontological resources in accordance with established scientific principles and resource management practices:

- The Monument will inventory its paleontological resources. Knowing what resources are present is an essential first step in managing those resources.

- The Monument will routinely monitor the condition and stability of its paleontological resources for degradation risk factors or changes in condition, in order to inform management decisions.

- The Monument will assess the potential impact of non-paleontological activities, such as construction, on areas where fossils or paleoenvironmental indicators may be found.

- As exposed fossils are non-renewable and eventually subject to natural destruction, in some cases collecting fossils and storing them in repositories is the best method of preservation.

- At other times, it is to the benefit of the Monument and public enjoyment for exposed fossils to remain visible in situ or as float; this is particularly true for fossils of low scientific significance, such as small bone fragments.

- All fossils collected, whether for salvage, interpretation, or research, must be stored in a qualified repository that meets NPS standards. 
- The condition/status of specimens classed as controlled property (e.g., holotypes) must be checked annually. Other specimens are checked when their specimen numbers are selected in an annual random sample.

○ Conditions at non-federal repositories must be assessed once every five years unless the facility is accredited by the American Alliance of Museums.

- Records related to any activity involving paleontological resources within or relevant to AGFO must be preserved in Monument archives and backed up to NPS paleontology archives.

- This preserves a history of management actions and provides a knowledge base for staff or visiting researchers to become informed.

- Resource management decisions should always be based on current scientific understanding.

- Monument staff should be aware of their level of expertise in the field, and be willing to consult outside specialists for advice on subjects where staff lack requisite knowledge.

\section{Supporting and Overseeing Scientific Inquiry}

The Paleontological Resources Preservation Act requires both protecting and managing paleontological resources "using scientific principles and expertise" and "[development of] appropriate plans for ... scientific... use of paleontological resources." AGFO was authorized as a unit of the National Park Service partly to "provide a center for continuing paleontological research."

Because the NPS must manage resources under its care according to the best available science, it is imperative that scientific study be encouraged and assisted at AGFO. However, especially in regard to non-renewable resources like fossils, scientific study can degrade, remove, or destroy resources. Thus, scientific and scholarly inquiry must be balanced alongside the NPS mandates to preserve and interpret resources. Therefore, permits and the permit approval process are critical to ensuring that proposed research is scientifically significant and has negligible or acceptable impacts on other park operations, condition of resources, public or cultural opinion, and/or safety. AGFO should post parkspecific permitting conditions, and review all proposed research in a timely and fair manner. Longterm partnerships should be considered to facilitate research in the Monument and to more effectively integrate potential research into existing resource management activities (e.g., inventory, monitoring).

Most importantly, proposed research must fulfill one or more of the following criteria:

- Research furthers understanding of scientific questions related to the paleontological resources of AGFO;

- Research improves the ability of AGFO staff to interpret the fossil record for the Monument;

- Research informs AGFO staff about the scope, significance, location, distribution, condition, stability, required mitigation, and other management issues associated with the stewardship of non-renewable paleontological resources. 


\section{Public Education and Interpretation}

The Paleontological Resources Preservation Act requires "[development of] appropriate plans for... educational use of paleontological resources.” AGFO's founding legislation and its Foundation Document (NPS 2012) include "interpretation of Miocene epoch fossils" as a core function of the Monument.

AGFO's interpretive program currently focuses on conveying four primary themes to visitors. These themes are essential for developing visitor knowledge and understanding of the resources, reflect the Monument's purpose and significance, and connect the resources to relevant current ideas, hypotheses, events, and values. The four primary themes are as follows (text paraphrased from Foundation Document and Long-Range Interpretive Plan [NPS 2011]):

- Transitions: "Agate Fossil Beds National Monument provides an example of how the earth has changed in appearance, over eons of geologic time, and how changing conditions altered the ways that animals and humans lived, and died, on these lands."

- Interactions: "Animals, and more recently humans, have gathered for millions of years on land within the park, providing a window into the interactions of diverse species and cultural groups."

- Discovery: "For more than a century, the park's lands have been the focus of scholarly inquiry, illustrating how the study of science has matured over time, and how stewardship has protected a landscape now deemed a national treasure."

- Discoveries: "Decades of scholarly investigation not only opened our eyes to other worlds inhabited by different-looking creatures but also revealed multiple lessons that shed light on subjects relevant to the $21^{\text {st }}$ century including extinction, evolution, climate change, and cultural interaction."

Aside from these core themes, AGFO is also focused on educating students from pre-school to college level, as well as families; providing visitors interactions with "real" things; ensuring accessibility of interpretive programs for all visitors; reaching out to and encouraging stewardship in local audiences; and providing interpretive and educational experiences to those unable to physically visit the Monument.

Lastly, the Monument attempts to teach good stewardship and the importance of resource preservation to visitors. Doing so helps prevent anthropogenic disturbances, informs about the significance of the fossils, builds public advocacy for paleontological and other natural resources, and educates about the scientific process and the breadth of knowledge contained within fossils and their geological contexts. Methods range from Junior Ranger programs for children, to exhibits for all ages discussing the key importance of in situ context in paleontological study.

\section{Paleontological Resource Inventories}

Paleontological resource inventories help to establish a baseline of information essential for the design and implementation of other management actions and procedures involving fossils. Paleontological resource inventories assess the scope, distribution, initial conditions, and management issues associated with a park's paleontological resources. A paleontological resource 
inventory is more than a field survey of fossiliferous strata and localities, because it also includes reviews of museum collections, historical records, and other available archives related to NPS paleontology. The end product of an inventory project is an inventory report, published in the Natural Resource Report series (NRR), which assembles all of this information.

A paleontological resource inventory is not a routine management action. Even if it does not include a comprehensive field survey, an inventory is time-intensive to complete and provides a broad baseline for scope and condition for fossil resources not expected to significantly change in the short term. As such, paleontological inventories are intended to stand for a span of decades. If done properly, a paleontological resource inventory for a given park should be adequate until major changes necessitate a new one. Such changes could include: changes to park boundaries that either bring in additional fossil sites or remove previously known sites; post-inventory research leading to a revised understanding of a park's fossils and/or their context; the discovery of new localities; a natural event that impacts the fossil resources; or simply the passage of time. Even in these cases, the production of a small updated supplementary report is recommended over a full inventory if possible.

An inventory project may be performed by qualified AGFO or other NPS staff, volunteers and/or interns with adequate training, or trusted non-NPS personnel (Photo 7). Given the scale of a full inventory, even at a relatively small NPS unit like AGFO, it is recommended that an inventory project be conducted by a small team and not a single individual. This is especially true if the primary worker is a volunteer, intern, or non-NPS personnel. Park paleontological inventories may require multiple years to complete; however, given previous work and the size of the Monument, an inventory for AGFO could likely be completed in one year. Alternatively, an inventory project can be spread out in discrete seasons over several years and/or subjects to ease logistics and work-load; if this is the case, at least one person on the inventory team should be constant throughout the entire process to ensure continuity and consistency.

The 2011 NPS Northern Great Plains Network Paleontological Resource Inventory and Monitoring report provides a background and summary of paleontological resources at several NPS units, including AGFO (Tweet et al. 2011). This document can serve as a base for the development of a full-scale inventory report at AGFO. Detailed recommendations regarding inventory and the creation of an inventory report at AGFO, as well as current efforts to inventory and reorganize the AGFO paleontological archives, are included in "Summary, Conclusions, and Recommendations". 


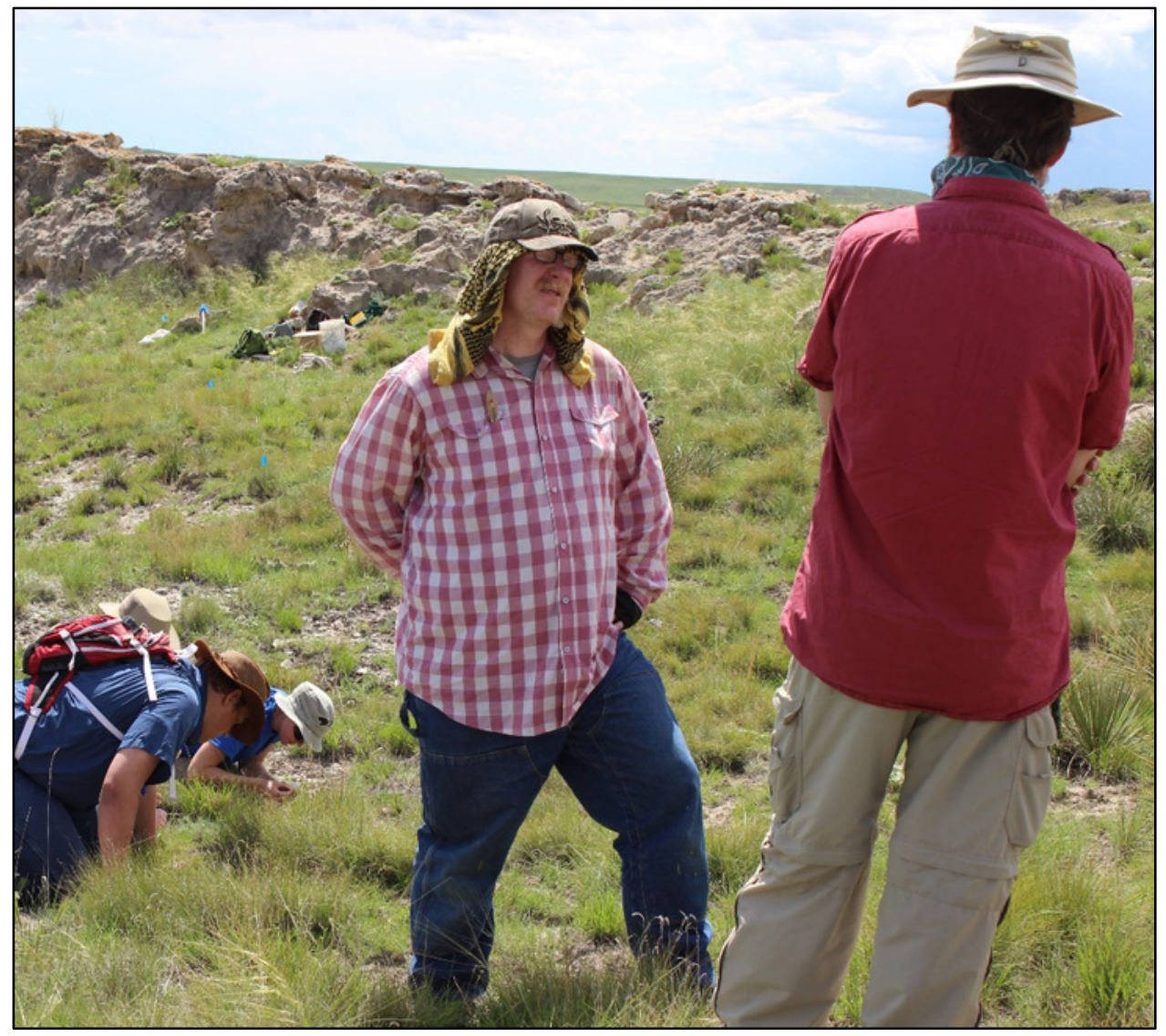

Photo 7. Dr. Darrin Pagnac (South Dakota School of Mines and Technology) conducting a survey of a locality in 2015 with his field paleontology class. Inventory projects can make use of permitted non-NPS researchers to help conduct inventory as part of their studies, especially field surveys. Completed inventories can be augmented with the results of later research as well (NPS).

\section{When Are Specimens Collected During Inventory?}

During field inventory/survey, it is highly likely that staff will encounter fossils. In most cases, these fossils should be noted, photographed, and recorded, then left as they were found. However, there are scenarios where collection of specimens is justified as part of, or in addition to, the baseline inventory. The first scenario is emergency salvage, where a specimen is found to be in sufficient peril from an imminent threat (e.g., heavy erosion) that to not recover it would result in its swift utter loss or destruction. The other scenario is when collecting a specimen would be instrumental to the inventory process. This includes taking specimens that may have qualities indicative of a locality's paleontological and/or management significance and are difficult to assess in the field. Examples of such qualities include, but are not limited to: complete or articulated specimens; unusual preservation; evidence of pathologies; complex or cryptic ichnofossil assemblages; or a fossil suspected to belong to a taxon previously unknown at a given park unit.

Factors other than scientific and/or management merit, such as impact on park operations or historical/cultural value of the resources, must be considered in determining whether collection is appropriate in these cases. Collection in any circumstances either requires a valid permit or explicit 
permission of the superintendent. Collection should only be undertaken by qualified personnel, and must be accompanied by appropriate recording of the specimen and its context prior to removal. Documentation of in situ fossils is often accomplished through photography or photogrammetry without the need to actually collect a specimen from the geologic strata. Further details about scientific significance, research goals, and justifications/qualifications/procedures in regard to field collection are detailed in "the Paleontological Research Management" section.

\section{Documenting and Numbering New Fossil Localities}

NPS Director's Order 77 provides a minimum recommendation for the documentation of paleontological sites. The metadata collected for each locality consists of information identifying the precise location, geologic context, types and significance of fossils, and the condition of the locality.

New fossil localities discovered during inventory should be documented using the locality information sheet (Appendix B) and locality condition form (Appendix C). All fields on these forms should be filled out. Additional information not accounted for on these sheets that a recorder thinks pertinent should be written on a separate sheet which is then archived along with the two aforementioned forms.

Part of this process involves taking photographs of the locality; there should be a minimum of two photographs, one a wide shot of the entire locality including enough visible landmarks or other details to relocate it, and one a close shot displaying pertinent details of the locality, such as exposed fossils or characteristic sedimentary structures. Taking more photographs is recommended, including photographs that document individual fossils exposed at the locality's surface. A common item or scale bar should be included for scale when taking photographs of outcrops or fossils. Photographs should also be accompanied by data listing the number and/or name of the site, the direction in which the photographer was facing, the photographer's name, the date on which it was taken, and any corresponding GPS tags.

If appropriate, inventory at a new locality can be combined with setting up any tools or methods needed for future routine management activity, like installing erosion stakes for monitoring. However, in many cases it is better to assess the information gathered during the field work before implementing any other management procedures at a new locality.

The new locality is assigned a new locality number, which for AGFO is in the format of AGFO-FL$\# \# \#$, where the final number is the next number after the last previously named and numbered locality. For example, the current AGFO localities are numbered from AGFO-FL-0001 to AGFOFL-0030. The next new locality would be numbered AGFO-FL-0031. Photographs taken at a locality should have this number recorded on them somewhere.

Confidentiality of Fossil Localities

Section 207 of the National Parks Omnibus Act of 1998 authorizes the NPS to withhold information concerning the nature and specific location of paleontological resources and/or localities within NPS units, even in response to requests under the Freedom of Information Act (NPS DO 77). A park is therefore not obligated to provide individuals with precise locality information, although it may do so 
at its discretion, such as for qualified researchers. The PRPA also provides for the non-disclosure of paleontological data if disclosure will jeopardize the resources.

Parks should have researchers sign a confidentiality agreement when providing assistance with research requests. The agreement outlines what the researchers' responsibilities are and what restrictions are in place on using/sharing the data. Research requests should be documented so that parks can track the following: where the data is going; how many times the specimens or data is being accessed; and how long it takes to process a research request. Documentation of this information benefits park planning purposes and records how often a collection is used (useful for justifying the importance of park collections).

\section{Paleontological Resource Monitoring}

Monitoring is a necessary step in management of in situ paleontological resource, because it assesses change in condition of the resources and their localities over time. This indicates when management priorities and actions need to change in order to best preserve fossil resources (Santucci and Koch 2003; Santucci et al. 2009).

\section{Threats to Fossil Resources}

\section{Natural Processes}

The biggest threat to in situ or float fossil resources is loss or damage due to erosion (Santucci et al. 2009). Sedimentary rocks such as sandstones and mudstones are relatively soft and highly susceptible to erosion by wind and water compared to other types of rocks. The majority of the fossils recovered from the Harrison Formation occur in a mixture of bentonitic mud and sandstone. Fossils from the Anderson Ranch Formation occur in very fine, tuffaceous, and silty sandstone.

One characteristic of mudstone and siltstone is that when wetted they may revert back to their original forms: mud and silt. In addition, bentonitic mudstones contain a large amount of volcanic ash, which allows them to absorb several times their own mass in water, which causes them to swell. This causes mudstone to break apart rapidly when wetted, possibly heavily damaging or destroying any fossil bone present in the rock.

The expansion and contraction of ice caused by freeze-thaw, as the temperature moves back and forth across the freezing point of water, can also be a major agent of erosion by widening cracks. AGFO is located in a continental climate which frequently experiences this change in temperature during the fall, winter, and spring.

While most quarries in the Monument are protected by much more durable capstone, erosion from natural sources still results in about $0.3 \mathrm{~m}(1 \mathrm{ft})$ of erosion per decade. This rate of erosion threatens the degradation or loss of fossil resources on a human time scale. For example, there is an interpretive sign on the Daemonelix Trail that attempts to point out a series of Daemonelix in a cliffside, but the fossils are far more eroded than their depiction in the sign's photograph and therefore are difficult to spot. Thus, it is imperative that highly fossiliferous areas are frequently monitored to protect previously exposed fossils and find new ones before they are damaged or destroyed, as mandated by NPS DO 77. 
Assessment of these types of threats includes the following considerations: extent of fossiliferous strata consolidation and rate of natural erosion; fragility of the fossils themselves; rate of fossil loss/destruction by natural causes; whether excessive erosion is being actively mitigated via stabilization techniques; and whether routine monitoring and cyclic prospecting has been successfully maintained.

\section{Human Impacts to Paleontological Resources}

The second biggest threat to fossil resources is human activity. Humans may disturb or destroy fossils either intentionally or unintentionally. As an NPS unit open to the public, AGFO's fossil resources are constantly exposed to human activity and attention.

Unintentional harm usually comes from ignorance or carelessness, where fossils are stepped on or moved without knowing what they are, or without recognizing the scientific importance of context. Visitors may scratch away at the matrix surrounding in situ fossils to get a better view, handle fragile fossils in the field, or take a fossil to get it identified with the intent to put it back. Impacts may be indirect as well, such as visitors increasing the rate of erosion via hiking or climbing fossiliferous outcrops (Santucci and Koch 2003; Santucci et al. 2009).

Intentional harm comes in the forms of theft and vandalism. Theft, where fossils are removed from a park unit, may occur for monetary gain, personal collecting and enjoyment, a misguided attempt to preserve the fossils, or in the pursuit of scientific study without acquiring a proper permit. Fossils perceived as highly valuable are at special risk of theft, as are fossils with low perceived value due to the misconception that it is okay to take minor fossils as souvenirs. Further elaboration about types of fossil theft and mitigation is found in "Unauthorized Collecting, Theft or Disturbance to Paleontological Resources," below. Vandalism, wherein resources are damaged or destroyed, usually occurs through gross carelessness, in the process of a failed theft, as a byproduct of theft, or for the enjoyment of the vandal. Vandalism is best countered by encouraging good resource stewardship in visitors, monitoring sites for signs of vandalism, and hiding evidence of vandalism to prevent copycats of major vandalism or the normalization of minor vandalism (e.g., carving names into the rocks) (Santucci and Koch 2003; Santucci et al. 2009, 2016).

Assessment of these types of threats includes the following considerations: abundance of fossils; recognizability of fossils; desirability of fossils (abundant, valuable, and easily recognized fossils attract and encourage theft/vandalism); rate of fossil loss/destruction because of theft, vandalism, and carelessness (e.g., increasing erosion by walking off trails); accessibility of locality; whether disturbance is being actively mitigated by enforcement and/or interpretation; and whether routine monitoring and cyclic prospecting has been successfully maintained.

\section{Unauthorized Collecting, Theft or Disturbance to Paleontological Resources}

Aside from a few isolated cases of excavation by parties with dubious qualifications, there are almost no documented cases of fossil theft in AGFO. This is probably due to several factors: 1) fossils are at the end of long trails; 2) few visitors are able to identify fossil vertebrates or invertebrates in the field; and 3) the Monument has little way of actually determining if this type of resource theft has occurred unless evidence for excavation exists. 
Fossil resource theft may be discouraged in several ways: 1) educating the public on the scientific importance of fossil resources and the loss of information which may result from theft (Hockett 2008); 2) educating the public on the ethical and legal ramifications of resource theft (Hockett 2008); 3 ) increasing staff presence in areas containing fossil accumulations, including by increasing backcountry patrols into less accessible areas; 4) providing paleontological resource training for park staff, emphasizing where fossils commonly occur and what they look like; 5) maintaining localities in good condition as detailed in the monitoring section of this plan; and 6) periodically monitoring local rock shops, online auctions, and rockhound forums to determine if they are selling vertebrate fossils that may have come from the park (Santucci and Koch 2003; Santucci et al. 2009, 2016).

Improper collection and preparation of fossils can also damage fossils and diminish their scientific value. The context in which a fossil occurs (such as its location, and the stratigraphic position and lithology of the rocks that it was found in) provides information as important as the fossil itself. Collecting fossils without recording this information seriously damages the specimen's scientific value, and may even render it useless. Management should dissuade unqualified staff from collecting any fossils, even for the purpose of showing it to the park paleontology specialist. Instead, staff should note where the fossil occurs and give this information to resource management staff. It is highly suggested that the location of fossils be recorded using hand-held GPS units, and that such units be purchased if the park does not already possess any.

The qualifications of outside researchers should be analyzed before providing them with an excavation permit in order to determine whether they possess the experience necessary to conduct a successful excavation. Qualifications can be assessed via examining a researcher's work history, publications, field notes from prior projects, and recommendations from peers in their field of study. Fossils should only be prepared by trained staff or volunteers. Unqualified staff or volunteers should be supervised until they show proficiency.

\section{Monitoring Strategies, Methods and Techniques}

\section{Frequency of Monitoring}

The various localities present at AGFO will have different monitoring needs, and therefore different recommended monitoring periods, based on factors such as rate of erosion and public accessibility (Santucci et al. 2009; see also Appendix E in this document). The localities of the three main fossil hills, for example, are subject both to erosion and constant disturbance by visitors, whereas remote localities such as the Stenomylus Quarry are mainly threatened by erosion. Relative significance of different localities may also figure into how frequently they must be monitored; neither Artiodactyl Locality 1 nor the Stenomylus Quarry are publicly accessible, but the resources of the Quarry have are more significant and so that site must be visited more frequently to ensure their stability.

The 2014 version of the AGFO locality database (see Appendix I for an abbreviated version) lists recommended frequencies of monitoring for all 30 localities found within the Monument, but both the database and its suggestions need to be updated. In particular, AGFO should aim to monitor its most significant and at-risk sites twice a year. At the main hills and the Daemonelix trail, monitoring should occur once in mid-late May and again in mid-November. These dates coincide with the end 
of spring snowmelt/rainy season and with the end of peak visitation season, respectively. Thus, it is predicted that the spring monitoring season will primarily observe the relative impact of natural weathering and that the fall season will record more of the impact resulting from visitor disturbance. The Stenomylus Quarry, being especially fossiliferous and subject to relatively intense erosion, should also be monitored twice a year at minimum despite not being open to the public. Previous recommendations by paleontologists have suggested monitoring the quarry as frequently as once per month, though once a quarter may be more reasonable for a maximum. Less important localities, and those not publicly advertised, may need monitoring only once every one-to-two years.

In addition, AGFO is situated in a river valley and several of its fossil sites are located in or near localized flood channels. In spring 2019, a flood in the valley containing the Stenomylus Quarry created a localized lake that knocked out fencing and dug deep trenches in the valley floor. Though the elevation of the quarry put it above the flood, this event illustrates how extreme weather events threaten AGFO fossil resources. Policy should be established requiring emergency monitoring to be undertaken at important and at-risk localities after sufficiently severe weather events, including: torrential rain and flash flooding, extreme windstorms and tornadoes, severe hailstorms, wildfires, and blizzards. AGFO staff are also advised to investigate other areas that experience heavy erosion during severe weather and after fires, in case new paleontological localities are uncovered.

Similar emergency monitoring may be warranted in the case of severe anthropogenic disruptions, such as a large-scale protest or occupation of the Monument. If the gathering in question is not hostile, the Monument could potentially draw on its experience handling the large crowds present at the solar eclipse in 2017. If the gathering is hostile, emergency monitoring would likely take place after the threat has passed.

Locality Information and Condition Forms

All sites will have a locality information form (Appendix B) and a locality condition form (Appendix C). The locality information form describes the locality in detail, which is important for providing a baseline for comparison during monitoring. Locality condition forms are filled out for each episode of monitoring. This is a foundational and required step for monitoring at all localities. Any trained staff or volunteers can fill out these forms, though it is preferable that the forms for entirely new localities be filled out by a paleontologist or otherwise well-trained staff member. Fields included on these sheets, and brief explanations of their intended contents, are listed in their respective appendices.

\section{Repeat Photography}

Taking photos of localities and fossils from the same perspective at different points in time is an easy, inexpensive, and time-efficient (on the scale of hours) method of documenting changes in erosion, exposure, and disturbance (Santucci et al. 2009). It can be done by any staff member or volunteer with a minimal amount of training. It should be done for every locality and all significant fossils found therein, beginning with the photographs taken for the locality information sheet. Precise intensity of work at a given locality will vary based on the number and significance of fossils exposed (Santucci et al. 2009). Every subject of photography needs at least one longer distance shot to establish relative position and one close-up shot to establish detail, and these must be taken from 
consistent points of reference each time the locality or fossil is monitored. A detailed written description should accompany the initial photographs taken of new localities or fossils, including compass direction the photo was taken in and other identifying factors for the point of reference. GPS data may also be taken alongside photography, to assist in relocating localities and specimens. A GPS touch camera can combine both functionalities in one device. Photos should include a label detailing date taken (format is Year_Month_Day; e.g., 2020_05_08) and locality number, either physically or integrated into the file name for digital photos.

\section{Photogrammetry}

The use of structure-from-motion (SfM) photogrammetry has become a useful tool in paleontological resources management, especially for monitoring in situ fossils in parks (Wood and Santucci 2014). Three-dimensional (3D) data and the products which can be derived from this data can be applied to the long-term monitoring and evaluation of fossils maintained in the field at AGFO. Changes in condition and stability for paleontological specimens, subjected to both natural processes and anthropogenic activities, are able to be observed and measured through repeat photogrammetry. Data obtained through repeat photogrammetry can inform park and resource managers regarding factors which may require some type of mitigation efforts to reduce impacts to exposed paleontological resources. Repeat photogrammetry requires a greater amount of training than repeat photography, but offers a superior record of changes between past and present by capturing the 3D structure of the resource.

\section{Erosion Stakes or GIS Markers}

Setting up and routinely monitoring/measuring erosion stakes requires relatively little effort and training, and provides quantitative measurements repeat photography cannot supply on its own (barring more intense methods such as photogrammetry). Erosion stakes are markers driven or otherwise placed perpendicularly into the sediment or strata of a fossil locality, which have a clear mark on them indicating where the surface was at the time they were placed. At later monitoring sessions, erosion can be quantitatively measured by observing how exposed the stakes have become from their original marks and/or the distance between the stakes and an erosional surface. Multiple stakes can be placed into different positions at a locality, both to measure regional variations in erosion and to enable a more accurate assessment of erosion by checking the difference in ground surface relative to several stakes (Santucci et al. 2009).

The initial installment of erosion stakes should be done by a trained paleontologist or geologist. It is recommended that at least three stakes be used per locality at AGFO, at least at major sites, to provide a higher resolution assessment of erosion. The stakes should be made of galvanized steel, or another oxidation-resistant metal, and their positions must be marked using GPS. The stakes should not be installed in any position that would harm the resource or draw undue attention from visitors. If a stake is knocked out by natural or human causes, it should be possible to reconstruct its position from GPS and written records plus the positions/measurements of the other stakes relative to its own before being dislodged. Once installed, measurements from the stakes to an erosional surface can be accomplished by non-scientist staff or volunteers with some training. This method should be used alongside repeat photography (Santucci et al. 2009). 
A higher-tech alternative to stakes is setting super-high resolution GIS markers. This method does not drive any physical objects into the locality, which minimizes damage and eliminates the risk of identifying a locality to visitors (Santucci et al. 2009). This has its advantages at AGFO, where the rock strata are poorly consolidated and many important fossil localities are open to the public. However, the software and hardware needed to set the initial markers and measure changes during routine monitoring, are far more expensive and require much more training than erosion stakes. Given these logistical constraints at AGFO, this method is not recommended unless the budget allows and a professional technician or GIS trained paleontologist will handle all monitoring in full.

\section{Emergency Stabilization or Collection of Endangered Fossils}

When it is found that fossils are being damaged by weathering or disturbance, the significance of the fossils should be evaluated by a trained staff member, preferably a paleontologist, to determine what if any action is needed. Because of the abundance of fossils, attention should be focused on fossils that are rarely encountered at AGFO or previously unknown there, or that have some other unusual scientific relevance, such as articulated specimens, unusually well-preserved specimens, juvenile specimens, material relevant to any ongoing research projects, and so on. Such significant fossils should be collected as soon as possible to prevent further damage or loss. Any significant fossil find that cannot be collected immediately should be stabilized by a trained staff member or paleontology specialist (NPS DO 77). A locality where such specimens are or have been found should be marked as important, and be subject to monitoring at least twice a year.

Common techniques for stabilization range from using professional glues and consolidants, to plaster caps, to simple reburial. These stabilized resources should then be routinely monitored and receive further stabilization if needed, until they can be properly collected. Stabilization and collection should only be attempted by professionals with suitable training. NPS DO 77 provides further guidance regarding paleontological excavation. In special cases where the fossils cannot be collected, or the disturbance caused by collection would be harmful to other resources, park management may wish to manage the resources in situ.

It is also possible to stabilize the geologic formations in which fossils are found, slowing down erosion. A common method that may be of use at other parks is to backfill heavily weathered areas with eroded sediment. This is distinct from reburying a fossil or backfilling an excavation after work is completed. The backfill should be screened for fossils prior to backfilling. However, this method of erosion control is not recommended at AGFO and has been rejected by prior resource managers. The reasons why backfilling as an erosion control measure is not appropriate at AGFO include: logistical shortfalls make it difficult to routinely screen backfill for fossils; backfill would be extensively fossiliferous; the nature of the rock, the eroded sediment, and the erosional profile would make backfilling difficult to implement and minimally effective in preventing further erosion; and backfilling would negatively impact the appearance and visitor experience of publicly accessible localities.

\section{Paleontologist Oversight of Routine Monitoring}

Paleontological resource monitoring results should be checked on-site by a trained NPS paleontologist, paleontology specialist, or paleontology technician annually to ensure AGFO staff 
compliance with monitoring policy and goals (and SOPs if/when they are set). This oversight applies to all sites, but should be focused upon important and vulnerable localities such as those found at the Fossil Hills or the Stenomylus Quarry.

Alternatively, depending on arrangements made with other parks, AGFO may wholly outsource monitoring duties to an NPS paleontologist. Under this arrangement, an NPS paleontologist stationed at another park would come to AGFO to do all routine monitoring, rather than only double-checking monitoring work done by AGFO staff. AGFO staff would still need to be trained for emergency monitoring situations, as outside personnel may not be able to respond in a timely manner.

This list of suggested methods is not meant to be prescriptive or comprehensive. A standalone Paleontological Monitoring Plan for AGFO should be created to set specific and detailed Standard Operating Procedures (SOPs) in regard to monitoring. The results of monitoring and condition assessment should inform and direct management policy and action related to fossil resources at AGFO. This may manifest in the form of emergency and/or short-term efforts to mitigate an imminent problem, or long-term changes to the schedule of cyclic monitoring and the Paleontological Monitoring Plan.

\section{Resource Condition Assessment}

As part of monitoring, a locality condition assessment form must be filled out to document the relative health and stability of the locality's resources. This assessment covers the physical condition of the strata and fossils, natural threats like the rate of erosion, anthropogenic risk factors, and the current intensity of active mitigation, monitoring, and surveillance occurring at a locality.

The results of the locality condition form produce a score which serves as a rough assessment of the locality's condition: $<45$ is poor, $45-80$ is marginal, and $>80$ is good. Sites scoring 80 or less likely require additional management and/or mitigation action, and such a score may indicate a necessity for additional monitoring. Inversely, a locality of low importance that scores as good consistently may not need to be monitored as frequently. This assessment is a broad overview of an entire locality; individual specimens may be at higher risk and require special action to stabilize or collect, even if the locality they are found within scores as "good."

Good: The site shows no evidence of noticeable deterioration by natural or anthropogenic forces, and sufficient efforts are in place to monitor and protect it. The locality is stable and its paleontological resources are not threatened. Currently prescribed management policies regarding this site are sufficient, or perhaps even unnecessarily intensive, and either do not need to be changed or can be relaxed.

Marginal: The site shows evidence of noticeable deterioration by natural or anthropogenic forces. If this degradation is not prevented or mitigated, the site will degrade to poor condition and its value to science, history, education, and/or visitor enjoyment will be reduced. Additional management activity is recommended to correct the degradation.

Poor: The site shows evidence of severe degradation by natural or anthropogenic forces, and/or current management policy is inadequate to protect it or entirely lacking. If this degradation is not 
halted, the locality's resources may be entirely lost or degraded to the point they lose all value to science or education.

Destroyed: A destroyed locality has degraded to the point that there are no more resources evident there or those remaining are damaged so badly they have no scientific, historical, interpretive, enjoyment, or other value. Sites considered destroyed no longer warrant being monitored; however, depending on the thickness of a fossiliferous unit, further erosion of a seemingly destroyed locality may again reveal significant fossils (e.g., there is evidence that the destroyed/depleted former Fossil Cycad National Monument still contains subsurface fossil resources) (Santucci and Hughes 1998; Santucci and Ghist 2014).

\section{Disturbance and/or Recovery of Paleontological Resources During Other Activities}

Fossils can be disturbed or discovered during any park activity that takes place over fossiliferous units or in any location that float may be transported to via erosion or other means. To properly preserve and protect fossil resources as mandated by law and policy, park staff need to be prepared to respond properly when fossils are unexpectedly uncovered during other activities. Furthermore, activities that are highly likely to disturb, or could harm, paleontological resources (e.g., construction) must be preceded by an assessment of the area for potential paleontological resources.

At AGFO, it is possible that fossils may be found while performing such activities as: interpretive field trips (newly exposed fossil sighted by staff or guests); law enforcement (routine patrols or responding to theft/vandalism attempt); management of non-paleontological resources (invasive plant management at a fossil locality, fossils found at an archeological site); maintenance (work near a fossil locality, repairs to structures built into fossiliferous units); and construction (excavation into fossiliferous units). General and specific guidelines for handling fossils disturbed during these activities are detailed below.

\section{Disturbance and Recovery During Routine Park Activities}

Paleontological resources discovered, exposed, or otherwise disturbed during routine management, interpretive, or maintenance activities should be recorded and reported to the Monument resource manager and the superintendent. The resources should not be removed from their location when first found, even if the staff member is qualified and has permission for salvage collection. The occurrence should be documented thoroughly (like any other paleontological locality) and measures should be taken to protect the resource (such as reburial or other covering, temporary closure of an area, etc.) until qualified assistance can arrive to better assess it. Recording should include relative location, description of the resource to the finder's best ability, and photographs if able. The information included on official records and forms (e.g., those on the locality information sheet, Appendix B) are good guidelines for the type of information to be recorded. If visitors are present and aware of the disturbed resource, they should be encouraged to not further disturb or remove it. Do not alert unaware visitors to the presence of disturbed paleontological resources if they cannot be supervised prior to further management action regarding the resources. Resource managers and the superintendent will then determine how to manage and more thoroughly document the resource. It is at this point that collection of the resources may be considered as a management option, based on guidelines found in other sections of this plan. 
If the resources are under immediate threat of destruction, theft, or vandalism, the appropriate authorities should be notified as soon as possible (e.g., park law enforcement in the case of a crime) and the staff member who found the resource should continue to observe it and any threats (so long as it is safe to do so) until qualified staff arrive to handle the situation. A fossil injury SOP, akin to that of Hagerman Fossil Beds National Monument, is recommended to provide specific instruction on how to deal with fossil theft/vandalism and how to protect remaining resources at the scene of the crime.

Disturbance and Recovery Relating to Crime and Law Enforcement If non-law enforcement staff encounter a crime in-progress, they should immediately get to a safe location, contact law enforcement, and report the crime. Non-law enforcement staff should avoid confrontation or contact with the suspects, even if theft or destruction of paleontological resources is imminent. Likewise, if non-law enforcement staff encounter the aftermath of suspected fossil theft or vandalism, they should immediately contact law enforcement. While limited recording of the site is possible while awaiting the arrival of law enforcement, non-law enforcement staff should not do anything which could tamper with the evidence (e.g., long-distance photographs may be taken, but the site should not be entered or its contents disturbed).

Law Enforcement's role is to watch for evidence of suspicious disturbance, which may be a sign of criminal activity. If such disturbance is detected, it is subjected to investigative process to determine if loss of resources has occurred and, if it has, if a suspect can be identified. Fossil resources determined to be stolen federal property (e.g., collected without permit from public lands) are to be recovered via proper warrant. Anyone determined by the investigative process to have committed criminal offense will be prosecuted.

Citations to policy and applicable laws regarding enforcement include: 36 CFR, 16 U.S. Code $\S 470$ aaa-5, 18 USC $\S 1361,18$ USC $\S 1865$, and USC 54 §100721.

\section{Construction Compliance}

According to NPS management policies (NPS DO 77) any NPS construction projects in areas with potential paleontological resources must be preceded by a pre-construction surface assessment prior to disturbance. At AGFO, the assessment will usually be performed by an archeologist from the Midwest Regional Office because of the presence of cultural and historical artifacts within AGFO's boundaries, but an NPS paleontologist should also perform an assessment, if available.

If fossil resources (or other protected resources) are determined to be present, the site will be avoided, or if necessary, the fossil resources will be collected and curated prior to the initiation of the work. Even in the latter case, construction should proceed with caution in case further resources are disturbed during excavation. Areas with potential paleontological resources should also be monitored during construction projects, in case buried resources not found during the initial assessment are disturbed. If monitoring reveals the presence of paleontological resources during a project, work should be halted immediately until resource management staff can evaluate the situation. At AGFO, AGFO staff or an approved NPS partner will do the monitoring, as the archeologist or paleontologist 
who performed the initial assessment will likely not remain at AGFO for the duration of the construction project.

\section{Other Considerations Related to Paleontological Resources Monitoring}

There are several considerations related to monitoring of paleontological resources during periods where there is a closure of the federal government resulting in staff potentially not being available or on site at AGFO. Federal government closures are usually short-term, but more extended periods where staff may not be present on site at a park have been experienced recently with the COVID-19 pandemic, lapses in federal appropriations, and climatic events. During closure of the federal government between December 22, 2018 and January 25, 2019, several NPS areas including Joshua Tree National Park and Organ Pipe Cactus National Monument experienced resource impacts due to visitor activities including intentional vandalism. This plan recommends that strategies are developed to safeguard the protection of non-renewable resources during periods when staff may not be present at the Monument. A key piece of resource management during interruptions of staffing is to ensure continuity of the existing monitoring program, which allows site condition comparisons over time. 


\section{Paleontological Research Management}

\section{Evaluation of Research Proposals}

AGFO's history and the rationale for it being designated a national monument are inextricably tied to paleontological research. AGFO's authorizing legislation (1965) calls for the Monument to become " a center for continuing paleontological research." Research at AGFO helped define the beginning of the Miocene Epoch, provided some of the earliest evidence of carnivoran denning behavior, and supported the hypothesis that Miocene North America was similar to the modern savannah of Africa. According to the National Park Service Natural Resources Management Guidelines (NPS-77), "Paleontological research by the academic community will be encouraged and facilitated under the terms of a permit...." Laws, such as the National Parks Omnibus Management Act and the Paleontological Resources Preservation Act, require the NPS to manage paleontological resources according to "scientific principles", which necessitates continued research as scientific understandings and methodologies constantly evolve.

The NPS upholds many other mandates beyond facilitating scientific study, and therefore the bureau must balance its duty to encourage research with other priorities. Without careful planning and oversight, research may be disruptive, even destructive, to park resources; therefore, research methods must consider the potential risks sometimes inherent and unavoidable when dealing with non-renewable resources like fossils. In accordance with existing law and policy, the NPS must preserve fossil resources unimpaired for the enjoyment and education of the public, as well as for the preservation of those resources and the environment in which they occur.

Thus, research within parks must be scientifically relevant, ethically conducted, protect the resources studied, and not diminish other park values. In the context of paleontology, proposed research must add new scientific knowledge to warrant disturbing, degrading, or removing fossils. Furthermore, the ideal paleontological research proposal not only seeks to answer scientifically relevant questions, but also provides utility to park efforts in managing or interpreting fossil resources. Therefore, research at AGFO must meet at least one of the following two criteria:

- Research furthers understanding of scientific questions related to the paleontological resources of AGFO;

- Additionally, the research must be unable to produce satisfactory results using only specimens already in museum collections or information in existing literature.

- Research improves the ability of AGFO staff to interpret the fossil record for the Monument;

- Research informs AGFO staff about the scope, significance, location, distribution, condition, stability, required mitigation, and other management issues associated with the stewardship of non-renewable paleontological resources.

○ This research may aid and overlap with new or existing inventory or monitoring efforts.

Research that meets these criteria, possesses sufficient scientific significance, and benefits the park in overall aspect more than it harms should have its application permitted. Research that is not 
consistent with these factors should not be issued a permit, though the park must explain why to the applicant. If the park wants to reject a permit application on grounds of insufficient scientific merit, it must secure external peer review for guidance in both making the decision to approve or reject and in providing a response to the applicant. NPS Management Policies 2006:4.2-4.2.4, Management Policies 2006:7.5.4, and Management Policies 2006:8.10 include guidelines applicable to assessing proposed research in light of management priorities.

In general, these criteria and policies require park staff to carefully consider the benefit to science, park management, and visitors versus any potential impacts to resource preservation. This is especially true of research that proposes removing material from its natural location, involves ground disturbance, or otherwise permanently diminishes the resources, such as collection and excavation. The occurrence of fossils within a park's stratigraphic units is finite. Maximizing the lifetime of the resources in AGFO requires minimizing loss of fossils and the value they provide, both scientific and otherwise. Collection can ultimately be a net positive or net negative for long-term resource preservation, depending on the details and circumstances. Resource managers should weigh the immediate loss of resources by collection against the potential scientific and management knowledge gained on remaining in situ resources and against the risk of total loss from erosion or theft. Research methods that do not remove or disturb fossil resources should be considered and supported where appropriate; fossil sampling alternatives to collection include silicon peel molds and photogrammetry, though these are not appropriate or sufficient for all research questions requiring ex situ study of fossils.

Monument staff should make efforts to learn about the current state of paleontology and its outstanding questions, so that they can make informed decisions on scientific significance. In some cases, making a judgement on significance may require staff to consult with paleontology specialists within the NPS, other agencies or academia. Handling logistics and overseeing compliance for excavations may require a specialist to be working at or with AGFO for the duration of the research. Beyond the generalities of scientific significance discussed above, the need for collection can also be justified based on criteria established in other sections of this plan (see "Paleontological Research and Collecting Permits" below).

Monument staff should work with researchers to determine the best time of year to carry out a project, but always retain the final say on when research can and cannot be performed. Research should be carefully planned based on factors such as safety (e.g., storms, dangerous temperatures, etc.), interference with other park events (e.g., closing off a public section of a park on National Fossil Day), honoring cultural beliefs or perspectives (e.g., during any Native American spiritual events at or near AGFO), or prevention of unwanted behavior from visitors. While visible research offers opportunities for interpretation and enjoyment, the presence of researchers (especially if not clearly identified as such) can also unintentionally give visitors the idea that it is okay to take resources or travel off designated trails.

\section{Paleontological Research and Collecting Permits}

The permitting process ensures that projects maximize information gain while minimizing adverse impacts to park resources, other research projects, park operations, or visitor experience. The NPS 
has prepared an administrative guide for park research coordinators to aid in administering Research and Collecting Permits according to 36 CFR 2.5. A copy of this guide can be found at http://npshistory.com/publications/interdisciplinary/research-admin/research-admin-guide.pdf. Activities in parks allowed for the general public without restrictions do not require a permit when conducted by researchers.

The NPS provides a website for researchers to use when applying to conduct research in National Parks: https://irma.nps.gov/rprs/, the Research Permit and Reporting System (RPRS). See also Appendix $\mathrm{F}$ for additional information on the application process. A full description of the permitting process, including how to apply for a permit, is found on RPRS.

If a Scientific Research and Collecting Permit is issued to a researcher it is automatically accompanied by the General Conditions that apply to all research projects in all NPS units. A park may provide additional park-specific and project-specific conditions to the permit. AGFO should always consider imposing such specific conditions, especially in regard to setting limits on collection of fossils, either at specific localities or parkwide. Curatorial requirements are also one of the general conditions that may be further explained by a park-specific condition. AGFO should endeavor to make sure these conditions are set in as much detail as possible, including preparation and final storage. AGFO will post all park-specific conditions on its RPRS page. A list of suggested parkspecific conditions is listed below:

- Potential researchers should belong to a recognized institution, preferably an accredited academic institution or museum with prior history and on good terms with the NPS.

- Qualified amateurs with no institution should be enrolled as a Volunteer-in-the-Park, making the NPS their institution and providing greater accountability for them.

- Potential researchers must present a clear plan of research in their application, and are encouraged to include how their research will benefit the Monument.

- These are subject to evaluation by AGFO staff to determine significance.

- Only qualified personnel, from either the collecting institutions or the NPS, will collect or excavate fossils under an approved permit.

- Researchers will check in at the Visitor Center and Museum before initiating any fieldwork, and generally keep the front desk informed of their schedule and whereabouts.

- Vehicular travel within AGFO should be limited to established roads, and researchers should take a Monument-provided radio with them (available at the front desk).

- If the research involves any excavation, the researcher must agree to and present a plan for remediating the site to natural conditions after work is completed.

- Researchers must provide proper locality data (see "Documenting and Numbering New Fossil Localities") for all observed, photographed, molded/cast, and collected specimens. Failure to do so will result in revocation of the permit.

- Researchers will give all collected specimens unique field numbers, and record those into a field notebook and on field collection tags that remain permanently with the specimens. 
- Store all collected specimens in a Monument-designated processing area, for determination of needed preparation and for ease in curation.

- Collected specimens remain federal property, and are accessioned and cataloged in AGFO collections.

- Specimens may be housed in AGFO or regional NPS facilities, or placed on loan to non-NPS museums that meet NPS repository standards. Permit applicant can offer suggestions, but NPS makes the determination.

- A plan must be provided for how, when, and where collected specimens will be prepared.

- Only qualified personnel, at either the collecting institution or NPS facilities, will prepare fossils.

- Preparators must keep detailed preparation records for all specimens. The information in these records must remain part of the permanent museum record for the specimen.

- At minimum, include who did the work and when, tools and techniques used, chemicals (including adhesives) applied to specimens, and damage resulting from preparation.

- The orientation of different bones to each other in associated or articulated specimens must be noted and mapped.

- Photos of specimens should be taken before, during, and after preparation.

- Unless otherwise agreed to, the collecting institution holds responsibility for preparing specimens and submitting cataloging data to AGFO.

- Researchers must also provide archival supplies to house the collected specimens (researchers should contact AGFO about preferred archival materials/housing).

- Researchers are responsible for labeling specimens with NPS catalog numbers.

- This responsibility includes organizing NPS labels with the specimens (the Monument can provide NPS labels exported from ICMS once cataloged).

- Researchers must provide copies of field notes, locality information, site photos, and any publications, conference materials, or other manuscripts resulting from research to the NPS.

- Including the research permit number in the acknowledgements of papers including data from AGFO will also help with long-term tracking.

- A detailed spreadsheet of materials documented or collected in the Monument must be supplied before departure from AGFO to allow staff to update monitoring records or track collections status.

- If using AGFO guest housing, researchers will obey provided housing rules and requirements. This includes washing linens and kitchen dishes and utensils before leaving the Monument.

Further discussion of conditions for research permits is included in Appendix G.

NPS staff have to follow all requirements when conducting scientific study in parks (Management Policies 2006:4.2.1). In the past, the superintendent authorized NPS staff to collect fossils without a 
permit when those resources were in imminent danger of loss or damage through erosion, weathering, theft or vandalism, per NPS Director's Order 77. It is currently recommended that a permit be issued at AGFO annually to address the issue of emergency recovery and salvage of significant paleontological material exposed at the surface, threatened by natural process, or threatened by unauthorized human collection. Issuing an annual permit assists in data/specimen tracking, maintaining accountability, and providing an administrative record for the activity. Collection will occur under the authorization and discretion of the superintendent. The actual recovery of the fossil specimen should be undertaken by a professional paleontologist either within the NPS or in an academic institution that maintains an academic paleontology program and museum collection. This recommendation is interim guidance until further guidance is provided at the regional or Washington level, pending future updates to Director's Order 77.

Laws enabling the NPS permitting process include the National Park Service Organic Act (54 USC § 100101), National Parks Omnibus Management Act of 1998 (54 USC § 100705), and Paleontological Resources Preservation Act (16 USC $\S 470 \mathrm{aaa})$. Individuals or groups making unauthorized collections are subject to NPS regulations at 36 CFR Part 2, as well as USC $54 \S 100721$ (System Unit Resource Protection), 18 USC $\S 1361$ (Theft of Government Property), 18 USC $\S 1865$, and 16 USC $\S 470$ aaa-5 (Paleontological Resources Preservation-Prohibited acts; criminal penalties).

\section{Field Collection and Excavation}

As previously stated, AGFO should seek to carefully assess the benefits, risks, and significance of research involving collection and excavation. Beyond the general guidelines for evaluation discussed previously, there are concerns specific to AGFO which must enter into analysis of proposed research involving collection:

- There are significant collections of fossil material from AGFO in many repositories (see page 54), which in aggregate should be adequate for some paleontological studies (e.g., morphometrics).

- Further excavation at the historic quarries that yielded this material is therefore less likely to significantly contribute to the nature of this dataset, beyond sample size.

- Much of AGFO's potential continued relevance to modern paleontology and paleoecology research depends upon a specimen's context in situ.

- However, continued relevance also depends upon the continuation of research, and investigations on contextual materials may require their removal and/or destruction.

- Visitors sometimes complain that no fossils are visible out at the fossil hills, since AGFO staff reburied prior in situ exhibits and exposed fossils because of deterioration from light exposure and destructive climatic conditions.

- Visible research that provides a clear view of fossils, and highlights their continuing importance, helps address this complaint. However, "vacuum cleaner" research that removes too much of the resource will worsen it in the long term. 
- The most historically productive localities possess historical and interpretive values that would be irreparably damaged by further excavating these areas, especially given the need to remove overburden.

- However, the significance of scientific inquiry could exceed the historical value of leaving a site as it is, and erosion is constantly degrading sites regardless.

- Historical sites can and should be documented in writing and by photography, in case of alteration or loss; they should also be monitored.

- It can be difficult to restore the site of an excavation to how it was prior, as exemplified by the current condition of Beardog Hill.

- Other localities have produced specimens of limited significance. This is potentially subject to change, but inventorying is needed to establish site importance level.

- Active quarries are powerful sources of visitor education and enjoyment, but also require logistical outlays (e.g., ensuring compliance and quarry protection) that may not always be feasible.

- AGFO staff must evaluate whether the scientific and interpretive benefits of visible research outweigh the challenges and risks involved, as well as the long-term impacts of an opportunity for visitor enjoyment (research produced, resources removed, site restoration post-dig, etc.)

- AGFO staff currently lack the resources to oversee systematic, non-salvage, collection projects, let alone quarry-sized excavations.

- Whether a specialist can be retained even temporarily is thus a needed consideration.

Any proposed research necessitating collection or excavation of fossils must be of sufficient importance and benefit, to either management objectives or scientific understanding, to overcome the accumulated risks posed by any of the above concerns that are applicable. Researchers should discuss in their proposals the relevance, or lack thereof, of existing material from AGFO held in museums and other repositories; successful proposals will convincingly argue that current collections are insufficient for their project's needs. Consideration should also be given to whether non-collecting alternatives, or utilizing specimens previously collected as salvage, would be sufficient for answering the scientific question at hand. Furthermore, because of the historical and cultural value held by the historic quarries, requests for research permits involving work at these sites should be subject to a higher standard of significance. Any such work must also comply with Section 106 of the National Historic Preservation Act. Similarly, there are several less important paleontological localities within AGFO that are suspected to be coincident with archeological sites.

Beyond scientific and interpretive value, collection may be needed to ensure the safety of paleontological resources if they are threatened with immediate danger of degradation or loss that cannot be mitigated through stabilization techniques. This, too, requires assessment of the fossils, their environment, and the nature of the threat. Regular salvage collecting still requires a permit, but the usual review process can be waived by the superintendent where the threat is of such an immediate nature that the time involved in normal review would result in the loss of the specimen. 
The permit issued still serves as a permanent record of the salvage in RPRS and carries with it all the normal conditions of a permit, such as requiring submission of Investigator's Annual Reports (IARs).

Prior to excavation and extraction, personnel will complete an assessment that justifies the need for collection (see above), determines the likely size of the quarry and the sizes of any samples to be removed, describes the planned process of retrieval, and identifies mitigation measures.

Collection in the field of any data, not just collection and removal of fossils and geologic samples, should be undertaken by trained individuals. This includes routine inventory and monitoring undertaken by Monument staff. The degree of required training ought to reflect to the degree of specialized knowledge required for the task at hand. Additionally, AGFO may issue annual permits to trained staff, allowing them to collect fossils in case of emergency salvage (Photo 8). Non-NPS researchers may have authorization for such salvage work included within their project-specific permit, at Monument discretion. Unqualified staff, researchers, or volunteers should report in situ paleontological resources to AGFO resource management staff and not attempt to remove the specimens themselves.

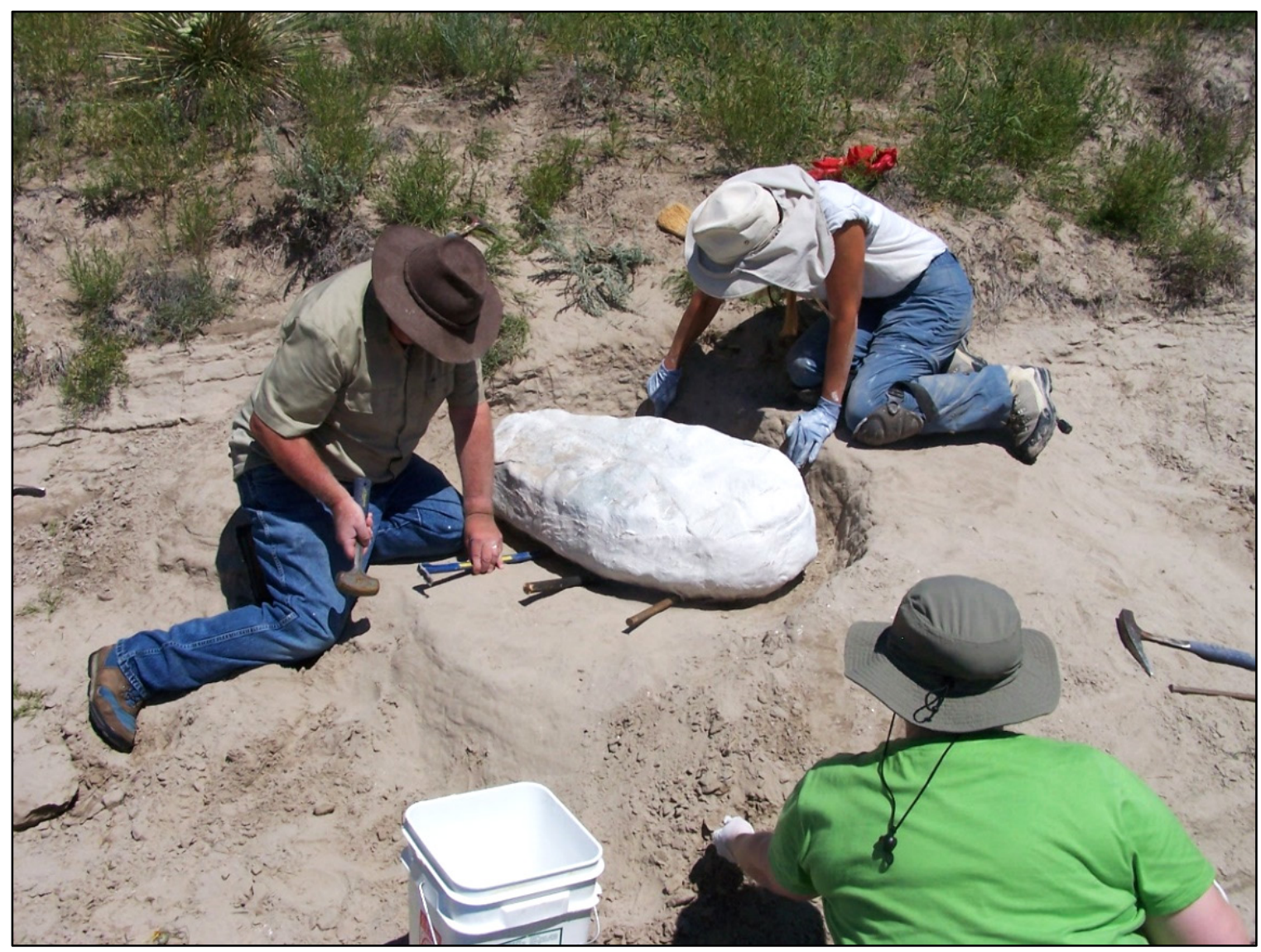

Photo 8. NPS paleontologist Ellen Starck, Bureau of Land Management paleontologist Greg McDonald, and others preparing to remove a field-jacketed Stenomylus specimen collected as salvage at AGFO in 2013. This specimen was rapidly eroding out of the rock and was at risk of destruction, necessitating its collection (NPS). 
Unless specifically authorized through a Minimum Requirement analysis, excavation and extraction will be conducted without the use of motorized tools or mechanical transport. Care should be taken at all times not to damage other types of resources or government property in the process of a paleontological excavation, beyond that which is acknowledged in the permit and its conditions (e.g., overburden removed as part of excavation). Upon completion of any excavation, the quarry or section will be backfilled to restore natural conditions and avoid safety hazards. Restoration shall also include any regions through which researchers traveled and caused damage in order to access a dig site. AGFO is strongly encouraged to stipulate planning and carrying out remediation as a prerequisite for issuing a permit (see list of suggested park-specific permit requirements, above).

Excavations in the Monument require compliance clearance under the National Historic Preservation Act of 1966 as amended (Section 106, 16 USC 470; 36 CFR 800) and the National Environmental Policy Act of 1969 (42 USC 4321-4370). Likewise, excavation of specimens in areas that are very close to archeological sites and/or artifacts also require this clearance. Compliance clearance covers not only the excavation pit, but also routes taken to access the site, areas for equipment staging, and the site(s) where the soil overburden will be deposited.

Minimum data collected with fossils and related geologic samples shall include GPS coordinates (and datum), stratigraphic position, collector, photographs of specimens, and date of collection, and one or more photographs must be taken with enough of the background visible to allow for relocation of the site (NPS DO 77).

\section{Special Considerations for the Stenomylus Quarry}

According to the Superintendent's Compendium, the Stenomylus Quarry is "closed all year to public use year-round," based upon the fragility and scientific significance of this fossil locality. There is a secondary concern regarding the fact that access to the quarry requires crossing private property. This closure is renewed every year. Access can be granted by "scientific research permit, special use permit, or written approval of the superintendent."

However, informal policy since the 1980s and recommendations from NPS and non-NPS sources have called for exceptionally high standards when judging permit application proposing to collect specimens from the Quarry for non-salvage purposes. Dr. Robert Hunt, Jr. of University of Nebraska recommended that the Stenomylus Quarry not be excavated further, because of its fragility and the ample sample of specimens already collected from the locality. Rachel Benton, former BADL paleontologist, recommended that the location of any new fossil quarries should "be away from the historic quarries and should not require a major removal of overburden" (R. Benton, BADL emeritus, pers. comm. to AGFO, 1997 and 2010). Excavation at the Stenomylus Quarry would likely require a tremendous removal of overburden. Toni Culver, the creator of the AGFO Paleontological Locality Database, also recommended restricting access to the Stenomylus Quarry (Culver 2003). Furthermore, it seems generally agreed upon that existing research collections in repositories should be sufficient for most studies of Stenomylus from what is now AGFO. As a result, the current perspective at AGFO should be that there is a temporary moratorium from further collection at the Stenomylus Quarry, and any proposals requesting fossil collecting or excavation should consider both the short-term and long-term benefits and impacts to this significant, sensitive and finite 
paleontological resource at this historically significant site. Approval would require that all concerns about resource fragility, excessive removal of overburden, and the large sample of specimens already in museums be addressed and solved by the proposal. The AGFO staff should work with the BADL paleontologist and the NPS Paleontology Program to develop a Standard Operating Procedure to address access and collecting at the Stenomylus Quarry.

Permit applications for research that do not require excavation should be considered and supported where they are appropriate. In this case, the chief concern is the fragility of the locality and its remoteness from the rest of AGFO. Salvage collection of endangered fossils should continue at the locality, but should generally be planned and led by NPS staff following routine monitoring. There is also the possibility that evolving technologies will allow greater extraction of information from the locality in the future, or will permit as-yet unforeseen methods of study. 



\section{Museum Collections and Curation}

Paleontological specimens preserved in NPS museum collections or on loan to authorized external repositories are critical tools for understanding, protecting, and preserving natural resources within the parks. These specimens document park resources and scientific studies for the purposes of information, resource protection and management, and future analysis. Systematically collected specimens are the products and subjects of vital research that provide baseline data necessary for continued and effective park management. Museum specimens collected in the past may also provide information that is otherwise no longer obtainable. All collected fossil resources from AGFO must ultimately be stored within AGFO's museum collection, an NPS regional repository, or an approved external repository that has made an agreement with AGFO or the NPS. Director's Order 24: NPS Museum Collections and NPS Museum Handbook (especially appendix Q: Curatorial Care of Natural History Collection; NPS 1999), NPS DO 77, and 36 CFR $\S 2.5$ outline guidance for museum collections, including repository and curatorial obligations.

\section{Monument Collections}

The AGFO collection contains 5,117 paleontological specimens according to the 2018 NPS Collections Management Report. Collections held within the Monument are stored in the Visitor Center, either in the museum if on display, or in the collection storage area. Some paleontological specimens kept at AGFO in collection storage, especially several larger specimens still in jackets, have had only limited, if any, preparation. Furthermore, inadequate protective housing is also frequent among smaller fossils kept in drawers, resulting in wear on the fossils. Though all drawers have archival padding on the bottom, not all specimens are independently boxed and several that are do not have archival padding in their boxes. The quality and detail of labels is also highly variable, with newer specimens tending to have more detailed labels than older ones. Improving these conditions would increase the collection's usefulness for research, exhibit, and education purposes.

Some fossil specimens belonging to the Cook collection are not native to AGFO or its stratigraphic units. Because these have low relevance to the paleontological context of AGFO, and were personal items displayed in the Cook household, these are likely more usefully classed as historical specimens (AGFO Scope of Collections Statement; Young 2016). There are also several oreodont fossils dating from the 1980s and 1990s labeled as being from the "White River Badlands"-potentially from the White River Group units of the Nebraska panhandle in the absence of further information.

AGFO collections also include archived documents, including correspondence between James Cook and researchers and some historical field notes from the early digs. These resources are no less important to paleontology and its history than fossils are. When possible, AGFO should obtain and archive correspondence and field notes from research projects undertaken after the authorization of the Monument, such as those of Dr. Robert Hunt, Jr. over his decades-long relationship with AGFO. Future researchers are required to submit physical and/or electronic copies of field notes to AGFO for archiving upon completion of their study, per park-specific permit conditions.

In addition, AGFO also has several unique considerations that must be taken into account for curation of fossil resources. It is anticipated that AGFO's collection of fossils and associated 
resources will grow in the future as the result of resource management and authorized research collection. There is also the possibility that AGFO could be offered or request specimens and/or replicas of specimens from other institutions. Because collection and curatorial storage space is highly limited at AGFO, as well as the capacity for preparation, AGFO needs to be very selective about accepting new material until such time as these conditions change. Material from outside of Monument boundaries must have some relevance to the paleontology of AGFO, e.g., specimens of species known from AGFO sites.

Because of existing curatorial limitations, AGFO should seek to create, renew, and/or maintain memorandums of agreement with institutions more capable of adequately preparing and curating fossils. Potential non-NPS partners include the University of Nebraska-Lincoln or the South Dakota School of Mines and Technology. Notably, the University of Nebraska State Museum is already a repository for many post-authorization AGFO specimens. Potential NPS partners include Midwest Archeological Center (MWAC) and BADL. Agreements could also be made for the restorative conservation of specimens too damaged to be repaired at AGFO. It is recommended that AGFO have a staff member on-site trained in basic conservation techniques involving non-reactive adhesives, which can serve to repair simple fractures and stabilize especially friable specimens.

More information on the types of specimens kept within AGFO collections, how they are organized, and their intended purposes can be found in the Scope of Collections Statement (Young 2016).

Further specifics on AGFO's specific museum management goals, curatorial methods, storage options, suggestions, and protocol can be found in the AGFO Museum Collection Management Plan (Reilly and Kennedy 2003).

\section{Fossil Preparation}

Natural Resource Management Reference Manual \#77 states that "although collection will prevent the natural destruction of a fossil specimen, preparation in the lab is often required before the specimen is available for scientific evaluation and study." Collection of fossils is typically done by removing the fossil as well as a portion of the encasing rock (matrix) to ensure the protection of fragile specimens during transport from the field. Removal of this encasing rock is called preparation. Preparation can also include methods of restorative conservation, whereby damage caused by erosion, exposure, excavation, poor preparation, and inadequate preventative conservation is repaired.

Preparation is a key step in making fossils useful in research, exhibit, or education; unprepared fossils are often not much more than a jumbled mass of rock and bone fragments (Photo 9). AGFO does have two unprepared, jacketed slabs of bonebed material on display in the museum. The unprepared material serves as an example of how thickly packed the bonebed is, and also serves as a contrast to the articulated replicas of prepared skeletons. That said, there is no significant need for additional unprepared blocks, and therefore AGFO should attempt to minimize the number of unprepared fossils in storage. 

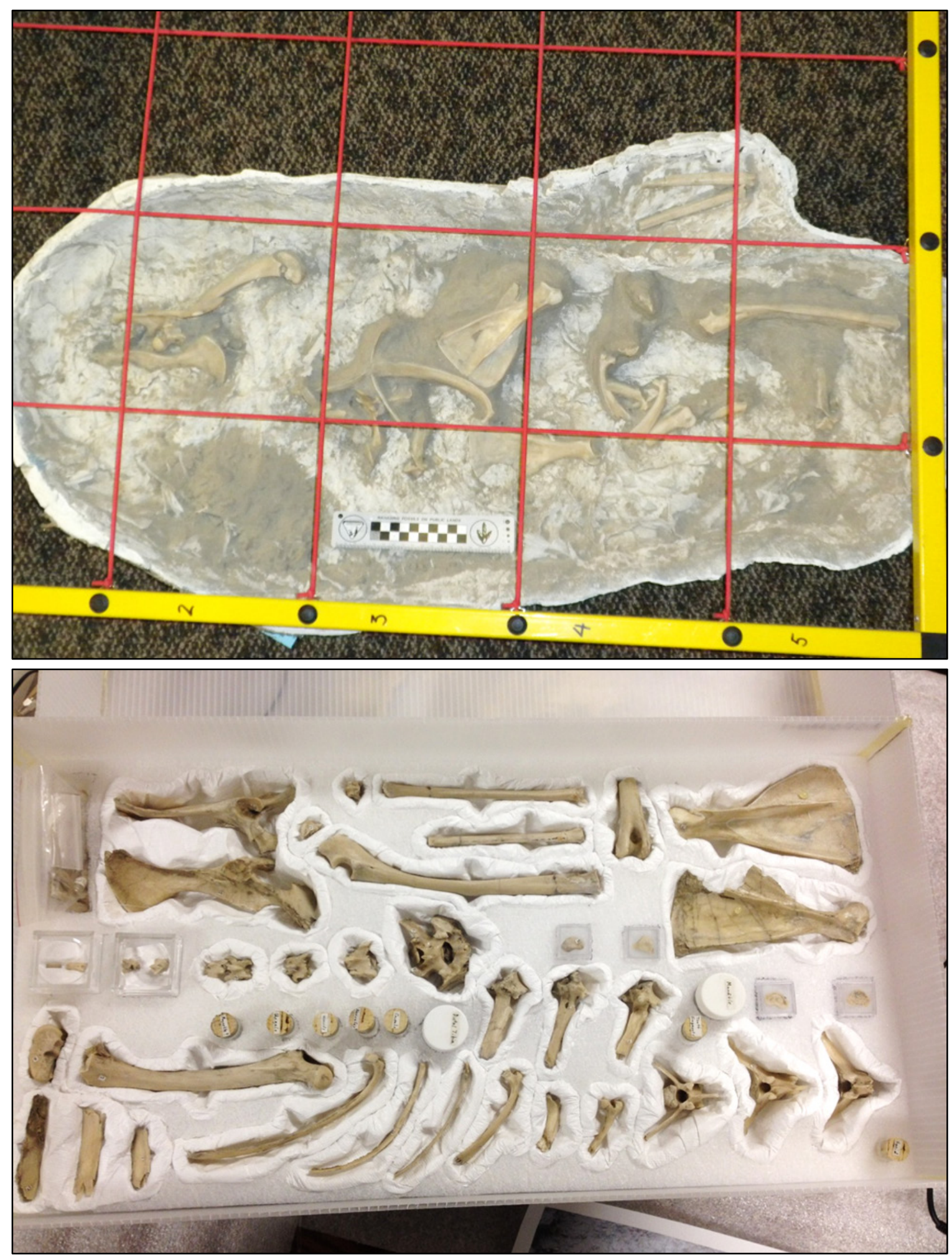

Photo 9. Photographs illustrating fossil preparation. Top: The Stenomylus block from Photo 8 with its jacket opened. The bones are being mapped in their original orientation within the surrounding matrix. Bottom: Same bones after preparation and housing in a custom fitted archival foam tray (NPS). 
Fossil preparation is a specialized subdiscipline of paleontology and preparation should only be performed by professionals with suitable training (NPS DO 77). Fossils recovered from the field in jackets are much more than a single specimen or data point. The encasing matrix of a fossil is a preserved piece of the environment from which it came, and is often as scientifically valuable as the body or trace fossil itself. At AGFO, the encasing sediment at the fossil hills includes lake sediment containing tracks of watering animals or scavengers. In other areas, such as Beardog Hill and most of the localities situated in the Harrison Formation, the fossiliferous matrix is formed of paleosols containing trace fossils (e.g., burrows and root casts) and microfossils (e.g., small vertebrates, hardshelled invertebrates, plant phytoliths), and could potentially yield geochemical proxies useful for paleoecological research. Preparators are often the first paleontologists to notice and collect these data, which typically remain obscured in the field. Preparation by untrained or unqualified staff often results in irrevocable damage or even possibly total loss of the specimen and their associated data.

AGFO does not currently have an adequate preparation lab nor the staff to run one. As such, most prepared AGFO specimens have been worked on by staff at the repositories where they are curated and many of the fossil specimens kept at AGFO have gone unprepared. It is recommended that, if safe for the specimens, AGFO request repositories to create casts of significant specimens to be sent to and held within AGFO on-site collections. This enables researcher convenience and access to resources for which the original is too fragile or sensitive for study. Such requests may also allow AGFO to obtain replicas of fossils collected pre-authorization of the Monument, which are not public property. Not all repositories have preparation facilities. In such cases, drafting an agreement with a third party that does (e.g., UNSM, SDSMT) is a recommended prerequisite for research permits that may result in a need for fossil preparation.

\section{Photographic Archives}

As a result of past research and inventory projects, photographs associated with paleontology now reside in AGFO collections. These photos should exist in a digital form that meets current NPS digital preservation standards, preferably in a high resolution filetype such as .tiff. All photographs featuring AGFO fossils or localities should be linked to the locality database. Physical photographs should be both preserved in the on-site collections and be scanned onto a digital medium. Future photographs should include as much information as possible regarding the site or specimen photographed, the orientation of the photo, the photographer, and the date. More information on this topic can be found under "Paleontological Resource Data Management".

\section{Collections in Other Repositories}

The vast majority of specimens collected from AGFO sites are kept in non-NPS repositories (Photo 10). These specimens are not NPS property, but are tracked to foster paleontological understanding of the region and to inform NPS staff/researchers about what specimens exist. The list below documents repositories known to have fossils collected within what is now AGFO, almost exclusively before the Monument was established (Hunt 1984). It is not exhaustive, and probably no such list can ever be complete due to inadequate records. For example, many institutions have fossils with provenance information limited to "Sioux County," "Agate," or similar that are typical of the fossil sites at AGFO, but the exact provenance within these general areas cannot be determined. In 
addition, institutions have long traded or gifted fossils to other institutions, potentially spreading a locality's fossils far beyond those institutions that collected there. The Carnegie Museum is known to have done so extensively with fossils collected from what is now Dinosaur National Monument, which was excavated during the same time frame as the Agate sites.

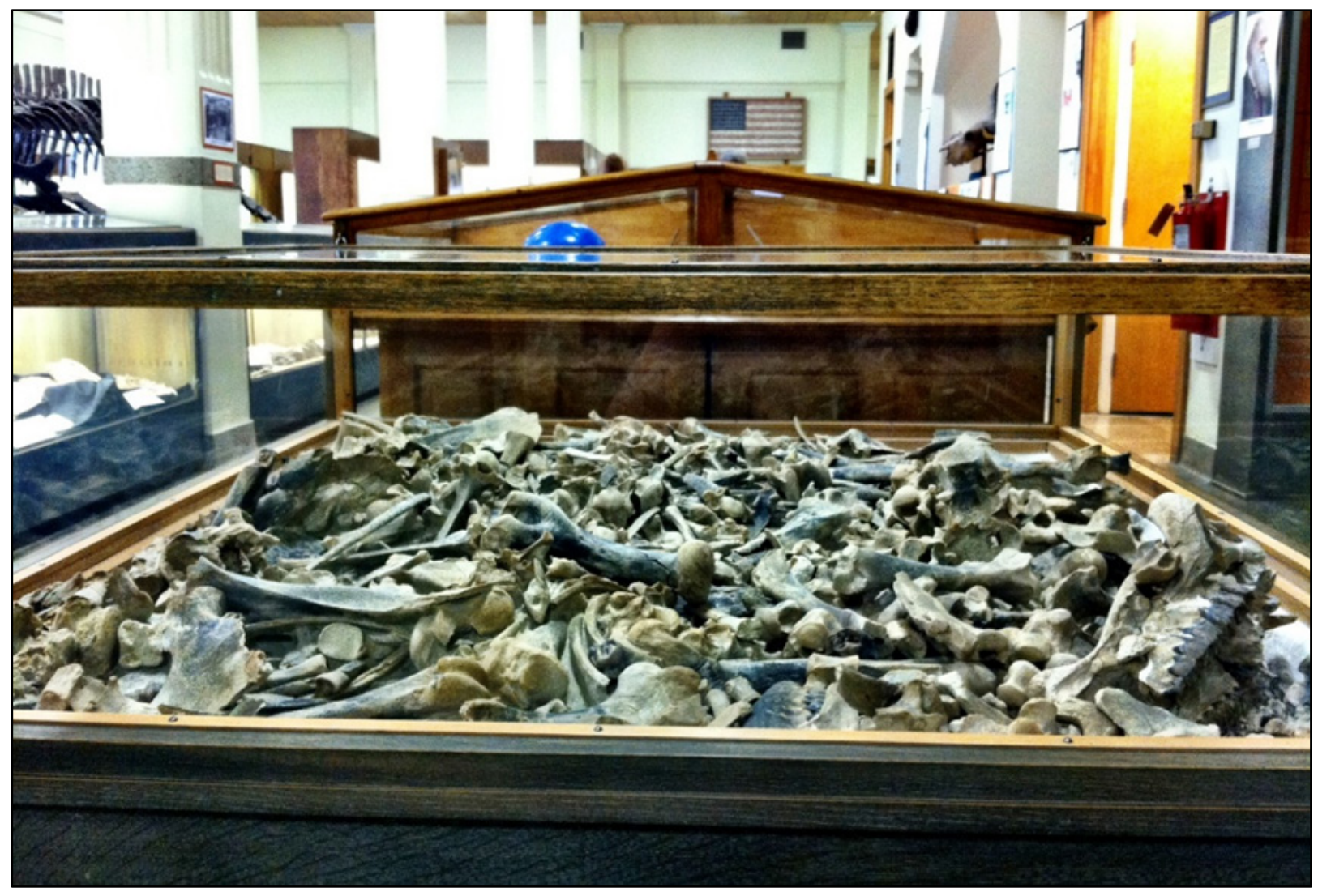

Photo 10. Bonebed slab from AGFO exhibited at the South Dakota School of Mines and Technology Museum of Geology. This bonebed slab was collected pre-authorization, and is typical of the types of fossils collected from what is now AGFO for museum study and display in the early $20^{\text {th }}$ century (NPS).

Most material collected from AGFO post-authorization that is not stored within the Monument itself is held at the University of Nebraska State Museum. These specimens were collected as part of work at AGFO during the 1980s and later (Hunt 1988b). Some salvage collections have also been stored at the University of Nebraska State Museum Repository. These materials are annually inventoried and accounted for according to NPS policy.

The following list documents all known repositories of AGFO paleontological resources, both preand post-authorization. "*” indicates a repository which only contains specimens collected postauthorization; “**” indicates a repository which contains specimens collected both pre- and postauthorization; no asterisks indicates a repository which only contains specimens collected preauthorization. 
Confirmed:

- Agate Fossil Beds National Monument* (excluding Cook Collection specimens)

- American Museum of Natural History

- Beneski Museum of Natural History at Amherst

- Carnegie Museum of Natural History

- Cincinnati Museum Center

- Denver Museum of Nature and Science

- Field Museum of Natural History

- Florida Museum of Natural History

- Foothill College

- Liberty University*

- Midwest Archeological Center*

- Museum of Comparative Zoology

- Natural History Museum of Los Angeles County

- Raymond Alf Museum

- Royal Ontario Museum

- Sam Noble Oklahoma Museum of Natural History

- Scotts Bluff National Monument

- Smithsonian National Museum of Natural History

- South Dakota School of Mines and Technology Museum of Geology**

- University of California Museum of Paleontology

- University of Colorado Museum

- University of Kansas

- University of Michigan Museum of Paleontology

- University of Nebraska State Museum** (UNSM specimens from AGFO are also on display at the Trailside Museum of Natural History at Fort Robinson, part of the UNSM system)

- University of Wyoming

- Yale Peabody Museum

Former:

- Harold Cook Collection fossils (now mostly held at the American Museum of Natural History)

- Princeton (now Yale Peabody Museum)

- University of Chicago (now Field Museum) 


\section{Type Specimens}

At least 25 fossil species have been named from fossils found within modern AGFO boundaries (Table 3). As with many other taxa named in the $19^{\text {th }}$ and early $20^{\text {th }}$ century, many of these have been reevaluated as synonyms of other species. Some still retain status as the type of a recognized taxon, however, and even those belonging to defunct taxonomic designations are critical pieces of paleontological history.

Table 3. Fossil taxa named from specimens found within AGFO.

\begin{tabular}{|c|c|c|c|c|}
\hline Taxon & Citation & Age, Formation & Type Specimen & Notes \\
\hline $\begin{array}{l}\text { Delotrochanter } \\
\text { oryktes }\end{array}$ & Hunt 2011 & $\begin{array}{l}\text { Miocene, } \\
\text { Harrison }\end{array}$ & ACM 4804 & Amphicyonid \\
\hline $\begin{array}{l}\text { Amphicyon } \\
\text { superbus }\end{array}$ & $\begin{array}{l}\text { Peterson } \\
1907\end{array}$ & $\begin{array}{l}\text { Miocene, } \\
\text { Anderson Ranch }\end{array}$ & CMNH 1589 & $\begin{array}{l}\text { Amphicyonid, now known as } \\
\text { Daphoenodon superbus }\end{array}$ \\
\hline $\begin{array}{l}\text { Stenomylus } \\
\text { hitchcocki }\end{array}$ & $\begin{array}{l}\text { Loomis } \\
1910\end{array}$ & $\begin{array}{l}\text { Miocene, } \\
\text { Harrison }\end{array}$ & ACM 2059 & Camel \\
\hline Ortalis tantala & $\begin{array}{l}\text { Wetmore } \\
1933\end{array}$ & $\begin{array}{l}\text { Miocene, } \\
\text { Anderson Ranch }\end{array}$ & $\begin{array}{l}\text { HC } 498 \text { (now AMNH FR } \\
8368 \text { ) }\end{array}$ & $\begin{array}{l}\text { Chachalaca, now known as } \\
\text { Boreortalis tantala }\end{array}$ \\
\hline Moropus cooki & $\begin{array}{l}\text { Barbour } \\
1908\end{array}$ & $\begin{array}{l}\text { Miocene, } \\
\text { Anderson Ranch }\end{array}$ & $\begin{array}{l}\text { UNSM 27-7-05 and 104- } \\
20-7-6 \text { (skull and } \\
\text { mandible, not necessarily } \\
\text { the same individual) }\end{array}$ & $\begin{array}{l}\text { Chalicothere, now considered a } \\
\text { synonym of Moropus elatus }\end{array}$ \\
\hline Moropus parvus & $\begin{array}{l}\text { Barbour } \\
1909\end{array}$ & $\begin{array}{l}\text { Miocene, } \\
\text { Anderson Ranch }\end{array}$ & UNSM 99-20-7-05L & $\begin{array}{l}\text { Chalicothere, now considered a } \\
\text { synonym of Moropus elatus }\end{array}$ \\
\hline $\begin{array}{l}\text { Moropus } \\
\text { petersoni }\end{array}$ & $\begin{array}{l}\text { Holland } \\
1908\end{array}$ & $\begin{array}{l}\text { Miocene, } \\
\text { Anderson Ranch }\end{array}$ & $\begin{array}{l}\text { CMNH } 1700,1701, \\
1703 \mathrm{~A}, 1703 \mathrm{~B}, 1703 \mathrm{C}, \\
\text { and } 1707\end{array}$ & $\begin{array}{l}\text { Chalicothere, now considered a } \\
\text { synonym of Moropus elatus }\end{array}$ \\
\hline $\begin{array}{l}\text { Nothocyon } \\
\text { annectens }\end{array}$ & $\begin{array}{l}\text { Peterson } \\
1907\end{array}$ & $\begin{array}{l}\text { Miocene, } \\
\text { Anderson Ranch }\end{array}$ & CMNH 1602 & $\begin{array}{l}\text { Dog, now known as Phlaocyon } \\
\text { annectens }\end{array}$ \\
\hline Daeodon minor & $\begin{array}{l}\text { Loomis } \\
1932\end{array}$ & $\begin{array}{l}\text { Miocene, } \\
\text { Harrison }\end{array}$ & $\begin{array}{l}\text { ACM 31-22 (now ACM } \\
1871)\end{array}$ & $\begin{array}{l}\text { Entelodont, now considered a } \\
\text { synonym of Daeodon (or } \\
\text { Dinohyus) hollandi }\end{array}$ \\
\hline $\begin{array}{l}\text { Dinochoerus } \\
\text { hollandi }\end{array}$ & $\begin{array}{l}\text { Peterson } \\
1905\end{array}$ & $\begin{array}{l}\text { Miocene, } \\
\text { Anderson Ranch }\end{array}$ & CMNH 1594 & $\begin{array}{l}\text { Entelodont, now known as } \\
\text { Daeodon (or Dinohyus) hollandi }\end{array}$ \\
\hline $\begin{array}{l}\text { Palaealectoris } \\
\text { incertus }\end{array}$ & $\begin{array}{l}\text { Wetmore } \\
1930\end{array}$ & $\begin{array}{l}\text { Miocene, } \\
\text { unspecified }\end{array}$ & MCZ 2190 & Grouse \\
\hline Geranoaëtus ales & $\begin{array}{l}\text { Wetmore } \\
1926\end{array}$ & $\begin{array}{l}\text { Miocene, } \\
\text { Anderson Ranch }\end{array}$ & CMNH 1828 & Hawk, now known as Buteo ales \\
\hline Palaeastur atavus & $\begin{array}{l}\text { Wetmore } \\
1943\end{array}$ & $\begin{array}{l}\text { Miocene, } \\
\text { Harrison }\end{array}$ & $\begin{array}{l}\text { HC } 693 \text { (now AGFO } \\
18003 \text { ) }\end{array}$ & Hawk \\
\hline Proictinia efferus & $\begin{array}{l}\text { Wetmore } \\
1923\end{array}$ & $\begin{array}{l}\text { Miocene, } \\
\text { Anderson Ranch }\end{array}$ & AMNH FR 6299 & $\begin{array}{l}\text { Kite, now known as Promilio } \\
\text { efferus }\end{array}$ \\
\hline $\begin{array}{l}\text { Blastomeryx } \\
\text { pristinus }\end{array}$ & $\begin{array}{l}\text { Cook } \\
1934\end{array}$ & $\begin{array}{l}\text { Miocene, } \\
\text { Anderson Ranch }\end{array}$ & $\begin{array}{l}\text { HC } 669 \text { (now AMNH FM } \\
81014 \text { ) }\end{array}$ & $\begin{array}{l}\text { Moschid; nomen dubium, } \\
\text { reclassified as Aletomeryx }\end{array}$ \\
\hline
\end{tabular}


Table 3 (continued). Fossil taxa named from specimens found within AGFO.

\begin{tabular}{|c|c|c|c|c|}
\hline Taxon & Citation & Age, Formation & Type Specimen & Notes \\
\hline $\begin{array}{l}\text { Brachypsalis } \\
\text { simplicidens }\end{array}$ & $\begin{array}{l}\text { Peterson } \\
1907\end{array}$ & $\begin{array}{l}\text { Miocene, } \\
\text { Anderson Ranch }\end{array}$ & CMNH 1553 & $\begin{array}{l}\text { Mustelid, now considered a } \\
\text { synonym of Megalictis ferox. M. } \\
\text { ferox's FAD marks the } \\
\text { beginning of Ar4 }\end{array}$ \\
\hline $\begin{array}{l}\text { Paractiornis } \\
\text { perpusillus }\end{array}$ & $\begin{array}{l}\text { Wetmore } \\
1930\end{array}$ & $\begin{array}{l}\text { Miocene, } \\
\text { Anderson Ranch }\end{array}$ & MCZ 2191 & Pratincole \\
\hline $\begin{array}{l}\text { Diceratherium } \\
\text { niobrarense }\end{array}$ & $\begin{array}{l}\text { Peterson } \\
1906\end{array}$ & $\begin{array}{l}\text { Miocene, } \\
\text { Harrison }\end{array}$ & CMNH 1271 & Rhinoceros \\
\hline $\begin{array}{l}\text { Aceratherium } \\
\text { stigeri }\end{array}$ & $\begin{array}{l}\text { Loomis } \\
1908\end{array}$ & $\begin{array}{l}\text { Miocene, } \\
\text { Anderson Ranch }\end{array}$ & ACM 1040 & $\begin{array}{l}\text { Rhinoceros, now considered a } \\
\text { synonym of Menoceras } \\
\text { arikarense }\end{array}$ \\
\hline $\begin{array}{l}\text { Diceratherium } \\
\text { aberrans }\end{array}$ & $\begin{array}{l}\text { Loomis } \\
1908\end{array}$ & $\begin{array}{l}\text { Miocene, } \\
\text { Anderson Ranch }\end{array}$ & ACM 1321 & $\begin{array}{l}\text { Rhinoceros, now considered a } \\
\text { synonym of Menoceras } \\
\text { arikarense }\end{array}$ \\
\hline $\begin{array}{l}\text { Diceratherium } \\
\text { cooki }\end{array}$ & $\begin{array}{l}\text { Peterson } \\
1906\end{array}$ & $\begin{array}{l}\text { Miocene, } \\
\text { Harrison }\end{array}$ & CMNH 1572 & $\begin{array}{l}\text { Rhinoceros, now considered a } \\
\text { synonym of Menoceras } \\
\text { arikarense }\end{array}$ \\
\hline $\begin{array}{l}\text { Diceratherium } \\
\text { loomisi }\end{array}$ & $\begin{array}{l}\text { Cook } \\
1912\end{array}$ & $\begin{array}{l}\text { Miocene, } \\
\text { Anderson Ranch }\end{array}$ & $\begin{array}{l}\text { HC } 260 \text { (modern number } \\
\text { not known, assumed to be } \\
\text { at the AMNH if not lost) }\end{array}$ & $\begin{array}{l}\text { Rhinoceros, now considered a } \\
\text { synonym of Menoceras } \\
\text { arikarense }\end{array}$ \\
\hline $\begin{array}{l}\text { Diceratherium } \\
\text { petersoni }\end{array}$ & $\begin{array}{l}\text { Loomis } \\
1908\end{array}$ & $\begin{array}{l}\text { Miocene, } \\
\text { Anderson Ranch }\end{array}$ & ACM 1583 & $\begin{array}{l}\text { Rhinoceros, now considered a } \\
\text { synonym of Menoceras } \\
\text { arikarense }\end{array}$ \\
\hline $\begin{array}{l}\text { Diceratherium } \\
\text { schiffi }\end{array}$ & $\begin{array}{l}\text { Loomis } \\
1908\end{array}$ & $\begin{array}{l}\text { Miocene, } \\
\text { Anderson Ranch }\end{array}$ & ACM 1042 & $\begin{array}{l}\text { Rhinoceros, now considered a } \\
\text { synonym of Menoceras } \\
\text { arikarense }\end{array}$ \\
\hline $\begin{array}{l}\text { Diceratherium } \\
\text { arikarense }\end{array}$ & $\begin{array}{l}\text { Barbour } \\
1906\end{array}$ & $\begin{array}{l}\text { Miocene, } \\
\text { Harrison }\end{array}$ & UNSM 62008 & $\begin{array}{l}\text { Rhinoceros, now known as } \\
\text { Menoceras arikarense }\end{array}$ \\
\hline
\end{tabular}

\section{Museum Security and Fire Protection}

\section{Museum Security}

Museum security measures are in compliance with NPS policy, as laid out in chapter 14 of the NPS Museum Handbook (NPS 2002). See the AGFO Museum Collection Management Plan (Reilly and Kennedy 2003) and the sensitive version of this report for additional details.

The museum should have a visitor sign-in log. This log should be signed by anyone entering the repository, and should include the date, time of day, and reason for their visit. Staff supervising visitors or opening the door to the repository for them should also sign the log.

\section{Fire Protection}

Fire protection measures are in compliance with NPS, as laid out in chapter 9 of the NPS Museum Handbook (NPS 2019). See the AGFO Museum Collection Management Plan (Reilly and Kennedy 
2003) for detailed information. Measures include automated sprinklers, fire alarms, fire resistant specimen cabinets, and readily accessible fire extinguishers. 



\section{Interpretation}

\section{Current Long-Range Interpretive Plan}

Interpreting and educating the public about AGFO's fossil resources is a core mandate for the Monument as a unit of the National Park System. In 2011, AGFO produced a Long-Range Interpretive Plan (LRIP) to set themes, goals, and actions in regard to its interpretive program; this section includes some reworked and/or paraphrased text from that document (NPS 2011). At present, AGFO utilizes Visitor Center exhibits, trails and wayside signs, interaction with interpretive staff, and periodic programs and events to pursue its interpretive goals. These goals are summarized through four primary interpretive themes, discussed below. AGFO should begin preparing a new LRIP for 2021 and beyond.

\section{Primary Interpretive Themes}

Four primary themes make up the core of AGFO's interpretive program. These themes are so central to AGFO's significance that conveying them to every visitor is the baseline goal for AGFO. All themes apply to AGFO's paleontological resources, and some of them apply to other resource types such as cultural, geologic, and biologic (NPS 2011, 2012).

\section{Transitions}

"Agate Fossil Beds National Monument provides an example of how the earth has changed in appearance, over eons of geologic time, and how changing conditions altered the ways that animals and humans lived, and died, on these lands."

This theme focuses upon how and why the landscape of AGFO changed over time. In terms of paleontology, this includes the transition from the forested time of the Eocene units lying unexposed below the Monument, to the opening savanna of the Oligocene and Miocene, to the transition into the prairie steppe of the Pleistocene and today. Interpretive programs based on this theme help audiences visualize the broad sweep as well as the intimate details of the Monument's landscape. The changing assemblage of fauna and flora that lived upon the land is part of this theme, as are the changing climate and environmental conditions which forced adaptation, migration, and/or extinction.

\section{Interactions}

"Animals, and more recently humans, have gathered for millions of years on land within the park, providing a window into the interactions of diverse species and cultural groups."

This theme focuses upon the ecological interactions between fossil species at AGFO (other resource types also include varied interactions between modern species and humans under this theme). Interpretive programs present the paleoecology and behaviors of the fossil species at AGFO according to the current state of scientific knowledge. Points of interest include trace fossils such as Daemonelix, tracks upon the floor of the ancient watering hole, and the carnivore dens at Beardog Hill, as well as evidence of scavenging and other pre-burial taphonomic features of body fossils. Conveying this theme presents the specimens of AGFO as part of a living world, different yet familiar to today, rather than a collection of strange skeletons. The record of coexistence and competition between Miocene species in the face of disastrous drought within a drying climate plays 
into the Monument's ability to handle other themes, such as teaching about the impacts of climate change on modern ecologies.

\section{Discovery}

"For more than a century, the park's lands have been the focus of scholarly inquiry, illustrating how the study of science has matured over time, and how stewardship has protected a landscape now deemed a national treasure."

This theme focuses upon the process and history of scientific inquiry, as well as active land stewardship at AGFO. For paleontology, this means the history of scientific discovery and paleontological excavations at AGFO. Notably, the paleontological history of AGFO reflects the maturation of the science. Contrasting the competitive and exhibit-specimen-focused collections of the early $20^{\text {th }}$ century with later studies, such as the 1980 s excavations and recent publications, grants visitors insight about long-term changes in paleontology's focus and methods. The stewardship angle begins with Native Americans, moves to the Cook family's efforts to balance protection of and fair access to the fossil resources, then to the establishment of AGFO as a national monument, and finally ends with visitors' own responsibilities in regard to preserving and advocating for AGFO paleontological resources.

\section{Discoveries}

"Decades of scholarly investigation not only opened our eyes to other worlds inhabited by differentlooking creatures but also revealed multiple lessons that shed light on subjects relevant to the $21^{\text {st }}$ century including extinction, evolution, climate change, and cultural interaction."

This theme focuses on the discoveries that flow from scholarly investigation of AGFO's resources. Some are mere fun facts that visitors can take home with them; others are solemn and cautionary warnings about the future as informed by the past.

On one level, the work of paleontologists introduces a menagerie of animals, some vaguely familiar, others more like creatures of fantasy. Visitors are asked to envision Nebraska as an analogue to today's African Serengeti. This entry level of paleontology as curiosity is the hook that initially attracts many visitors, especially those with limited background in paleontology.

Following from these wondrous hooks is an interpretive depth that directly addresses relevance and meaning. Interpretation introduces visitors to both scientific understanding and scientific methods, urging on the development of scientific literary and critical thinking. Interpretation of the Miocene life and environments that existed at AGFO opens the door to dialogue on the impacts of climate change on species survival, not just then, but also now. Do the extinct animals discovered at AGFO have lessons for us about the limits of animal adaptation? What might Palaeocastor, Moropus, or Stenomylus teach us about evolution and environmental change?

\section{Interpretation Programs and Resources Related to Paleontological Resources}

\section{Visitor Center and Museum Exhibits}

The Visitor Center serves as the main attraction at AGFO year-round, and is outfitted with an information desk, sales area, children's discovery area, film hall, and exhibits. The main hall includes 
all of the paleontological exhibits (except for an exhibited bonebed slab in the entryway) as well as the information desk. These exhibits cover the fossil species assemblage, depositional environment, paleoecology, paleoclimate, current hypotheses about the formation of the fossil beds, and history/methods of scientific study at AGFO. They include: articulated replicas of Moropus, Daeodon, Daphoenodon, and Stenomylus; disarticulated or isolated replicas of bones from these taxa as well as Menoceras and a few others; a slab with Menoceras footprints and a replica rhinoceros footprint for reference; a bonebed slab (different from the aforementioned ones) with original fossils still in matrix; a Daemonelix; paleontologist tools; and interpretive signs for the exhibited materials (Photo 6 and 11). Currently, a framed, complete, in-slab skeleton of Stenomylus is also exhibited, but this is personal property of the Cook family and not a permanent fixture. Some of the exhibits are interactive.

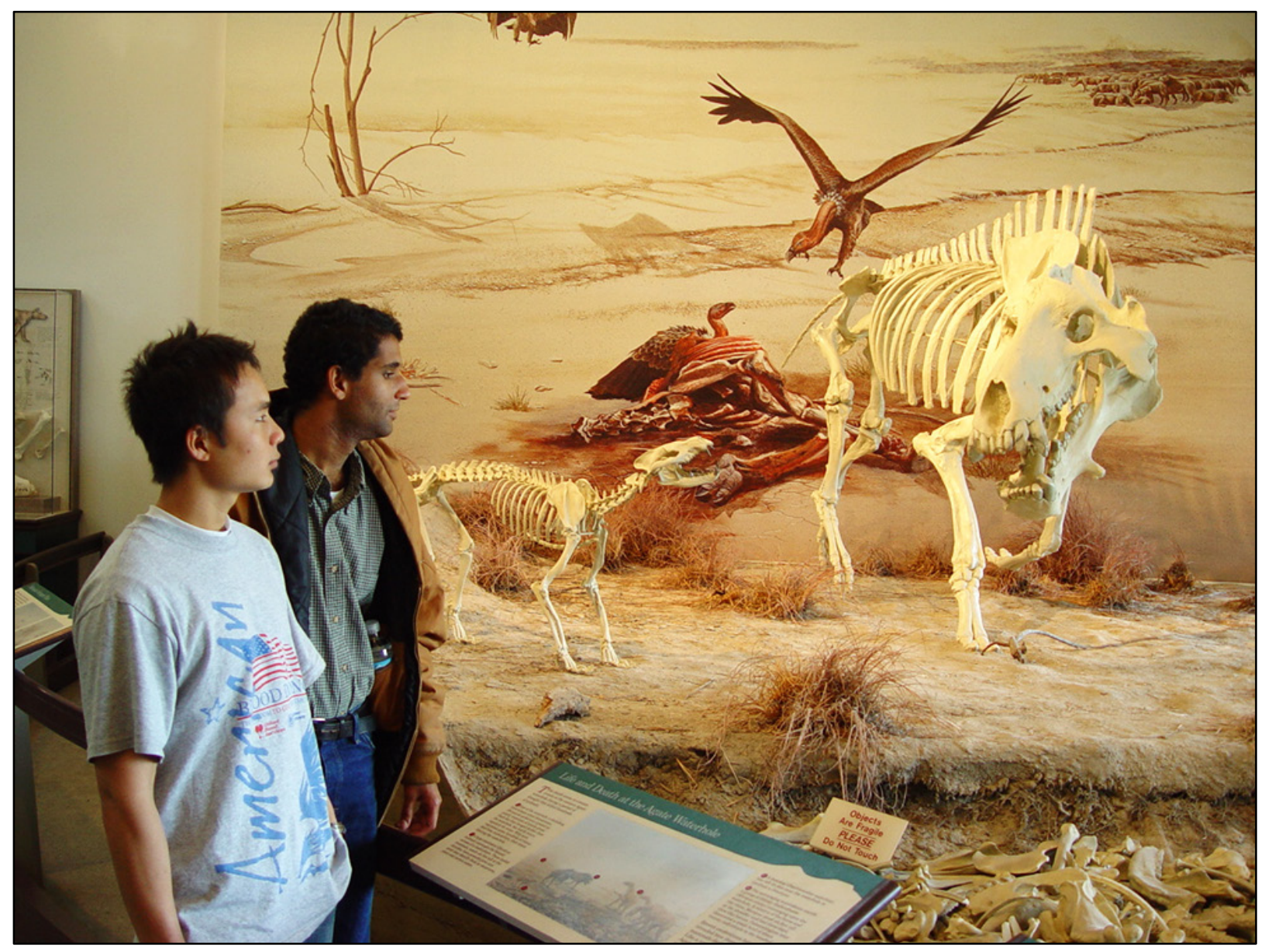

Photo 11. Visitors observing the exhibits and replica skeletons within the AGFO Visitor Center (NPS).

There is an exhibit which plays videos featuring Dr. Robert Hunt, Jr. leading an interpretive walk of the Monument's trails; this serves as a potential substitute for walking the trails, meant for those short on time or otherwise unable to walk them (though the trails themselves were designed in accordance with accessibility guidelines; see below). The film hall plays a 12-minute-long film on 
paleontology, current scientific theories, and the history of the fossil discoveries. This room is sometimes used for other events and functions as well.

The Visitor Center is the main place where Monument interpretive staff interact with the public, outside of special events. Interpretive staff walk the floor of the museum, staff the information desk, and run the movie in the film hall (sometimes prefacing it with a short topical lecture of their own), being available for visitor questions in all of these capacities.

The Visitor Center and its exhibits are currently in excellent condition, and serve as the backbone of the interpretive experience. However, the comprehensive nature of the Visitor Center is cited in the LRIP as potentially discouraging visitors from utilizing other interpretive opportunities such as the trails. This issue, and its potential solutions, are discussed elsewhere in this section.

\section{Trails and Wayside Exhibits}

AGFO has three walking trails: the Fossil Hills Trail, the Bone Cabin Trail (not officially named, begins off of the Fossil Hills Trail), and the Daemonelix Trail (D-Trail). The primary interpretive tools on these trails are wayside markers, which both point out interesting features and comment on topics relating to the Monument's landscape, history, and resources. There are also wayside markers along the main road that runs through the Monument, which either cover big-picture topics about AGFO or discuss distant landmarks for those who do not plan to walk the trails and see them up close (e.g., the bone cabin).

The Fossil Hills Trail is the longest at $4.3 \mathrm{~km}$ (2.7 mi). Beginning near the Visitor Center, this paved trail passes through marsh and prairie before ascending up a mild gradient to Carnegie Hill, University Hill, and Beardog Hill. The trail was explicitly built to meet accessibility standards. It has wayside markers discussing the modern environment and wildlife, the paleoenvironment and fossil species, the methods and history of excavations at the Fossil Hills, and the history of the Niobrara Valley at large (Photo 12). There are no in situ fossil exhibits since the previous ones were reburied in the 1990s due to damage, and since then staff have usually reburied, otherwise hid, or collected any obvious exposed fossils of significant value. The only fossils thus available for the public to view are fragmentary float and a cross-section of tracks (pointed out by a wayside marker). This policy of keeping fossils obscured is meant to both protect the resources and protect visitors, as there is a risk of rockfalls along the cliff faces where non-fragmentary fossils are most likely to become exposed.

The Bone Cabin Trail is a mown grass trail which splits off from the Fossil Hills Trail. It leads to John Cook's grave and the bone cabin, and also provides a view of the Hoffman House. The bone cabin can be observed from the outside, but not entered. This trail is currently not marked on AGFO maps or brochures and has no official name. A wooden sign along the Fossil Hills Trail does point visitors along this path, towards the grave and the bone cabin. There are no wayside markers along this trail. 


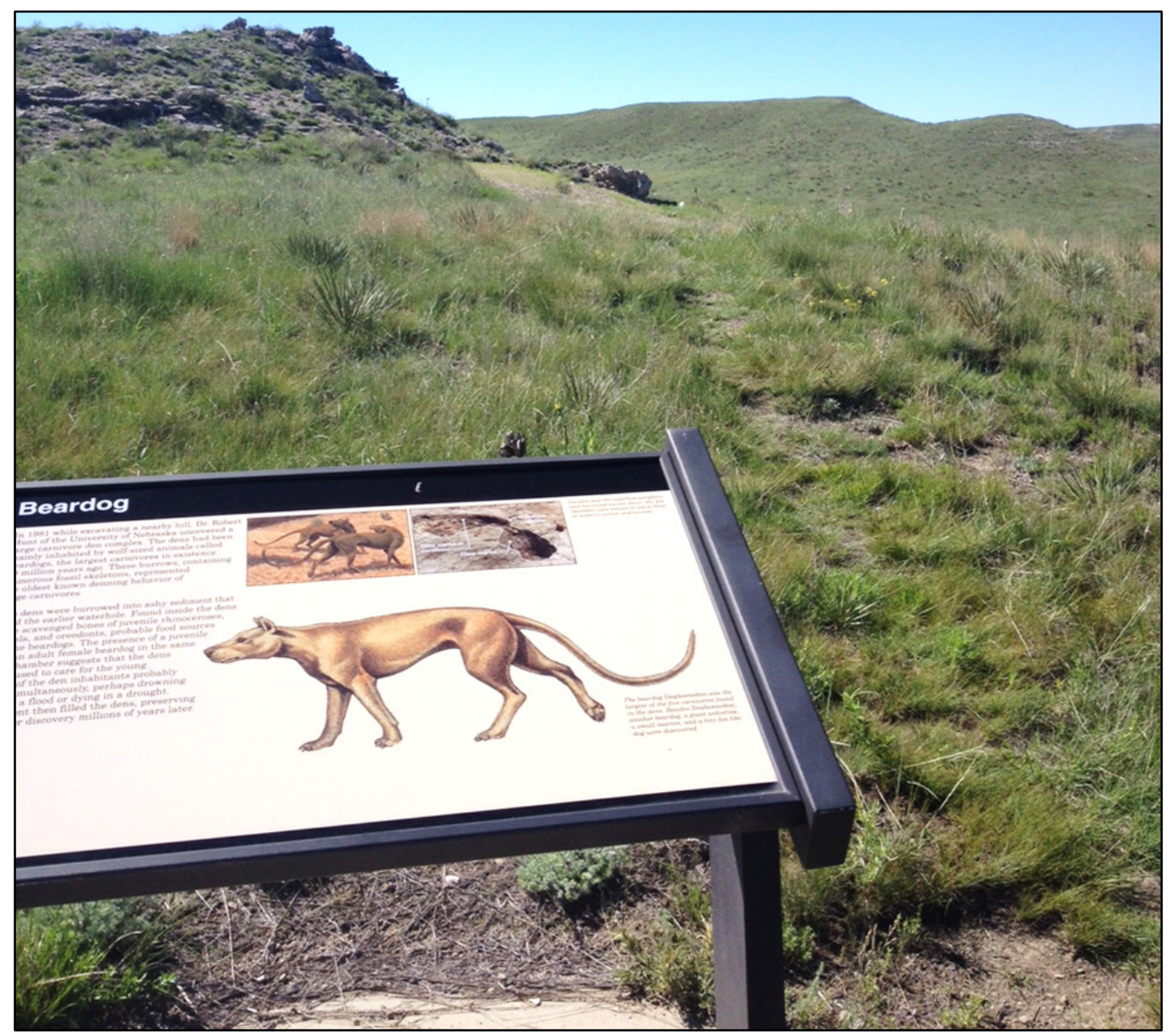

Photo 12. Example of an interpretive wayside exhibit at Beardog Hill along the Fossil Hills Trail (NPS).

The D-Trail is a crushed rock trail that begins from a parking lot just off of highway 29, across from the Agate Springs Ranch. It leads visitors through some of the older stratigraphic units within the Monument, focusing upon a section of the Harrison Formation that contains a large number of Daemonelix fossils. The eastern side of the loop has some steep sections, which may be difficult for some disabled visitors to traverse. The trail has two in situ Daemonelix exhibits housed in protective casings. Wayside markers along the trail discuss Sharps Formation sand dunes, and point out and discuss the origins of Daemonelix, paleosols, the Agate Springs Ranch, and an old camp site previously used by the Lakota on their visits to Agate Springs. Notably, natural erosion and a small amount of visitor disturbance have significantly degraded several unprotected Daemonelix along the trail (as evidenced by photographs on the waysides) and one of the in situ displays' protective casings is showing wear despite regular maintenance. Interpretive staff may find the damaged Daemonelix specimens useful for outreach purposes, using them as an example of why visitors should not disturb paleontological resources.

Two wayside markers found on a pull-off along River Road discuss the modern prairie ecosystem and the bone cabin, which is visible in the distance. 


\section{Informational Activities, Publications, and Website}

AGFO has a Junior Ranger activity book, which directs children and their families to engage with the exhibits and trails in ways best designed to impart key themes to young audiences. This book is advertised at the front desk and has been improved upon several times.

Informational brochures are posted in the Visitor Center on a variety of topics. For those related to geology and paleontology, the information is largely a summary of what is discussed in the exhibits and waysides. Two self-guided trail pamphlets cover the two main trails (Fossil Hills and D-Trail; the mown trail to the bone cabin is not mentioned), describing safety procedures, important stops, landmarks, and modern plants and animals. The D-Trail's pamphlet can also be found at its trailhead. Much of the information offered within these guides is supplementary to that included upon the trail waysides, to not override the benefit of those waysides by making visitors feel the information provided is redundant.

AGFO's official website (https://www.nps.gov/agfo/index.htm) covers basic information about the Monument, visit planning, ways to get involved with the Monument, and educational pages meant to summarize core information about the Monument's resources. The LRIP cited the website as lacking interpretation according to the Monument's main themes, but since 2011 the website seems to have markedly improved. The geology, fossil taxa, their paleoenvironment and ecosystem, and the history of excavations at the bonebed are now all included on the website, and present concise versions of several Visitor Center exhibits. Pages relating to other types of resources also seem to be improved. However, it is somewhat unintuitive to navigate to the pages about the paleontological resources because users must navigate three tabs deep within the website (Learn About the Park $\backslash$ Nature $\backslash$ Natural Features and Ecosystems) before seeing any pages with explicit paleontological titles.

Under certain circumstances, the use of social media may be considered for use in paleontological resource education, interpretation, and outreach. Use of social media should be done in consultation with the regional or Washington public affairs office and the NPS paleontology program. The use of social media should not disclose information or share photographs that may place NPS paleontological resources at risk. AGFO currently has a Facebook page and has participated in broader social media programs such as the NPS centennial LEGO vignettes.

\section{Photogrammetric Models for Interpretation}

The NPS paleontology program has utilized 3D photogrammetry to produce online virtual museum websites showcasing interactive digital models of park fossils. Photogrammetry can also be used to produce replicas of fossils. These replicas can be used as educational specimens for the public without putting the original fossils at risk.

In September 2018, Jack Wood (NPS Geologic Resources Division; GRD) created a 3D model of a well-preserved Stenomylus hitchcocki specimen on loan to AGFO. The GRD maintains the photogrammetric files if there is future interest in developing a website or printing a model. The files have been processed, and a digital model is available. It is highly recommended that AGFO use the files to create a physical model of the specimen if its owners choose to terminate the loan. 


\section{Staff Interaction with Guests and Special Events and Programs}

As previously stated, most interpretive staff interaction with visitors occurs at the Visitor Center. At least one staff member is on-hand during operating hours, working the information desk and running the movie in the film hall. Extra interpretive staff walk the exhibit floor or assist special visitors such as Artists-in-Residence. Staff proactively introduce new visitors to the Monument, the Visitor Center, and the available activities, and reactively answer visitor questions. Staff handle phone calls and answer visitor questions in that manner as well, though some visitor phone calls may be transferred or initially answered by personnel in the administrative office.

Staff also run special events, such as school trips, summer camps, or represent AGFO at a symposium or fair (Photo 13). These may require the staff to lead visitors around the Monument's trails, give a presentation at AGFO or another institution (e.g., the Trailside Museum), or give lessons/seminars via distance learning, among other possible activities. These events are usually planned and more structured than day-to-day interaction in the Visitor Center, though staff need to be flexible and prepared for additional visitor questions or needs.

Specific examples of special events related to fossil resources held at AGFO include:

- 2012 Fossil Summer Camp

- 2013 Fossil Fall Science Day

- National Fossil Day Events

- Junior Ranger Careers presentation at Midwest Theatre

- 2019 Fall Science Day

\section{Partnerships}

AGFO has formed partnerships with other institutions for a variety of needs, some of them related to interpretive and educational goals. Some of these partnerships include:

- Nebraska Natural Resource District

- Midwest Theatre

- Riverside Discovery Center

- Legacy of the Plains

- US Forest Service (especially Hudson-Meng Bison Kill)

- YMCA

- Scottsbluff National Monument (SCBL)

- Fossil Freeway (union of several paleontological sites over multiple states) 


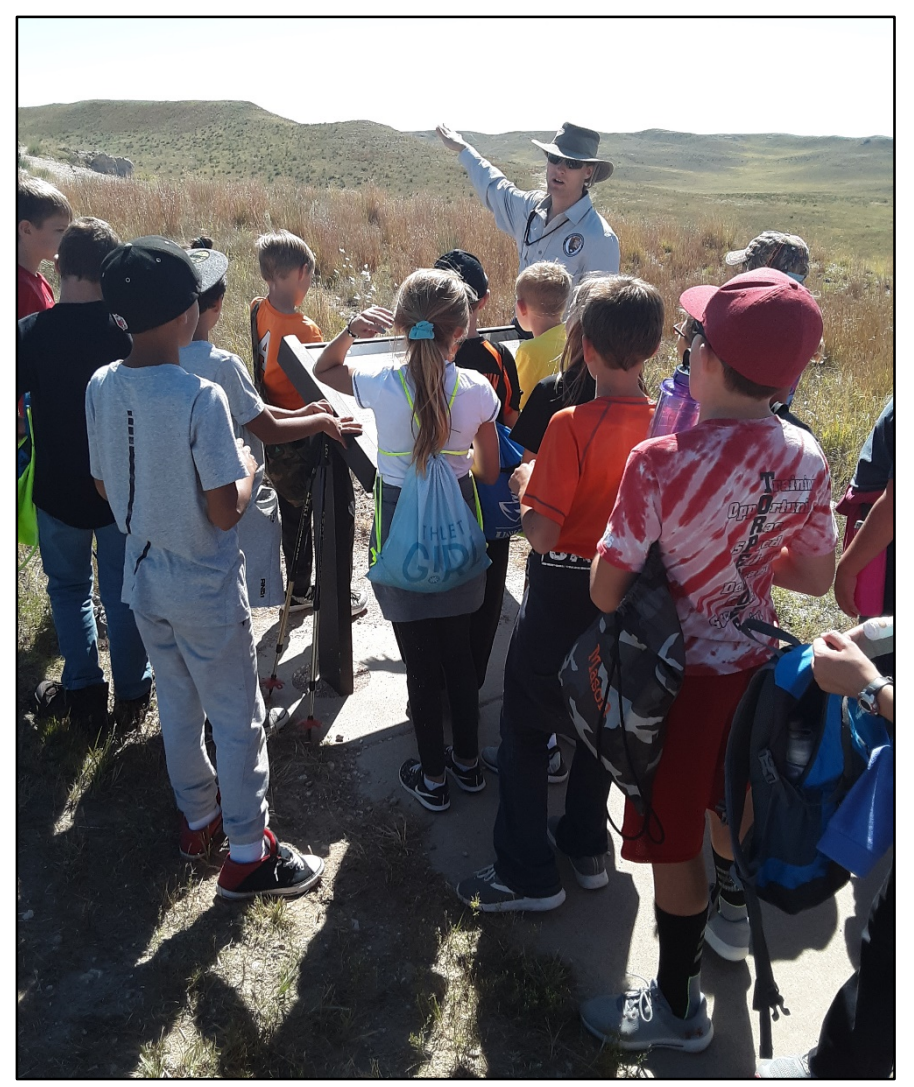

Photo 13. Scott Kottkamp gives a presentation about beardogs, paleoecology, and the importance of context as scientific data to a school group at Beardog Hill. Guided field trips to and presentations at locations along the Fossil Hills Trail are some of the most common and important interpretive activities held at AGFO (NPS).

\section{Target Audiences}

Visitors from all backgrounds are always welcome at AGFO, but the LRIP targeted four groups of "high priority" visitors to design the interpretive experience toward. Interpretive programs must be designed with some or all of these target audiences in mind. The four groups are:

1. Youth and education groups, including college classes, local schools, summer camps, scout and cultural center groups.

2. Families, especially those with children.

3. "Local" audiences and opinion leaders from towns within easy day-trip range. A major goal here is to increase local investment of interest and engagement with AGFO.

4. Those accessing Monument information digitally, whether off-site viewers of the AGFO website, or on-site visitors who wish to use the internet to augment their experience.

Thus, AGFO's interpretive experience is largely aimed at audiences with limited backgrounds in geology and paleontology. It is set up to begin with the basics of paleontology, explained in the context of the Monument's specific resources and story, before moving into more detail on current hypotheses about the fossil taxa and the paleoenvironment. Interpretation avoids excessive jargon, 
seeks to tell an understandable story, and works to inspire critical thinking about what AGFO's paleontological resources reveal about the past, present and future. Though AGFO's interpretive program is not aimed at specialists, AGFO staff should try to remain informed about major research related to AGFO's resources and amend exhibits if/as hypotheses change.

\section{Resource Preservation in Interpretation}

Resource preservation is a critical topic to teach for understanding of paleontological resources (Hockett 2008; Santucci et al. 2016). Audiences should be informed about why the fossil resources are preserved, instead of being "strip-mined" at one extreme or allowed to just naturally weather away on the other. The scientific value of contextual details should be stressed, and tied into a message about not disturbing or collecting fossil resources without authorization. What the Monument does to manage and preserve fossil resources should be shared in a manner that does not reveal sensitive information, to show visitors that the resources are being cared for (which may dissuade visitors from collecting fossils "in good faith"). This topic can be intertwined with how AGFO's story reflects changing ethos and maturation in paleontology, contrasting the indiscriminate collection of the early $20^{\text {th }}$ century with a modern approach balancing multiple needs (where collection is done out of scientific merit or to salvage an endangered specimen). While this goal is applicable to visitors of all ages, as part of teaching good stewardship it is a key inclusion in interpretive efforts aimed at children (e.g., the Junior Ranger program).

\section{Use of Visitor Site Reports}

Visitors constantly interact with paleontological resources in a direct manner at AGFO, owing to the highly fossiliferous nature of several localities along public trails (e.g., the Fossil Hills Trail). This interaction has been managed mostly on an improvised basis, requiring a careful balance between protecting the paleontological resources while not discouraging visitor engagement with them.

Visitor site reports are a potential method to constructively harness and encourage visitor engagement with paleontological resources. Visitor site reports have been implemented successfully at several other NPS units, including BADL. Visitor site report forms are provided for the public at a visitor center, are filled out by visitors when they discover paleontological resources, and are then turned in to park staff at the visitor center. The forms document an approximate location and description of the resource. While these forms can lead to the discovery of previously unknown resources, their larger benefit is in fostering good stewardship practices in visitors and increasing visitor engagement with paleontological resources without damaging them. Some visitors at AGFO have removed fossils from their contexts with the intent to report the resources to, or have the resources identified by, staff. By being provided visitor site forms to document fossils, visitors are subtly encouraged to leave fossils in their original contexts instead. Visitor use of these forms also provides a quantifiable metric of public engagement in paleontological resource stewardship, management, and protection.

See Appendix D for an example of a visitor site report form for AGFO. Visitor site forms are not currently implemented at AGFO. The provided form in Appendix D is only a draft and needs to go through the Office of Management and Budget (OMB) for approval, due to its social science function. 


\section{Educational Goals}

The overall goal of interpretation should be to convey the four primary themes, especially in manners that are effective to the target audiences. The audience will be able to connect the tangible resources to intangible concepts and derive something meaningful from the experience. Visitors should leave AGFO with an accurate understanding of the Monument's story (both prehistoric and historic) and the details surrounding its resources, and be made to think about how AGFO's story is relevant to current issues.

Interpretive and educational efforts at AGFO should encourage a broader interest in related subject matter. If visitors only take away the AGFO story as a set of trivial facts, the Monument has not accomplished its purpose. Audiences should leave with a heightened awareness of, and interest in learning more about paleontology and related fields. As previously stated, this includes imparting upon audiences the significance of both paleontology at large and AGFO's paleontological record in particular, as well as their relevance to modern events. Paleontology and geology provide the longterm (thousands, millions, billions of years) record of biology, ecology, and climatology needed to formulate and support hypotheses made about the present since neontologic and modern climate records have only been kept for decades, to centuries at most. Along with this, AGFO should strive to provide visitors a sense of the scale of geologic time, and in turn a sense of how comparatively rapid and thus severe several modern issues are (e.g., climate change, shifting environments, modern mass extinction).

The LRIP puts strong emphasis on visitors being able to experience "real things" and a sense of place. In context, this means experiencing the resources firsthand rather than merely as text, being able to see and/or interact with fossils or their replicas. Visitors should be encouraged to walk the trails or watch the virtual trail guide. While allowing access to real fossils in situ carries too many risks to be advisable, exhibits with real fossils, interactive exhibits with replicas the visitors can touch and manipulate, visible Daemonelix on the D-Trail, and guided tours of the trails are all currently used to supply this sort of experience. Should a study of sufficient scientific merit requiring excavation ever occur again at AGFO, the active quarry should be incorporated into the interpretive program to give visitors insight into the realities of field paleontology.

Given the remote location of AGFO, educational outreach with the community and in the schools is currently limited. The Monument has invested in the development of long-distance learning modules (Photo 14), with target audiences mostly limited to schools with the state of Nebraska. Future educational programming at AGFO may consider ways of integrating Monument interpretive/educational programming into science education standards at the state or national level (American Association for the Advancement of Science 1988; National Research Council 1996). The use of standards-based science curriculum in interpretation and education programming and planning provides a vision for science communication and engaging local communities and schools. These are considerations to address in planning (e.g., the Long-Range Interpretive Plan), and training/development for AGFO staff. 


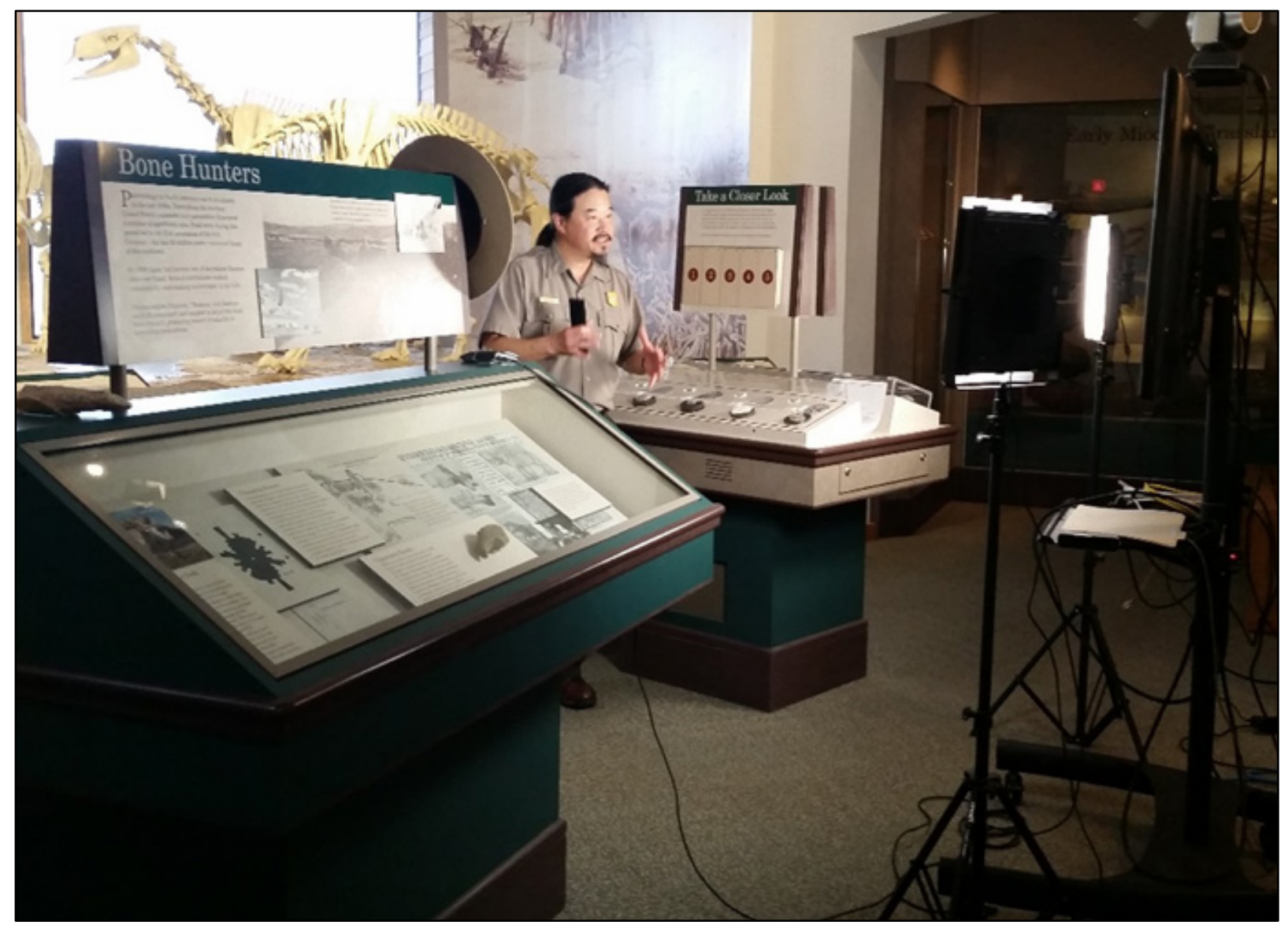

Photo 14. Alvis Mar gives a lecture on AGFO to a remote classroom via distance learning. The distance learning program is a critical method by which AGFO offers education and outreach to communities who cannot otherwise visit the Monument (NPS).

\section{Public Access and Accessibility}

Public access is restricted to River Road, the three trails, and the Visitor Center. Visitors are prohibited from traveling off-trail by any means, driving down service roads, accessing the Stenomylus Quarry, or trespassing on the Agate Springs Ranch (which is private property). There may be rare exceptions, such as researchers with an approved permit. The Stenomylus Quarry and other off-road/off-trail sections of AGFO are closed to the public by order of the Superintendent, for a period of one year renewed each year. Service roads and private property are denoted with signage.

The Visitor Center and Fossil Hills Trail were designed to meet accessibility standards. The Fossil Hills Trail is paved and designed to approach the hills from an angle which produces no more than a 1:12 slope at any point, which makes it wheelchair accessible by ADA standards. The D-Trail's lower, western portion is wheelchair accessible, but the steeper eastern side which leads to the panoramic lookout point and the double Daemonelix is not. There are reserved parking spaces in the parking lots located at the Visitor Center and museum as well as at the Daemonelix Trail trailhead. The picnic area adjacent to the Visitor Center and museum is accessible by paved and gravel trails and features wheelchair-friendly tables. The Visitor Center, including the museum exhibits, is 
wheelchair accessible, and as previously mentioned there is a digital/video trail tour offered in the museum for those who cannot or do not want to walk the trails. A wheelchair is available on request for on-site use.

AGFO's public outreach, distance learning program, and website are intended to provide access and education to the Monument's story and resources to those unable to physically visit (Photo 14).

AGFO is currently trying to ensure most publicly available Monument records also meet disabled accessibility standards. 


\section{Relation of Paleontological Resources to Other AGFO Programs and Resources}

\section{Interactions of Park Divisions with Paleontological Resources}

As stated in NPS DO 77 the SUPERINTENDENT is ultimately responsible for the protection and management of paleontological resources, although day-to-day management is the responsibility of the park paleontology specialist. In addition, several of the other park divisions have some responsibility for the paleontological resources.

ADMINISTRATION oversees daily operations of AGFO and all subdivisions and employees, approves staffing, scheduling, budgets, and project development/management.

INTERPRETATION AND EDUCATION STAFF provide educational talks, outreach programs, films, and documents regarding the paleontological resources of AGFO to the general public. This information is provided by resource management staff and specialists.

The park paleontology specialist should work with the interpretation and education staff to make sure that the information the latter are providing is up-to-date and congruent with the latest scientific research. This includes reviewing interpretive products featuring geology and paleontology and providing regular talks especially aimed at keeping the interpretation and education staff up-to-date regarding new findings in these disciplines. Emphasis on paleontology's nature as a hybrid science is emphasized by linking it to biology, geology, and other sciences (Knudson 1996). The paleontology specialist should also provide special programs and documents when requested.

LAW ENFORCEMENT/VISITOR SERVICES STAFF are the main in-the-field unit overseeing the protection of paleontological resources. Law enforcement rangers educate the public about the negative aspects of resource theft, and issue citations when theft or vandalism occur.

Resource management staff should work in tandem with law enforcement staff regarding resource protection from theft and vandalism. The park paleontology specialist should provide yearly training to LE staff regarding identification of fossil materials and of excavated areas. In addition, the paleontology specialist can provide professional expertise regarding resource theft cases, including site documentation, forensic assistance, and damage assessments.

NATURAL RESOURCE STAFF manage various types of resources ranging from animals to plants, to water and air, to soil and earth. They handle wildlife and plant management, including taking efforts to suppress invasive species. These staff handle paleontological resources when such are found or disturbed during the course of the staff's regular duties. Natural resource staff may also become involved with paleontological resources while attending duties having to do with erosion, or when assessing the impact of proposed paleontological resources on other natural resources (e.g., nesting animals, impact to the topography, disturbance leading to infestation by invasive plants, etc.).

CULTURAL RESOURCE STAFF manage the cultural and archeological resources found within AGFO's collections and upon its lands. These include the gifts from Red Cloud to the Cook family, 
historical artifacts from the Cooks and their guests, related historical records, and archeological sites and associated artifacts found within AGFO.

Paleontological resources and cultural resources intersect in several places at AGFO. At least one cultural artifact in AGFO's collections was fashioned from a fossil limb bone. At least one paleontological locality at AGFO is coincident with an archeological site. Cultural and historical resources include records of paleontological research and artifacts from the quarries ranging from tools to trash. By law, items that are both a paleontological and cultural/archeological/historical resource fall primarily under the care and purview of cultural resources policies and staff. Thus, especially since curatorial duties for the AGFO collections as a whole (see below) have generally fallen to a cultural resources specialist, cultural resource staff will have the responsibility for managing paleontological resources which are also — or occur in the context of — cultural resources.

CURATION STAFF handle the accession, preparation, storage, conservation, cataloging, and deaccession of specimens in the museum collection and historical archives (paleontological, cultural, archeological, and historical). In a paleontological resource context, this includes fossil specimens and historical records related to the history of paleontology at AGFO.

Curation staff will likely fall under other staff categories as well, both through necessity given the scope of collections and by individual specialization; the curator at AGFO has sometimes also been a member of the cultural resources staff. It is possible that a future paleontology specialist could also be a curator. Paleontology specialists who are not formally part of the curatorial staff should still offer advice and assist curatorial staff with their projects if requested and qualified.

MAINTENANCE STAFF handle everyday maintenance of facilities, construction, horticulture, and other various duties to keep the Monument and working environments in good condition. Although the relationship between maintenance and paleontology may not seem as obvious as for some of the other divisions, maintenance has a significant role. Maintenance staff can provide assistance in excavations including use of machinery, tools, and/or physical labor. They may also uncover paleontological resources in the course of their regular duties. In addition, maintenance staff assemble and provide advice for maintaining the exhibit displays, including conservation efforts such as dusting and cleaning of the dioramas, cases, and artifacts. They also maintain walking paths and quarries.

PLANNING AND DEVELOPMENT Currently, the Foundation Document (NPS 2012) for AGFO does not contain much information other than background regarding the general significance of the Monument's paleontological resources. It provides little guidance to their future management or their influence on park planning, although the Foundation Document does place a "high" priority on the development of a "Comprehensive Paleontological Resource Plan." Since fossils and research are expressly noted in the enabling legislation and the park mission, these resources need to be strongly considered during all future phases of park planning and development. For this Paleontological Resource Management Plan to be successful, it must be integrated into park operations. 


\section{Impact of Paleontological Resource Management on Other AGFO Resources}

\section{Archeological Resources}

Anthropogenically disturbed Miocene fossils have been found in archeological contexts.

Paleontological resources uncovered in association with an archeological site are considered archeological resources and subject to the Archaeological Resources Protection Act (ARPA) and associated policy (16 USC $\S 470 \mathrm{aa}$ ) instead of the Paleontological Resources Preservation Act (PRPA) and associated policy (16 USC $\S 470 \mathrm{aaa})$. As such, an ongoing archeological project does not need to be halted and no further assessment is necessary at the archeological site, though a paleontologist should still be consulted in regard to the fossils. In a similar manner, fossils found in a cultural context or as cultural artifacts are counted as cultural resources and are therefore under the protection of 25 USC $\S 3001$ instead. In either case, experts should try to determine if the paleontological resources are also archeological/cultural resources or if they are merely coincidental.

Conversely, the disturbance of archeological resources and/or cultural artifacts during paleontological management or research requires that the paleontological project cease immediately. The paleontological activity is put indefinitely on hold while management options for the archeological/cultural resources are assessed.

More information about paleontological resources found in archeological or cultural contexts within NPS units can be found in Kenworthy and Santucci (2006).

\section{Biological Resources}

\section{Vegetation}

Systematically walking outcrops for paleontological materials could result in the trampling of sensitive soils or plants. This is especially true for cryptobiotic soils. This can be mitigated by employees being cognizant of the route that they traverse, and being sure not to travel repeatedly over the same track in order to avoid repeated trampling. In addition, older excavation areas should be examined periodically for exotic or invasive plants that prefer disturbed areas. Upon discovery these plants should be documented and then removed. Field workers should be sure to avoid areas with loose and unconsolidated soils if at all possible, and to avoid stepping directly on plants. Performing surveys in the late summer and fall would be greatly preferable because this would allow plants to complete their annual growing and flowering cycles prior to sustaining any trampling injuries. By timing surveys later in the season and being careful in choosing routes, the impacts to vegetation from paleontological surveys should be minimized. In general, however, the areas with the highest concentration of fossils at AGFO tend to be inhospitable and barren of most plants.

\section{$\underline{\text { Wildlife }}$}

Monitoring and collection of paleontological specimens at AGFO pose no known threat to endangered species and should have no impact on wildlife. However, since researchers may travel through remote areas of the Monument searching for and/or monitoring sites, care must be taken not to disturb nesting areas or other sensitive spots. Locations of coyote or fox dens should be recorded in the paleo locality database with recommendations, when warranted, for preferable routes of access and egress. Exploration and excavations near occupied dens should be avoided until after the denning 
season (after juvenile animals have been moved from the site). Federal regulation prohibits approaching within 23 meters ( 25 yards) of active raptor nests or occupied den sites. Conversely, the travels of paleontology staff throughout areas of the Monument rarely accessed by other staff should allow paleontology staff to assist in wildlife management when necessary.

\section{Historic Structures}

While no historic structures are known to coincide with known fossil localities, several of the most important fossil localities (e.g., Carnegie Hill, University Hill, Stenomylus Quarry) are arguably historic sites in their own right because of the role these quarries played in the history of paleontology and the development of natural history museums. Historic artifacts in the form of cans and other refuse left by dig crews have been found at the Stenomylus Quarry. All potential cultural resources discovered in the process of fieldwork shall be reported to the appropriate staff.

Though no fossils have been found there, special mention must be given to the bone cabin, the homestead that Harold Cook staked to protect the Fossil Hills from being claimed by partisan interests. Visiting paleontologists also stayed there while collecting at the Agate Springs Ranch.

\section{Museum Collections}

Park museum collections not only include curated fossils, but also park archive and library collections. Park museum collections inform and enhance every aspect of park work, from resource management and interpretation, to research and public accountability. Featured in exhibits, interpretive programs, films, and print and electronic publications, museum collections are key resources for educators, students, researchers, park managers, park neighbors, and the general public.

The NPS Management Policies lay the foundation by which the NPS meets its responsibilities toward museum collections. Guidance for collecting and managing paleontological resources and associated field records can be found in the Code of Federal Regulations (36 CFR 2.5) and NPS guidance documents, including the NPS Museum Handbook. Paleontological specimens and their associated field records are managed as museum collections.

Once collected, the relationship between the fossil(s) and its geologic context can be lost. Thus, the records of an investigation are as vital as the specimens collected. Also, because of the wide range of preparation techniques and the ever-changing list of consolidants and preservatives used in paleontology, detailed preparation records should be kept whenever possible. All preparation techniques and methods should be recorded and retained as part of the museum records. Refer to the NPS Museum Handbook, Part II, Chapter 3, for guidance. Such data will be invaluable to those undertaking future preparation and long-term conservation of these specimens.

\section{Physical Resources}

Paleontological inventory or site cataloging activities would be expected to have a negligible effect on physical resources such as air quality, water quality, and soils. Site investigations requiring hiking, climbing and sampling of outcrops, would certainly impart minor wear and tear on rock outcrops, with the greatest impact being potential effects on the paleo-feature or context itself. With frequent visitation of certain localities, trails can develop, perhaps enhancing soil erosion and even increasing stream sediment load, but again, this would likely be short-term and localized. 


\section{Paleontological Resource Data Management}

\section{AGFO Paleo Archives and Library}

The data obtained via inventory, monitoring, other management actions, and research serve as the foundation for future inquiry, study, policy, and action. Thus, it is imperative that all data related to paleontological resources and associated records are archived and preserved for the benefit of future resource managers, scientists, and policy-makers. NPS Director's Order 11D 7.1-7.2 states that "Resource management records are those records and data sets that are most necessary for fulfillment of the NPS mission" and "will receive the highest priority for information preservation management activities and resources. They deserve archival care as soon as practical in the life of the record." The archival and data management systems discussed in this section exist to systematically preserve these records at both the park-specific and servicewide levels.

AGFO maintains physical copies of records and other documents that serve as an administrative history of the Monument, as mandated by the NPS. A subset of these archives is devoted to paleontological information and paleontological resource management activities undertaken at AGFO. AGFO also has a library of pertinent rare literature and publications of studies with useful, but indirect, relation to AGFO resources. This library is kept in the conference room and locked when not in use. Finally, some historical field notes, correspondence, and journals from before AGFO's authorization as a national monument are classed as historical objects; these are stored with the museum collections, though they are also considered part of the Monument's archives.

All archived materials are supposed to be backed up digitally and stored on secure servers at AGFO. Copies of these digital files should also be submitted to the NPS Paleontology Program Archives and Library. Backing up files in this way helps prevent complete loss of records due to disaster or mismanagement. Another benefit is higher convenience of access to the materials, though sensitive or confidential materials will have access restrictions imposed upon them to protect the resources and any Personally Identifiable Information (PII) associated with the records.

The AGFO archives in general, and therefore the paleontological archives, are currently poorly organized. For the physical documents, all resource management subjects are combined together with no systemic organization present (excepting the materials curated within the museum collection), and all materials are unpredictably spread out between filing cabinets and shelves within the administrative offices. The digital archival materials usually are divided by subject matter, but then are further scattered and cross-coded over several drives and folders belonging to different divisions. In addition, some of the subject folders have unintuitive titles or contents, which makes finding a given record time-consuming.

The library has similar organizational problems. Though shelves are sorted and labeled by subject matter, not all books have been placed or returned to the correct shelf. Some books have library catalog numbers, some do not, and books are no longer sorted by either library catalog number or alphabetical order of title or author. An additional problem, and potential source of disorganization, is lack of oversight about what is added to the library. This makes it difficult to keep records of what is in the library and to remove irrelevant material. One quarter of the library contains boxed-up 
resource management records, which belonged to prior resource managers and have since become separated from the rest of the archives. The contents of these boxes, and whether they have been backed up digitally, are unknown. Both these boxes and the archival filing cabinets in the administrative office also contain some old server backup cartridges and drives, which apparently belong to obsolete hardware no longer utilized at AGFO. It is unknown what information these cartridges hold or if it has been transferred to more modern storage media.

\section{Documents, Maps, Images, Data, Research Field Notes, etc.}

AGFO paleontological archives retain copies of all records that document activities at the Monument or of its employees in the establishment and administration of the Monument. These include, but are not limited to: resource management documents (e.g., inventory and monitoring forms); internal NPS reports; law enforcement records dealing with paleontological resource crimes (e.g., citations and arrests for unpermitted collection or vandalism); formal management recommendations; and copies of management plans or foundational documents related to paleontological resources (e.g., this PRMP). Anything that documents activities at the Monument, or of its employees in the establishment and administration of the Monument, should be subject to archiving.

AGFO archives maintain current and historical maps of the Monument's boundaries, its immediate vicinity, and some maps of related regions or topics. This includes maps of construction plans at AGFO (e.g., for the Visitor Center, housing, and the current Fossil Hills Trail), as well as topographic maps and GIS maps documenting things like water coverage or vegetation. Most importantly for paleontological resource management at AGFO, there are maps of the paleontological sites with individual localities outlined. However, currently all but one of these maps are only held in the physical copy of the AGFO Locality Database (see below).

AGFO has obtained an extensive collection of photographs related to paleontology over the course of management and interpretive activities. The Monument's museum collections also include many historical photographs of AGFO lands pre-authorization (Photo 15). Taking photographs is a key component of paleontological inventoring, establishing localities, monitoring fossils and localities, research and its documentation, and law enforcement investigations, among other activities.

Both the archives and the library include scientific publications. The archives house publications resulting from studies performed within the boundaries of AGFO (pre- or post-authorization) and from studies that utilize AGFO specimens. It is intended that this collection be as comprehensive as possible; it is unlikely that all publications that have ever mentioned a specimen from an AGFO locality can be located, but publications with an AGFO focus are accounted for, and new or previously overlooked publications are added as they are found. These serve as a history of significant scientific work, results, and discussion facilitated by AGFO and its resources. Researchers are required by park-specific permit conditions to supply AGFO with copies of publications resulting from research performed at the Monument or its designated repositories. The library holds select publications that cover paleontological topics directly or indirectly pertaining to AGFO's paleobiological, paleoecological, and associated geologic past. These works generally serve as reference for staff, thereby informing their ability to manage the resources and judge scientific significance. 


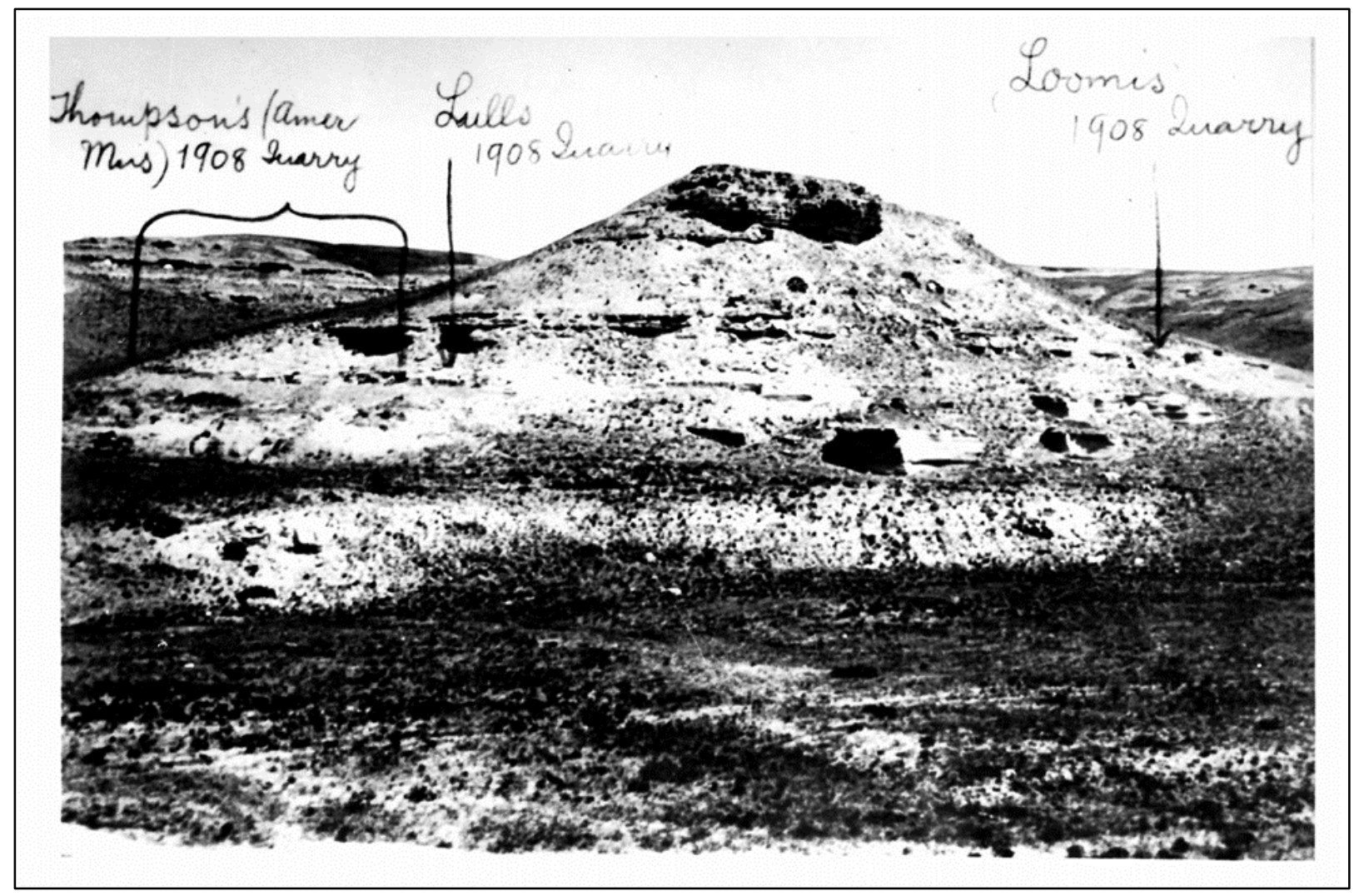

Photo 15. Historical photograph of Carnegie Hill, with written-on annotations recording the sites of different quarries at the hill for the year 1908. This is an example of the historical photographs and records kept within the AGFO archives (in this case within the museum collections archive) to document paleontological resources, research, and management actions (NPS).

AGFO archives include datasets from various sources, including: scientific research performed at the Monument; management activities utilizing quantitative methods; compiled weather data (temperature, humidity, precipitation, etc.); and metadata sets produced from analysis of archived information. These data may be found as part of a publication, but complete datasets are more often stored as separate or supplemental files. When researchers provide copies of publications resulting from studies at AGFO per the conditions of a permit, they should also supply their datasets as supplements for archiving.

Field notes of researchers are archived because they provide detailed records of research projects at AGFO. The information in field notes can provide details that resultant datasets, photographs, specimen labels, and publications do not. These details can encompass the weather, researcher thoughts and opinions, who found or excavated a given specimen, and any unusual occurrences (e.g., spotting trespassers near a locality). Written descriptions and/or sketches of localities and specimens in field notes can provide a backup if other records like locality sheets or photographs are lost. Critically, field notes can serve as legal documents in civil and criminal cases involving fossil resources. Per AGFO's park-specific permit conditions (see "Paleontological Research and Collecting Permits"), researchers must provide the Monument with copies of their field notes. This 
condition has not always been implemented or enforced, and as such AGFO should request copies of field notes for past research undertaken at the Monument.

\section{Historic Records, Letters and Correspondence}

The archives contain copies of letters and correspondence involving AGFO staff. This encompasses internal correspondence, correspondence with other NPS personnel, and correspondence with individuals outside of the NPS. All e-mails are continually backed up to the eMail Enterprise Records and Document Management System (ERDMS), per DOI policy, but the paleo archives may retain separate printed and digital copies of these messages if they relate to paleontology or paleontological resource management at the Monument. Physical letters, or copies and scans of them, are also retained in the archives. These records maintain the day-to-day operational history of AGFO, and can also retain important communication between the Monument and other entities (e.g., informal consultations with scientists via mail). Memos to file can also be included under this category; memos record obscure facts, post-facto comments on other records, or emails/correspondence not automatically recorded (e.g., emails or prints of emails between non-DOI personnel).

Records, maps, field notes, photographs, correspondence, and other original archival materials dating to the time of James and Harold Cook are stored as historical records in a climate-controlled museum collection storage room. Many are part of the Cook collection, and so must be properly curated and cared for as museum specimens (see "Museum Collections and Curation" and the AGFO Collections Management Plan). These materials are only considered part of the paleo archives if they directly deal with paleontological resources, research, or history at AGFO. Otherwise, if they don't fall under another archival category, they are treated as historical artifacts belonging solely to the collection. In some cases, portions of these materials have been scanned and the copies sent to other NPS institutions for archiving. With authorization, additional copies of select works could be made for easy reference and storage within the rest of the paleo archives at AGFO, in order to minimize disturbance of the originals.

\section{Gray Literature}

The archives and library also preserve a small selection of "gray literature," such as conference materials and unfinished or unpublished manuscripts. These are rare and precious documents that may be impossible to recover if lost; in some cases AGFO may possess the only extant copies of these works. Where possible, AGFO should consult with the authors about whether they plan to complete or publish such gray literature before submitting copies to the NPS Paleontology Program Archives.

\section{NPS Paleontology Program Archives and Library}

The NPS Paleontology Archives serve to compile, preserve, and provide a consolidated point of access to over 100 years of paleontological data and records generated on what are now NPS units. They also set servicewide archival standards for paleontological resource data. Created in 2015, the archives have both park-specific and servicewide components for the digital storage of NPS records, reports, researcher field notes, sketches, photographs, maps, locality information, and specimen data. The NPS Paleontology Library is the third component of the archives, housing a broad and inclusive 
selection of geology- and paleontology-focused publications. The library's main focus is to compile scans and pdfs of all publications known to document NPS paleontological resources, though it is not exclusively restricted to such and houses some essential reference materials as well. The NPS Paleontology Library is organized by last name of the author, and as of 2018 included approximately 7,000 digital documents. Additional information about the archives, including their present condition and history, is detailed in Santucci et al. (2018).

NPS Paleontology Archives keep and retain all of the same types of material that AGFO maintains, for many of the same reasons. However, the NPS archives keep both paleontological resource records for specific parks, essentially serving as a remote backup of that unit's archives, and records that apply to paleontological resource management servicewide. Anything that documents paleontological management and research activities within the NPS or the lands it manages is subject to archiving. Santucci et al. (2018) contains a detailed account of the archives' scope.

\section{Geospatial Database}

\section{AGFO Paleo Locality Data (GIS or Other)}

AGFO maintains a locality database in physical and digital format. Localities are organized by site; here meaning the broader geographic area in which they are situated (e.g., University Hill). This database includes background information, locality information sheets for every locality, at least two photographs of every locality (one at a distance and one close-up), photographs of notable fossils exposed at some localities, maps of paleontological sites including outlines of every locality, and a spreadsheet that compiles and summarizes the contents of the locality information sheets. AGFO currently retains both the original 2003 locality database and its 2014 update. Going forward, the database should be regularly updated with the results of routine monitoring, and each updated edition preserved. Recording GIS data should be part of establishing new localities.

AGFO has a park atlas of GIS data, which is kept on NPS Midwest Region (MWR) servers and on the superintendent's secure network at AGFO. This atlas records not only paleontological localities and fossil positions, but also data related to other types of resources, notably archaeological sites. Thus, access to this atlas and the data it contains is heavily restricted (see below). It is recommended that AGFO ask MWR to create separate atlases divided by resource type from the master atlas, so that it is easier for managers of a particular type of resource to access the data pertinent to them.

\section{Confidentiality of Sensitive Paleontological Resource Information}

Paleontological data can include sensitive details about the resources or their localities, which could pose a threat to the resources should they be disclosed to non-authorized entities. Sensitive information includes, but is not limited to: information about the precise location of localities; indepth detail about the exposure, condition, value, or significance of fossils; management and law enforcement schedules or records dealing with paleontological resources; and unpublished scientific data related to paleontological resources (or data published in venues that are not publicly accessible). GIS data in particular is sensitive, as it records the exact positions of localities and fossils. 
As such, the Library at AGFO and the NPS Paleontology Program Archives and Library restrict access to archived paleontological materials by default. Researchers or NPS staff in search of specific records or data of interest may request copies of them on an item by item basis. AGFO should enter into confidentiality agreements with researchers, museum repositories, and publishers who will work at AGFO, or with data and/or resources collected at AGFO, to limit the unauthorized disclosure of sensitive information about paleontological resources and localities. AGFO should require that external repositories have researchers enter into a case-by-case confidentiality agreement with the Monument prior to providing access to AGFO data or specimens. 


\section{Summary, Conclusions, and Recommendations}

\section{Summary of Completed Work}

This document is the first Paleontological Resource Management Plan for AGFO since the "Fossil Management Plan and Environmental Plan" developed in 1990. It provides needed updates to AGFO's resource management priorities and goals given the nearly three decades of changes in resource condition, park programs, service policy, and federal laws such as the Paleontological Resource Preservation Act. This document provides: a detailed summary of AGFO's history; its geology; specifics regarding its paleontological resources and fossil taxa; guidelines for planning and implementing inventory and monitoring; goals for research, interpretation, and data management; and descriptions or references to applicable law and policy in regard to handling paleontological resources.

This plan guides resource managers at AGFO on the best practices for preserving, interpreting, and facilitating scientific/scholarly inquiry about the site's primary resource: extremely significant Miocene fossils and critical records of paleontological history from the late $19^{\text {th }}$ century to today. It should also be used as a foundation for any more specialized plans or reports relating to paleontological resources at AGFO, such as an inventory or monitoring plan (see recommendations, below). In following this plan, AGFO will continue to meet the varied needs of scientists, visitors, and the preservation of the fossils/localities, ensuring that the Monument remains significant to science, educational to the public, and relevant to informing about modern issues such as extinction, climate change, and the maturation of paleontology.

\section{Current and Future Projects}

\section{Inventory and Reorganization of AGFO Records, Archives, and Library}

AGFO administrative staff are currently planning to reorganize and take inventory of all official records stored at the Monument, both digital and physical. The goal is to have all documents stored under correct coding, with minimal cross-coding, within an intuitive and easy to search system. A catalog of the library, and an assessment of whether any library materials should be deaccessioned, are also planned as part of this initiative. Paleontological records of import should be copied and submitted to the NPS Paleontological Archives. While much of this effort is still in the planning stage, an inventory of all digital records stored on the AGFO public drive is in progress at time of writing.

\section{Distance Learning Program}

As part of meeting LRIP guidelines for providing education on AGFO's resources to students, as well as those unable to visit the Monument, the interpretive team has hosted multiple distance learning programs. Most of these distance learning presentations take the form of virtual field trips of AGFO, though a few presentations are more specialized on specific aspects of the AGFO story (these tend to be aimed at older audiences). The distance learning program is primarily aimed at schools, from elementary school to college, but also for groups such as remote summer camps and other national parks (e.g., for Junior Ranger days). AGFO interpretive staff has proposed and is attempting 
to use the distance learning equipment to tap into presentations from other national parks to display in the AGFO visitor's center film hall.

\section{Shared Park Paleontologist}

Ellen Starck began work as a park paleontologist shared between BADL and AGFO in October 2019. She will provide AGFO with an official, non-seasonal paleontology specialist to assist in making and carrying out management decisions related to paleontological resources within the Monument. Ellen Starck has prior history doing paleontological work at AGFO and contributed to the writing of this PRMP.

\section{Recommendations}

The following are example recommendations of actions AGFO could take to better meet the guidelines presented in this plan for the improvement of paleontological resource management. These recommendations range from actions that could be implemented immediately at little to no cost, to long term goals that would require considerable funding, time, and staff with the appropriate expertise. All should be regarded as suggestions and evaluated for feasibility in light of AGFO's present logistics and priorities.

\section{Examples of Potential Research Beneficial to AGFO}

Scientific research is essential at AGFO to fulfill its mandate to be a continuing center for scholarly study and to provide data for informing management decisions. It is also necessary to update old data and revise management decisions based on that data. AGFO should encourage researchers to apply for research permits at AGFO, and properly assess permit applications for scientific merit and impact on Monument operations, programs, and resources. Additionally, AGFO should consider soliciting researchers to undertake the following recommended topics:

- A fossil survey of Sharps Formation, Runningwater Formation, and Quaternary outcrops/deposits on AGFO land. Some paleontologists hypothesize these units may be fossiliferous at AGFO because they are fossiliferous elsewhere in its vicinity. Notably, the Runningwater Formation has yielded fossils at localities less than 16 km (10 mi) from AGFO.

- Locating fossils within these units would extend the story AGFO tells about past life by millions of years in both directions: the Sharps Formation dates to about $\sim 28 \mathrm{Ma}$, the Runningwater Formation to $\sim 18 \mathrm{Ma}$, and the Quaternary deposits could be as old as 2 million years or as young as the last few hundred years.

- Studies related directly to monitoring, such as researching whether proximity to public access leads to swifter overturn of fossil material than isolated localities.

- Hydrologic studies observing or modeling surface runoff and flash flooding could be instructive for both safety and managing localities situated in localized flood channels.

- Several taxonomic groups have been neglected at AGFO because of apparent research/collection bias. These include fish, amphibians, squamates, and turtles, among others. Remains are mentioned in literature, but descriptions do not extend beyond the aforementioned broad taxonomic groups. 
- Micro-mammalian remains collected by the South Dakota School of Mines and Technology are pending description, but otherwise small mammals are also neglected at AGFO (Photo 16).

- These taxonomic groups have the potential to provide crucial paleoecological data, and it is recommended that AGFO staff encourage paleontologists to study them.

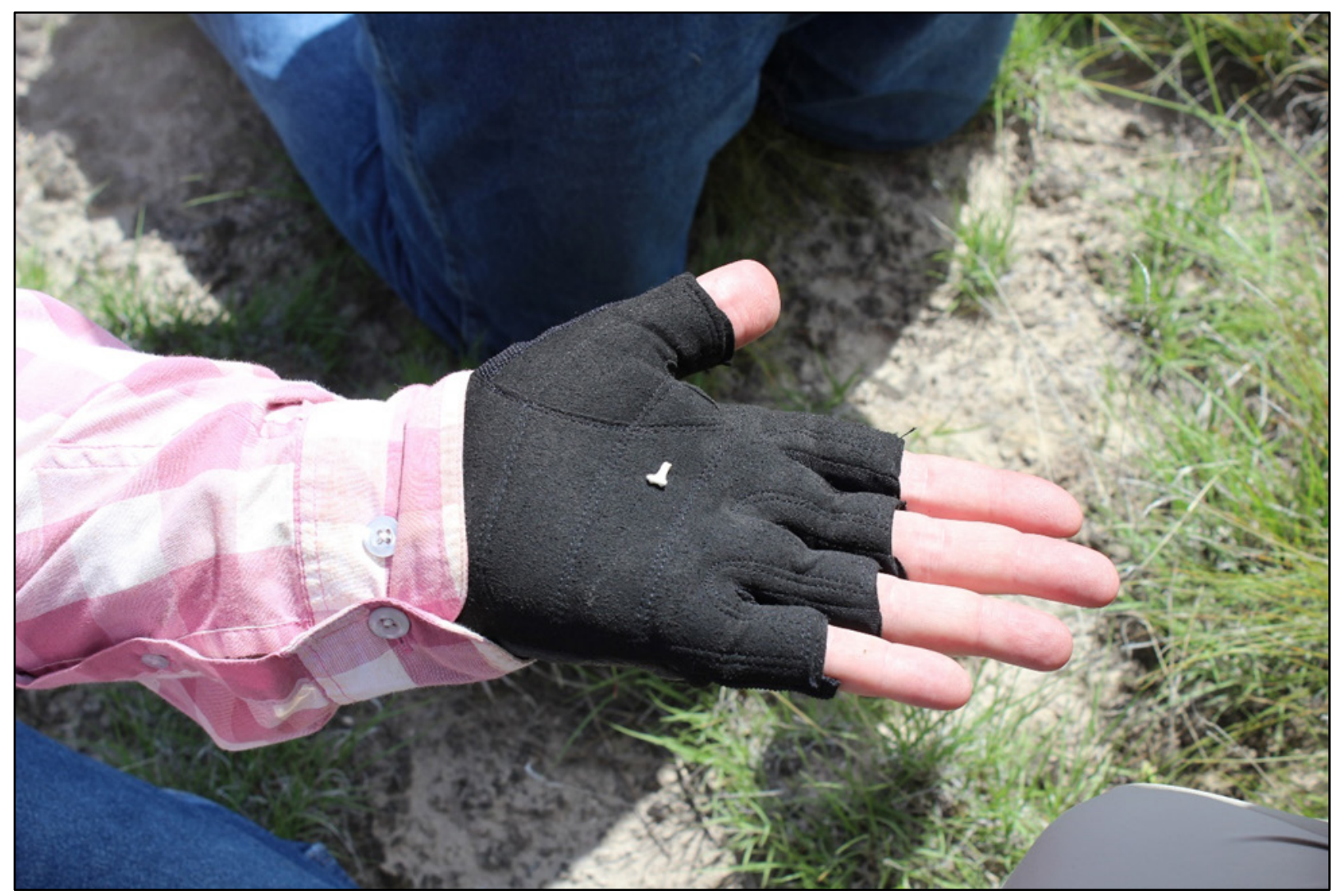

Photo 16. Dr. Darrin Pagnac holding a microfossil fragment. The discovery of fossils at this locality in 2015 should greatly increase the importance management places on it, which was assessed as having no known fossils when the AGFO Paleontological Locality Database was first created in 2003 and when it was updated in 2014. This illustrates the important role continuing research plays in supporting management efforts at AGFO (NPS).

- A taphonomic study of Harrison Formation localities, including the Stenomylus Quarry. Although prior work has already researched the taphonomy of the Anderson Ranch localities forming the main bonebed at AGFO, contributing to the interpretation of the site as an extended die-off around a waterhole during a drought, the older Harrison Formation sites have not been examined.

- Such a study could reveal details about the how the animals died, the environmental conditions of their death and burial, and diagenetic processes taking place later. It could also identify modern threats to site stability and successful management.

- The Stenomylus Quarry would also benefit from a more general geological and paleontological analysis of its depositional environment. Gandolfi (2013) presents the hypothesis of a fluvial 
environment, but this is unpublished and its findings are disputed (E. Evanoff, pers. comm., May 2020).

- Taking one or more pollen cores from the Niobrara River wetlands for paleoecological data.

Any research projects AGFO staff would like to suggest to researchers should be added to AGFO's page on the Research Permit and Reporting System website under "requested research."

\section{Examples of Potential Intern or Volunteer Projects}

Interns and volunteers can provide AGFO with additional personnel without having to hire seasonal or permanent NPS employees. These individuals can augment many programs, including, but not limited to, interpretation, resource management (including routine monitoring tasks like repeat photography or measuring erosion stakes), and curation.

Through programs such as Geoscientists-in-the-Parks (GIP), AGFO can also obtain paleontology specialists for projects needing qualified expertise. This is especially helpful if the Monument does not have a permanent specialist or that specialist must attend to other projects. Performing inventories, writing management plans, setting up more intensive monitoring efforts (e.g., installing stakes), salvage collection, fossil preparation, and collections conservation are examples of what these specialists can be brought in to accomplish.

The following are suggestions for tasks that could be assigned to interns or volunteers:

- Have an intern re-house and re-label fossil specimens in the AGFO collections.

- Have an intern assist with the inventory, archiving, and reorganization of AGFO's fossil and geologic resource records.

- Have an intern write a Paleontological Monitoring Plan for AGFO.

- Have volunteers handle routine monitoring tasks which do not require significant training.

- Hire volunteers or interns to augment interpretive staff if/when needed, either for routine tasks or special events.

\section{Paleontological Resource Inventory}

It is recommended that a paleontological inventory be completed for AGFO. This effort would integrate the results of the records/archives inventory and reorganization mentioned above, and once all resource records are accounted for would extend inventory efforts to localities and resources in the field. Given the relatively small size of AGFO, a walking inventory of the entire Monument is feasible. This inventory would check existing localities to develop a baseline for routine monitoring and search for new localities. This inventory could also be used to test the hypothesis that the Sharps and Runningwater formations, as well as the Quaternary sediments, at AGFO may be fossiliferous. Finding fossils in these units would greatly extend the temporal range of the AGFO story as it relates to paleontological resources and interpretation.

\section{Paleontological Resource Monitoring Plan}

As assigning detailed instructions for monitoring localities is beyond the scope of this plan, it is recommended that AGFO eventually write and publish a Paleontological Resource Monitoring Plan. 
This plan would determine specific monitoring goals, methods, and standard operating procedures in regard to monitoring, both for the Monument as a whole and for specific localities. It is highly recommended that a paleontology specialist, or a resource manager with extensive experience working with paleontological resources, be the primary author of this plan. If an NPS paleontology specialist cannot be retained to write this plan, hiring a qualified intern via a program such as GIP may be appropriate.

\section{Regarding Future Excavations}

In the past, several paleontologists have recommended that AGFO seek to open a new quarry for both research and interpretive purposes. It is the opinion of the authors that AGFO not do this. Rather, the potential for new research involving excavation should be kept open as an option, to be explored when a permit application for research of sufficient scientific merit involving collection is submitted to AGFO. Any approved collection research requiring the digging of a quarry should be considered for integration into the interpretive program, as a draw for visitors, a link between visitors and scholarly work, and as an educational experience. Any work done at currently fragile, remote, or restricted areas (e.g., the Stenomylus Quarry) is less likely to be appropriate as a publicly accessible excavation.

\section{Potential Improvements and Recommendations for Interpretation}

- Several waysides along the D-Trail need to have their listed dates for the age of the stratigraphic units updated in accordance with recent research.

- The movie shown in the Visitor Center needs to be updated for the same reason.

- Several staff members desired additional training in geology and paleontology, so that they can answer some recurring visitor questions (e.g., questions about agates and how they formed at AGFO, specific paleoenvironmental questions like the estimated temperature during the Miocene, and questions about the uplift of the Rocky Mountains and its effect on the Midwest throughout the Cenozoic).

- A workshop for fossil park interpretive staff could be set up to handle this education, either at AGFO or servicewide.

- If a full-time paleontology specialist can be hired or retained as a volunteer or intern, his or her knowledge base and familiarity with current scholarship would be a boon to the interpretive team.

- Having a paleontologist on hand to assist with identifying fossils on interpretive trips to the Fossil Hills is especially appreciated.

- If grant money could be acquired, a program could be set up with an academic institution such as the South Dakota School of Mines and Technology or University of Nebraska to have paleontology specialists from those schools provide additional education/training to AGFO staff.

- Visitor site reports can be used to encourage visitor resource stewardship and alert AGFO staff to new fossil occurrences, and the use of such forms would be a relatively lightweight program to implement. A sample form customized for AGFO is included as Appendix D. 


\section{Desired Future State of AGFO Archives and Recommendations}

- All archives will be organized in an intuitive way that incorporates proper record coding.

- Includes the creation of a distinct sub-archive for each resource type, including paleontology.

- AGFO staff will keep physical archives of a similar type in the same area, rather than being housed over several locations.

- Staff will transfer digital copies to updated systems and technology on a regular basis, to prevent them from becoming stranded on obsolete hardware or software.

- Staff must ensure that all archived materials exist in both a physical and digital form, unless there is significant reason not to do so for a particular item.

- AGFO staff will routinely share copies of new paleontological records with the NPS Paleontology Archives, and the NPS Paleontology Program will do the same with material they have which is not included in AGFO archives.

- Only relevant titles should be accessioned and retained in the library.

- The library will be neatly organized first by subject and then by alphabetical order (preferably by author's last name), all titles will have library numbers, and a library catalog will be kept.

AGFO administrative staff are already taking efforts to achieve these goals, beginning with a reorganization of the digital archives as mentioned in Current Projects. At the top level of organization will be division drives, such as maintenance, interpretation, or superintendent; access to these drives is intended to be restricted only to those authorized to see particular information. These drives will include a resources division for resource managers. Furthermore, a resources folder will be included within every other division for documents that must be cross-coded or are not by default accessible by all AGFO resource management staff. Within both the divisional and sub-divisional resources folder will be subfolders for each type of resource, such as paleontological, geological, or cultural. These will then be further subdivided by subject matter and/or record type. The goal is to combine an intuitive filing structure with the required record codings, and prevent the fragmentation and obscuring of records that has occurred at AGFO up to this point.

Once the digital archives have been reorganized, the physical archives will be reorganized into a format resembling the digital one. Those archives which are also part of the museum collection are an exception, as they will continue to be organized according to the Collections Management Plan and Scope of Collections Statement. During this reorganization, records which are extant as physical media will be copied into digital media, and vice versa. AGFO will confer with the NPS Paleontology Program Archives and Library, as well as MWR, to determine what documents each archive is missing. Copies of needed records will be produced and shared between these systems until all prior archival requirements are met; going forward, AGFO should produce copies of its archived materials for partner systems as soon as possible. 


\section{Literature Cited}

American Association for the Advancement of Science. 1988. Science teaching: making the system work. Washington, D.C.

Backwell, L., C. Steininger, J. Neveling, F. Abdala, L. Pereira, E. Mayer, L. Rossouw, P. de la Peña, and J. Brink. 2018. Holocene large mammal mass death assemblage from South Africa. Quaternary International 495:49-63.

Barbour, E. H. 1906. Notice of a new Miocene rhinoceros, Diceratherium arikarense. Science 24(624):780-781.

Barbour, E. H. 1908. The skull of Moropus. Nebraska Geological Survey, Lincoln, Nebraska. Publication 3, part 2, no. 11.

Barbour, E. H. 1909 [sometimes given as 1908]. Skeletal parts of Moropus. Nebraska Geological Survey, Lincoln, Nebraska. Publication 3, part 3, no. 12.

Barnosky, A. D., M. Holmes, R. Kirchholtes, E. Lindsey, K. C. Maguire, A. W. Poust, M. A Stegner, J. Sunseri, B. Swartz, J. Swift, and N. A. Villavicencio. 2014. Prelude to the Anthropocene: two new North American land mammal ages (NALMAs). The Anthropocene Review 1(3):225-242.

Benton, R. C., O. Dennis, Jr., E. Evanoff, and H. G. McDonald. 2015. The White River Badlands: geology and paleontology. Indiana University Press, Bloomington, Indiana.

Chandler, R. M. 1998. Additions and comments on the fossil birds of Agate Fossil Beds National Monument, Sioux County, Nebraska. Pages 1-4 in V. L. Santucci and L. McClelland, editors. National Park Service Paleontological Research. NPS/NRGRD/GRDTR-98/01.

Cook, H. J. 1912. A new species of rhinoceros, Diceratherium loomisi, from the lower Miocene of Nebraska. Nebraska Geological Survey, Lincoln, Nebraska. Publication 7, part 4, no. 48.

Cook, H. J. 1914. Note on the occurrence of the mammoth in Sioux County, Nebraska. Nebraska Geological Survey Bulletin 7(6):1-3.

Cook, H. 1934. New artiodactyls from the Oligocene and Lower Miocene of Nebraska. American Midland Naturalist 15(2):148-165.

Culver, T. 2003. Agate Fossil Beds National Monument Locality Database. On file at AGFO.

Department of the Interior. 2000. Report of the Secretary of the Interior: Assessment of fossil management on Federal \& Indian lands. Department of the Interior, Washington, D.C. Available at:

https://www.blm.gov/sites/blm.gov/files/programs_paleontology_quick $\% 20$ links_Assessment $\% 2$ 0of $\% 20$ Fossil $\% 20$ Management $\% 20$ on $\% 20$ Federal $\% 20 \% 26 \% 20$ Indian $\% 20$ Lands $\% 2 \mathrm{C} \% 20 \mathrm{May} \%$ 202000.pdf (accessed May 29, 2020). 
Diffendal, R. F., Jr. 1982. Regional implications of the geology of the Ogallala Group (Upper Tertiary) of southwestern Morrill County, Nebraska, and adjacent areas. Geological Society of America Bulletin 93(10):964-976.

Ducey, J. E. 1992. Fossil birds of the Nebraska region. Transactions of the Nebraska Academy of Sciences 19:83-96.

Evans-Hatch, G. E. H. 2008. Centuries along the upper Niobrara-Historic Resource Study: Agate Fossil Beds National Monument. Midwest Region, National Park Service. Available at: https://irma.nps.gov/DataStore/Reference/Profile/2185609 (accessed May 29, 2020).

Evernden, J. F., D. E. Savage, G. H. Curtis, and G. James. 1964. Potassium-argon dates and the Cenozoic mammalian chronology of North America. American Journal of Science 262(2):145198.

Foster, J. B. 1965. Mortality and aging of black rhinoceros in East Tsavo Park, Kenya. East African Wildlife Journal 3:118-119.

Gandolfi, J. 2013. Sedimentological and microfaunal analysis of Stenomylus Quarry (Arikareean), Agate Fossil Beds National Monument, Sioux County, Nebraska. Thesis. South Dakota School of Mines and Technology, Rapid City, South Dakota.

Graham, J. 2009. Agate Fossil Beds National Monument Geologic Resources Inventory Report. Natural Resource Report NPS/NRPC/GRD/NRR - 2009/080. National Park Service, Denver, Colorado. Available at: https://irma.nps.gov/DataStore/Reference/Profile/661528 (accessed May 29, 2020).

Hay, O. P. 1924. The Pleistocene of the middle region of North America and its vertebrated animals. Carnegie Institution of Washington Publication 322A.

Hayes, F. G. 2007. Magnetostratigraphy and paleontology of Wagner Quarry (Late Oligocene, early Arikareean), basal Arikaree Group of the Pine Ridge region, Dawes County, Nebraska. Bulletin of the Florida Museum of Natural History 47(1).

Hockett, K. S. 2008. Influence of interpretation on visitors' knowledge gain and respect for fossil resources in a National Monument. Dissertation. Virginia Tech, Blacksburg, Virginia.

Holland, W. J. 1908. A new species of the genus Moropus. Science 28(727):809-810.

Holland, W. J., and O. A. Peterson. 1914. The osteology of the Chalicotheroidea, with special reference to a mounted skeleton of Moropus elatus Marsh now installed in the Carnegie Museum. Memoirs of the Carnegie Museum 3(2):189-406.

Hunt, R. M., Jr. 1984. The Agate Hills: history of paleontological excavations, 1904-1925. Prepared under contract for the National Park Service, Midwest Regional Office. University of Nebraska Press, Lincoln, Nebraska. 
Hunt, R. M., Jr. 1985. Faunal succession, lithofacies, and depositional environments in Arikaree rocks (lower Miocene) of the Hartville Table, Nebraska and Wyoming. Dakoterra 2(2):155-204.

Hunt, R. M., Jr. 1988a. Geologic map of the Agate Fossil Beds National Monument. University of Nebraska State Museum and Department of Geology, Lincoln, Nebraska. Scale 1:16,896.

Hunt, R. M., Jr. 1988b. Report on paleontological excavations at Agate Fossil Beds National Monument undertaken by the University of Nebraska State Museum from June 25, 1985 to August 16, 1986. University of Nebraska State Museum and Department of Geology, Lincoln, Nebraska.

Hunt, R. M., Jr. 1990. Taphonomy and sedimentology of Arikaree (lower Miocene) fluvial, eolian, and lacustrine paleoenvironments, Nebraska and Wyoming: a paleobiota entombed in finegrained volcaniclastic rocks. Pages 69-111 in M. G. Lockley and A. Rice, editors. Volcanism and fossil biotas. Geological Society of America, Boulder, Colorado. Special Paper 244.

Hunt, R. M., Jr. 1992. Death at a 19 million year-old waterhole: the bonebed at Agate Fossil Beds National Monument, western Nebraska. University of Nebraska State Museum, Lincoln, Nebraska. Museum Notes 83.

Hunt, R. M., Jr. 1994. The Miocene carnivore dens of Agate Fossil Beds National Monument: oldest known carnivore den communities preserved in volcaniclastic sediments, western Nebraska. Abstracts with Programs - Geological Society of America 26(6):19.

Hunt, R. M., Jr. 1995. The Miocene carnivore dens of Agate Fossil Beds National Monument, Nebraska: oldest known denning behavior of large mammalian carnivores. Pages 3-7 in V. L Santucci and L. McClelland, editors. National Park Service Paleontological Research. NPS/NRPO/NRTR-95/16.

Hunt, R. M., Jr. 2002a. New amphicyonid carnivorans (Mammalia, Daphoeninae) from the Early Miocene of southeastern Wyoming. American Museum Novitates 3385.

Hunt, R. M., Jr. 2002b. Intercontinental migration of Neogene amphicyonids (Mammalia, Carnivora): appearance of the Eurasian beardog Ysengrinia in North America. American Museum Novitates 3384.

Hunt, R. M. 2004. Global climate and the evolution of large mammalian carnivores during the later Cenozoic in North America. Bulletin of the American Museum of Natural History 285(1):139156.

Hunt, R. M., Jr. 2009. Long-legged pursuit carnivorans (Amphicyonidae, Daphoeninae) from the Early Miocene of North America. Bulletin of the American Museum of Natural History 318:195. 
Hunt, R. M., Jr. 2011. Evolution of large carnivores during the mid-Cenozoic of North America: the temnocyonine radiation (Mammalia, Amphicyonidae). Bulletin of the American Museum of Natural History 358.

Hunt, R. M., Jr., and R. Skolnick. 1996. The giant mustelid Megalictis from the Early Miocene carnivore dens at Agate Fossil Beds National Monument, Nebraska: earliest evidence of dimorphism in New World Mustelidae (Carnivora, Mammalia). Contributions to Geology 31(1):35-48.

Hunt, R. M., Jr., X.-x. Xue, and J. Kaufman. 1983. Miocene burrows of extinct bear dogs: indication of early denning behavior of large mammalian carnivores. Science 221(4608):364-366.

Hunt, R. M., Jr., R. Skolnick, and J. Kaufman. 2018. The carnivores of Agate Fossil Beds National Monument: Miocene dens and waterhole in the valley of a dryland paleoriver. Zea Books, Lincoln, Nebraska.

Izett, G. A. 1968. The Miocene Troublesome Formation in Middle Park, northwestern Colorado. U.S. Geological Survey, Washington, D.C. Open-File Report 68-142. Available at: https://pubs.er.usgs.gov/publication/ofr68142 (accessed May 29, 2020).

Izett, G. A., and J. D. Obradovich. 2001. 40Ar/39Ar ages of Miocene tuffs in basin-fill deposits (Santa Fe Group, New Mexico, and Troublesome Formation, Colorado) of the Rio Grande Rift System. The Mountain Geologist 38(2):77-86.

Kenworthy, J. P., and V. L. Santucci. 2006. A preliminary investigation of National Park Service paleontological resources in cultural resource contexts, Part 1: general overview. New Mexico Museum of Natural History and Science Bulletin 34:70-76. Available at: https://irma.nps.gov/DataStore/Reference/Profile/2195223 (accessed May 15, 2020).

Knudson, R. 1996. Agate Fossil Beds National Monument linkage of paleontological, geological, biological, cultural, and historical education. Abstracts with Programs - Geological Society of America 28(7):A-144.

Korth, W. W., B. E. Bailey, and R. M. Hunt, Jr. 1990. Geomyoid rodents from the early Hemingfordian (Miocene) of Nebraska. Annals of Carnegie Museum 59(1):25-47.

Loomis, F. B. 1908. Rhinocerotidae of the lower Miocene. American Journal of Science 26(151):5164.

Loomis, F. B. 1910. Osteology and affinities of the genus Stenomylus. American Journal of Science 29:297-323.

Loomis, F. B. 1911. The camels of the Harrison beds, with three new species. American Journal of Science31(181):65-70.

Loomis, F. B. 1932. Two new Miocene entelodonts. Journal of Mammalogy 13(4):358-362. 
MacDonald, J. R., and L. J. Mac Donald. 1980. A landscape rich with life. US National Park Service, Agate Fossil Beds. National Park Handbook 107:22-73.

MacFadden, B. J. 2001. Three-toes browsing horse Anchitherium clarencei from the Early Miocene (Hemingfordian) Thomas Farm, Florida. Bulletin of the Florida Museum of Natural History 43(3):79-109.

MacFadden, B. J., and R. M. Hunt, Jr. 1998. Magnetic polarity stratigraphy and correlation of the Arikaree Group, Arikareean (Late Oligocene-Early Miocene) of northwestern Nebraska. Pages 143-165 in D. O. Terry, H. E. LaGarry, and R. M. Hunt, Jr., editors. Depositional environments, lithostratigraphy, and biostratigraphy of the White River and Arikaree groups (Late Eocene to Early Miocene, North America). Geological Society of America, Boulder, Colorado. Special Paper 325.

Martin, L. D., and D. K. Bennett. 1977. The burrows of the Miocene beaver Palaeocastor, western Nebraska, U.S.A. Palaeogeography, Palaeoclimatology, Palaeoecology 22(3):173-193.

McConnell, T. H. 1998. A preliminary biostratigraphy of the Sharps Formation, upper Oligocene of South Dakota. Conference on Fossil Resources - Abstracts with Programs 5:unpaginated.

McMillan, M. E., C. L. Angevine, and P. L. Heller. 2002. Postdepositional tilt of the MiocenePliocene Ogallala Group on the western Great Plains: evidence of late Cenozoic uplift of the Rocky Mountains. Geology 30(1):63-66.

National Park Service, Geologic Resources Division. 2003. Summary of Agate Fossil Beds NM, Scotts Bluff NM, and Fort Laramie NHS GRI meeting, March 3-4, 2003. National Park Service, Geologic Resources Division, Denver, Colorado. Available at: https://irma.nps.gov/DataStore/Reference/Profile/2250146 (accessed May 29, 2020).

National Park Service. 1999. NPS Museum Handbook, part I, appendix Q: Curatorial Care of Natural History Collections.

National Park Service. 2002. NPS Museum Handbook, part I, chapter 14: Museum Collections Security.

National Park Service. 2011. Agate Fossil Beds National Monument: Long-Range Interpretive Plan. On file at AGFO.

National Park Service. 2012. Agate Fossil Beds National Monument: Foundation Document. On file at AGFO.

National Park Service. 2019. NPS Museum Handbook, part I, chapter 9: Museum Fire Protection.

National Research Council. 1996. National science education standards. Washington, D.C., National Academy Press. 
Osborn, H. F. 1918. Equidae of the Oligocene, Miocene, and Pliocene of North America, iconographic type revision. Memoirs of the American Museum of Natural History, New Series 2(1).

Pagnac, D. 2015. Survey and salvage of fossil material from sites atop the Agate Ash, Agate Fossil Beds National Monument. NPS Permit Number AGFO-2015-SCI-0003. On file at AGFO.

Peterson, O. A. 1905. Preliminary note on a gigantic mammal from the Loup Fork Beds of Nebraska. Science 22(555):211-212.

Peterson, O. A. 1906. The Agate Spring fossil quarry. Annals of Carnegie Museum 3:487-494.

Peterson, O. A. 1907 [not 1906]. The Miocene beds of western Nebraska and eastern Wyoming and their vertebrate faunae. Annals of Carnegie Museum 4:21-72.

Peterson, O. A. 1909. A revision of the Entelodontidae. Memoirs of the Carnegie Museum 4:41-156.

Reilly, J. A., and T. Kennedy. 2003. Collections management plan for Agate Fossil Beds National Monument. National Park Service, Nebraska. On file at AGFO.

Retallack, G. J. 2004. Late Oligocene bunch grassland and Early Miocene sod grassland paleosols from central Oregon, USA. Palaeogeography, Palaeoclimatology, Palaeoecology 207(3-4):203237.

Santucci, V. L., and J. M. Ghist. 2014. Fossil Cycad National Monument: A history from discovery to deauthorization. Proceedings of the $10^{\text {th }}$ Conference on Fossil Resources. Dakoterra 6:82-93.

Santucci, V. L., and M. Hughes. 1998. Fossil Cycad National Monument: a case of paleontological resource mismanagement. Pages 84-89 in V. L. Santucci and L. McClelland, editors. National Park Service Paleontological Research 3. NPS/NRGRD/GRDTR-98/01.

Santucci, V. L., and A. Koch. 2003. Paleontological resource management strategies for the National Park Service. Park Science 22(1):22-25. Available at: https://irma.nps.gov/DataStore/Reference/Profile/2201293 (accessed May 15, 2020).

Santucci, V., A. Hunt, T. Nyborg, and J. Kenworthy. 2006. Additional fossil vertebrate tracks in National Park Service areas. New Mexico Museum of Natural History and Science Bulletin $34: 152-158$.

Santucci, V. L., J. P. Kenworthy, and A. L. Mims. 2009. Monitoring in situ paleontological resources. Pages 189-204 in R. Young and L. Norby, editors. Geological monitoring. Geological Society of America, Boulder, Colorado. Available at: https://irma.nps.gov/DataStore/Reference/Profile/2203105 (accessed May 15, 2020).

Santucci, V. L., P. Newman, and B. D. Taff. 2016. Toward a conceptual framework for assessing the human dimensions of paleontological resources. New Mexico Museum of Natural History and Science Bulletin 74:239-248. 
Santucci, V. L., J. S. Tweet, and T. B. Connors. 2018. The Paleontology Synthesis Project and establishing a framework for managing National Park Service paleontological resource archives and data. New Mexico Museum of Natural History and Science Bulletin 79:589-601. Available at https://irma.nps.gov/DataStore/Reference/Profile/2257152 (accessed May 15, 2020).

Schaller, G. B. 1972. The Serengeti lion: a study of predator-prey relations. University of Chicago Press, Chicago, Illinois.

Schultz, C. B. 1938. The Miocene of western Nebraska. American Journal of Science 210:441-444.

Schultz, C. B. 1966. The Agate Springs Fossil Quarries. University of Nebraska State Museum, Museum Notes 30:1-7.

Strömberg, C. A. E. 2002. The origin and spread of grass-dominated ecosystems in the late Tertiary of North America: preliminary results concerning the evolution of hypsodonty. Palaeogeography, Palaeoclimatology, Palaeoecology 177(1-2):59-75.

Strömberg, C. A. E. 2004. Using phytolith assemblages to reconstruct the origin and spread of grassdominated habitats in the Great Plains of North America during the Late Eocene to Early Miocene. Palaeogeography, Palaeoclimatology, Palaeoecology 207(3-4):239-275.

Swinehart, J. B., V. L. Souders, H. M. DeGraw, and R. F. Diffendal, Jr. 1985. Cenozoic paleogeography of western Nebraska. Pages 209-229 in R. M. Flores and S. S. Kaplan, editors. Cenozoic paleogeography of the west-central United States. Society of Economic Paleontologists and Mineralogists), Rocky Mountain Section, Denver, Colorado.

Tedford, R. H., L. B. Albright, III, A. D. Barnosky, I. Ferrusquia-Villafranca, R. M. Hunt, Jr., J. E. Storer, C. C. Swisher, III, M. R. Voorhies, S. D. Webb, and D. P. Whistler. 1987. Mammalian biochronology of the Arikareean through Hemphillian interval (Late Oligocene through Early Pliocene epochs). Pages 153-210 in M. O. Woodburne, editor. Cenozoic mammals of North America. University of California Press, Berkeley, California.

Tedford, R. H., L. B. Albright, III, A. D. Barnosky, I. Ferrusquia-Villafranca, R. M. Hunt, Jr., J. E. Storer, C. C. Swisher, III, M. R. Voorhies, S. D. Webb, and D. P. Whistler. 2004. Mammalian biochronology of the Arikareean through Hemphillian interval. Pages 169-231 in M. O. Woodburne, editor. Late Cretaceous and Cenozoic mammals of North America. Columbia University Press, New York, New York.

Tweet, J. S., V. L. Santucci, and J. P. Kenworthy. 2011. Paleontological resource inventory and monitoring: Northern Great Plains Network. Natural Resource Technical Report NPS/NRPC/NRTR—2011/437. National Park Service, Fort Collins, Colorado.

Vicars, R. G., and J. A. Breyer. 1981. Sedimentary facies in air-fall pyroclastic debris, Arikaree Group (Miocene), northwest Nebraska, U.S.A. Journal of Sedimentary Petrology 51(3):909-921. 
Wetmore, A. 1923. Avian fossils from the Miocene and Pliocene of Nebraska. Bulletin of The American Museum of Natural History 48(12):483-507.

Wetmore, A. 1926. Description of a fossil hawk from the Miocene of Nebraska. Annals of Carnegie Museum 16(3-4):403-406.

Wetmore, A. 1930. Two fossil birds from the Miocene of Nebraska. The Condor 32:152-154.

Wetmore, A. 1933. A fossil gallinaceous bird from the lower Miocene of Nebraska. The Condor 35(2):64-65.

Wetmore, A. 1943. Two more fossil hawks from the Miocene of Nebraska. The Condor 45(6):229231.

Wood, H. E., II, R. W. Chaney, J. Clark, E. H. Colbert, G. L. Jepsen, J. B. Reeside, Jr., C. Stock, and committee. 1941. Nomenclature and correlation of the North American continental Tertiary. Bulletin of the Geological Society of America 52(1):1-48.

Wood, J., and V. L. Santucci. 2014. Rapid prototyping of paleontological resources facilitates preservation and remote study. Proceedings of the $10^{\text {th }}$ Conference on Fossil Resources. Dakoterra 6:211-213.

Woodburne, M. O. editor. 2004. Late Cretaceous and Cenozoic mammals of North America: biostratigraphy and geochronology. Columbia University Press, New York, New York.

Young, H. 2016. Agate Fossil Beds National Monument: Scope of Collections Statement. On file at AGFO. 


\section{Appendix A. Historical Chronology for AGFO}

Natural History:

- 105-68 Ma (million years ago) - western Nebraska is under a shallow continental sea (Western Interior Seaway)

- 70-35 Ma - Laramide Orogeny creates Rocky Mountains; location of modern-day AGFO is subjected to rain shadow

- $66 \mathrm{Ma}$ - end-Cretaceous extinction (“K-Pg event”) causes the extinction of non-avian dinosaurs, pterosaurs, marine reptiles, ammonites, and many other organisms

- 65-34 Ma - transition to humid subtropical climate

- 34-23 Ma - transition to savannah habitat

- 23-21 Ma - transition to prairie grasslands habitat/steppe climate; significant mammalian mortality likely due to severe drought; formation of first layer of fossilized animal bone (North Ridge/Carnegie Quarry A).

○ 23-22 Ma - second major mortality event; formation of the two main bonebed deposits (Carnegie Hill and University Hill localities).

- Over the last 5 million years - uplift of AGFO area to its present elevation of $1,340 \mathrm{~m}(4,400$ $\mathrm{ft})$

- 26,500 years ago - last glacial maximum; habitat has transitioned to deciduous forest

Prehistory:

- Ca. 16,000 BCE - estimated arrival of Paleo-Indians

- 10,200-8,000 BCE - Plano Late Paleo-Indian culture dominates the Great Plains, focused on nomadic hunting and gathering, source of artifacts in and around AGFO (Hudson-Meng Site, $64 \mathrm{~km} / 40 \mathrm{mi}$ northeast of AGFO, bison kill site)

- 6,000 BCE-500 CE - with the retreat of the Laurentide continental glacier, habitat changes from moist deciduous woodlands to the current semi-arid prairie grassland; Great Plains Archaic culture dominates with a focus on more sedentary activities such as foraging and agriculture (Spring Creek Site, southwest Nebraska; Signal Butte Campsite, $80 \mathrm{~km} / 50 \mathrm{mi}$ S of AGFO)

- 800 BCE-1200 CE - emergence of High Plains Woodland cultural tradition, a semi-nomadic society that became increasingly agricultural and sedentary from west to east

- $\mathbf{0}$ BCE - High Plains Woodland cultural tradition arrives in what is now western Nebraska

- 900 CE-1450 CE - ascent of Central Plains cultural tradition, first truly sedentary culture of the region, though in western Nebraska evidence shows it was likely semi-nomadic possibly with seasonal habitation (McIntosh site near Enders Lake, north-central Nebraska; 1975: cultural material has been found inside of AGFO dating to $1000 \mathrm{CE}$, no specific campsites exist within the Monument) 
- 1200-1500 CE - decline of High Plains Woodland cultures (1973: Sioux Co. archeological site produces grave of 50 -year-old man dated to $1250 \mathrm{CE}$ )

- 1470-1510 CE - three prolonged droughts caused semi-permanent villages in the Niobrara and Republican River valleys to consolidate

- 1492-1524 CE - Arrival of Europeans to the continent; series of pandemics ensue ahead of contact with Natives ("virgin soil epidemics")

- 1600 CE - first material evidence of Pawnee culture in Nebraska; approximate timing of the "Little Ice Age"

- Late 1600s-Early 1700s CE - Occupation and eventual dispersal of the Apache culture in Western Nebraska ("Dismal River Phase"; Fort Robinson site on Slaughterhouse Creek near AGFO)

- 1734-1735 CE - arrival of epidemic diseases to the Northern Plains.

- Late 1700s-Early 1800s CE - first visible evidence of historic Native American tribes in the Great Plains as Europeans began to explore the region; European diseases are still ravaging Native peoples

Recorded History:

- 1803 - the Louisiana Purchase opened up the region to exploration and exploitation; a booming fur-trade likely led to first contact with local Native American tribes around this time

- 1827 - the American Fur Company dominated the area around AGFO with many trading posts, integrating Native American groups such as the Yankton Dakota, Teton Dakota, Pawnee, Cheyenne, Arapahoe, Arikara, Ponca, Oto, Omaha, Oglala and Brule Lakota Sioux, and Crow into the US economy

- 1836 - first migrant wagon train passes through via the historic Oregon Trail in Scottsbluff; northwestern Nebraska and other areas on the High Plains were considered less desirable compared to lands in what would become California, Oregon, and Washington, and thus were only traveled through at this time, not settled

- 1857 - Lieutenant G. K. Warren expedition for the US government explores the areas in and around AGFO for suitable passage, declaring the Niobrara River too small for trading vessels and suggesting a railroad instead; this effectively kept the Agate Springs area remote for another 25 years as his report discouraged permanent settlement

- 1861 - beginning of the American Civil War

- 1865 - end of the American Civil War, which spurned cattle ranchers north and into the Great Plains to expand their business into the open range without interfering with agricultural crops; the decrease of bison also facilitated this

- $\mathbf{1 8 6 6}$ - Oregon Trail wagon road along the Niobrara becomes redundant as the Union Pacific Railroad builds along the Platte River $130 \mathrm{~km}(80 \mathrm{mi})$ south

- 1875-1876 - "Sioux Wars" ended with a forced transfer of 4.9 million hectares (12 million acres) of land in the Panhandle region of Nebraska, belonging to Sioux, Northern Cheyenne, 
and Arapaho, to the US government; secession of land in this treaty was criticized by Chief Red Cloud

\section{Official AGFO History:}

- August 26, 1857 - Birth of James H. Cook in Kalamazoo, Michigan

- $\mathbf{1 8 6 9}$ - Cook, age 12 , heads west to start a career in cattle driving

- 1874 - Cook meets paleontologist Othniel C. Marsh of Yale University as he travels north to search for fossils; Marsh and Oglala Sioux Chief Red Cloud are prevented from altercation by a 17-year-old Cook, Cook subsequently starts his 35-year-friendship with the 53-year-old Chief

- 1878 - homeopathic Dr. Elisha B Graham moves his wife, two daughters, and practice from Albany, New York to Cheyenne, Wyoming

- 1878 - Cook starts a career as a hunting and ranging guide in the region based out of Cheyenne

- 1879 - James Cook and Elisha Graham meet in Cheyenne, Wyoming; Cook begins courting Kate Graham

- August 1879 - Elisha Graham purchases 04 Ranch, named after the $104^{\text {th }}$ Meridian, on the upper Niobrara within modern-day Sioux County, Nebraska.

- 1881 - the Grahams begin moving to 04 Ranch for several weeks each summer; James Cook, who befriended the family in Cheyenne (1879), visits the ranch with them several times

- 1882 - Erwin Barbour from the University of Nebraska is the first professional geologist to visit the area and prospect; he was a former student of O. C. Marsh at Yale University

- 1882 - Cook invests in a cattle ranch near Socorro, New Mexico, giving him the experience he would eventually use to run Agate Springs Ranch

- 1885 - James Cook stumbles upon "petrified" bones on the property of 04 Ranch, does not disclose this to the Grahams

- September 28, 1886 - James Cook marries Elisha Graham's youngest daughter Kate Graham

- December 1886 - Cook sells shares of WS Ranch, moves to California for a few months before returning to Cheyenne

- July 31, 1887 - the Cooks' first child Harold is born in Cheyenne, Wyoming

- September 1887 - Cook buys 49 hectares (120 acres) of the 04 Ranch for $\$ 800$ from Graham after the rapid decline of the cattle boom; new ranch dubbed Agate Springs Ranch due to the prevalent moss agate and natural springs

- February 1888 - Cook purchases 120 more hectares (300 acres) from Elisha Graham for $\$ 5,000$

- 1891 - Erwin Barbour first visits Agate Springs Ranch on invitation from James Cook; later this year sends students to prospect

- 1892 - Barbour receives funding from University of Nebraska regent Charles H. Morrill for an expedition; Barbour finds and removes a Daemonelix specimen

- 1895 - Cook purchases the "quarter section" of land owned by Mary Graham 
- 1898 - Cook purchases most of the land and irrigation systems of the McGinley and Stover Ranches to the west of Agate Springs Ranch

- 1904 - up until this year, no "serious" or "active" excavations were undertaken on Agate Springs Ranch (Evans-Hatch 2008)

- 1921 - James Cook proposes a Fort Laramie museum on the ranch and begins letting guests in to see his displays of fossils and artifacts; parts of the Cook family home were set aside for display of specimens and the "Cook Museum of Natural History" which maintained operation until the creation of the National Monument; the materials then went on to be part of what is now referred to as the "Cook Collection" which contained over 450 artifacts

- 1904-1923 - detailed list of expeditions and excavations can be found in Appendix A Table 1

- 1923 - James Cook's memoirs: Fifty Years on the Frontier are published

- 1927 - Harold Cook successfully connects Agate Springs Ranch to the original Nebraska State Highway 29

- 1929 - start of the Great Depression in the United States

- 1932 - James Cook takes part in the dedication of the Red Cloud Agency Monument near Fort Robinson, memorializing his friend and Sioux Chief Red Cloud

- 1934 - Harold Cook becomes the fourth custodian at Scotts Bluff National Monument and serves until 1935

- January 7, 1935 - due to increasing debt, 2,220 hectares (5,480 acres) of Agate Springs Ranch were almost auctioned off by the county sheriff, but last-minute loans and help from wealthy friends of the family put a halt to this

- 1935 - Harold writes NPS Acting Director Arthur Demaray, who comes to visit Agate Fossil Quarries and deems them impressive, but cuts talks short

- 1939 - end of the Great Depression in the United States

- January 27, 1942 - James H. Cook passes away at the age of 84; Harold takes up the reins of running the ranch

- 1952 - Harold receives honorary doctor of science degree from the South Dakota School of Mines for his life-long work and contributions to paleontology and geology

- September 29, 1962 - Harold Cook passes away at the age of 75; his widow and second wife Margaret maintained the museum and witnessed its authorization as a national monument in 1965

- 1965 - congressional legislation authorized the establishment of AGFO to preserve paleontological sites, Native American artifacts and relics, and the history of the Cook family's Agate Springs Ranch

- Mid-1970s - formal excavation begun by archeologists (Evans-Hatch 2008)

- 1981-1986 - detailed list of excavations can be found in Appendix A Table 2 
Appendix A Table 1. Summary of excavations at Agate Springs Ranch 1904-1923, adapted from EvansHatch (2008). See Appendix A Figure 1 for a map of major localities.

\begin{tabular}{|c|c|c|c|}
\hline Year & Leader & Affiliation & Excavation Site(s) \\
\hline 1904 & O. A. Peterson & Carnegie Museum & $\begin{array}{l}\text { Beardog Hill (Carnegie Quarry 3), North Ridge (Quarry A), } \\
\text { University Hill (surface prospects) }\end{array}$ \\
\hline 1905 & O. A. Peterson & Carnegie Museum & $\begin{array}{l}\text { Beardog Hill (Carnegie Quarry 3), Carnegie Hill (southwest } \\
\text { and northeast excavations) }\end{array}$ \\
\hline 1905 & E. H. Barbour & University of Nebraska & University Hill (University Quarry) \\
\hline 1906 & W. H. Utterback & Carnegie Museum & $\begin{array}{l}\text { Carnegie Hill (southwest, northwest, and northeast } \\
\text { excavations) }\end{array}$ \\
\hline 1906 & E. Riggs & $\begin{array}{l}\text { Field Museum of Natural } \\
\text { History (Chicago) }\end{array}$ & University Hill (University Quarry) \\
\hline 1906 & E. H. Barbour & University of Nebraska & University Hill (University Quarry) \\
\hline 1906 & $?$ & Kansas University & $?$ \\
\hline 1907 & F. B. Loomis & Amherst & $\begin{array}{l}\text { North Ridge (Quarry A), Carnegie Hill (northeast test point), } \\
\text { Amherst Hill (Stenomylus Quarry) }\end{array}$ \\
\hline 1907 & A. Thompson & $\begin{array}{l}\text { American Museum of } \\
\text { Natural History (AMNH) }\end{array}$ & Carnegie Hill (northeast excavation) \\
\hline 1908 & W. H. Utterback & Carnegie Museum & Resigned and left before work began \\
\hline 1908 & O. A. Peterson & Carnegie Museum & Carnegie Hill (southwest excavation) \\
\hline 1908 & E. H. Barbour & University of Nebraska & University Hill (University Quarry) \\
\hline 1908 & R. S. Lull & Yale & $\begin{array}{l}\text { University Hill (University Quarry), Amherst Hill (Stenomylus } \\
\text { Quarry) }\end{array}$ \\
\hline 1908 & F. B. Loomis & Amherst & Amherst Hill (Stenomylus Quarry) \\
\hline 1908 & A. Thomson & $\mathrm{AMNH}$ & Amherst Hill (Stenomylus Quarry) \\
\hline 1909 & O. A. Peterson & Carnegie Museum & Amherst Hill (Stenomylus Quarry) \\
\hline 1911 & A. Thomson & AMNH & Carnegie Hill (southwest excavation) \\
\hline 1912 & A. Thomson & AMNH & Carnegie Hill (southwest excavation) \\
\hline 1913 & A. Thomson & AMNH & Carnegie Hill (southwest excavation) \\
\hline 1914 & A. Thomson & AMNH & Carnegie Hill (southwest excavation) \\
\hline 1914 & W. J. Sinclair & Princeton & Carnegie Hill (southwest excavation) \\
\hline 1916 & A. Thomson & AMNH & Carnegie Hill (north excavation, test pits) \\
\hline 1917 & C. Barner & AMNH & Carnegie Hill (north excavation stripping) \\
\hline 1917 & Figgins & Denver Museum & Carnegie Hill (southwest excavation) \\
\hline 1918 & A. Thomson & AMNH & $\begin{array}{l}\text { Carnegie Hill (north excavation), Amherst Hill (inspection } \\
\text { only) }\end{array}$ \\
\hline 1919 & A. Thomson & AMNH & Carnegie Hill (southwest and north excavations) \\
\hline 1920 & A. Thomson & AMNH & Carnegie Hill (southwest excavation) \\
\hline
\end{tabular}


Appendix A Table 1 (continued). Summary of excavations at Agate Springs Ranch 1904-1923, adapted from Evans-Hatch (2008). See Appendix A Figure 1 for a map of major localities.

\begin{tabular}{|l|l|l|l|}
\hline Year & Leader & Affiliation & Excavation Site(s) \\
\hline 1920 & P. Miller & University of Chicago & Carnegie Hill (southwest excavation) \\
\hline 1922 & A. Thomson & AMNH & Carnegie Hill (south excavation) \\
\hline 1922 & H. Martin & Kansas University & Carnegie Hill (southwest excavation) \\
\hline 1922 & Buettner-Hussey & Michigan & Carnegie Hill (southwest excavation) \\
\hline 1923 & A. Thomson & AMNH & $\begin{array}{l}\text { Carnegie Hill (south excavation), Amherst Hill (Stenomylus } \\
\text { Quarry) }\end{array}$ \\
\hline
\end{tabular}

Appendix A Table 2. Chronology of University of Nebraska excavations, 1981-1986 (Hunt 1988b).

\begin{tabular}{|l|l|l|}
\hline Quarry & Year & Dates \\
\hline \multirow{5}{*}{ Carnegie Quarry 3 } & 1981 & September 9-16 \\
\cline { 2 - 3 } & 1982 & July 12-21, 27-30; October 16-21 \\
\cline { 2 - 3 } & 1983 & July 3-7 (mapping only) \\
\cline { 2 - 3 } & 1984 & June 16-27; July 1, 9-13 \\
\cline { 2 - 3 } & 1985 & June 25-July 10 \\
\hline \multirow{5}{*}{ Carnegie Hill } & 1983 & July 3-7 (mapping only) \\
\cline { 2 - 3 } & 1984 & June 26-30; July 2-13 \\
\cline { 2 - 3 } & 1985 & July 9-13; October 10-21 \\
\cline { 2 - 3 } & 1986 & June 1-August 16 \\
\hline
\end{tabular}




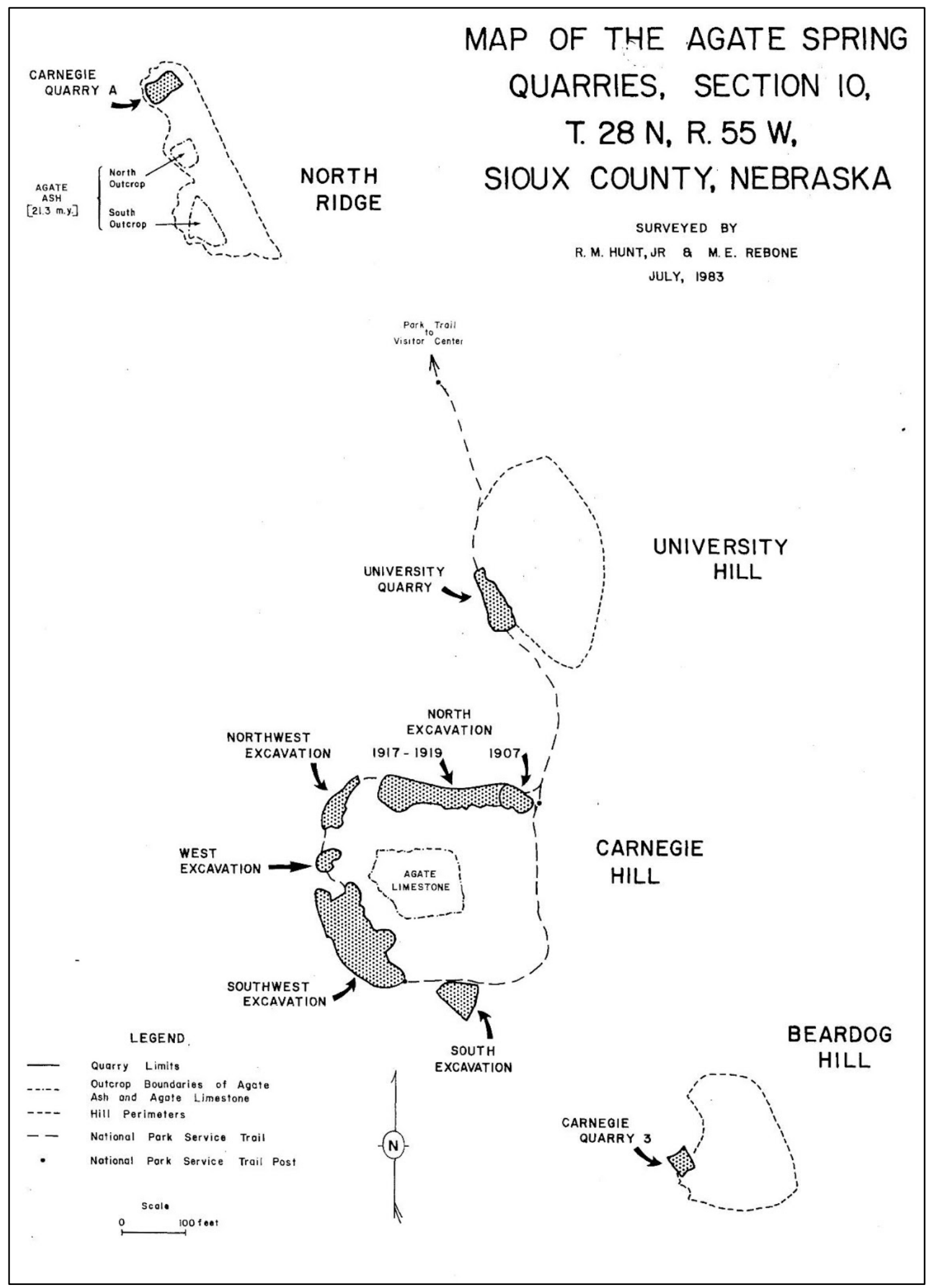

Appendix A Figure 1. Map of the major excavation sites at Beardog Hill, Carnegie Hill, North Ridge, and University Hill, from Hunt (1984). 



\section{Appendix B. AGFO Locality Form}

All AGFO paleontology locality record sheets contain the following fields, which are detailed here from top to bottom and left to right. This version has been adapted for Word. A tabular version exists as well.

Date Locality Investigated: The date the locality was investigated, including GPS readings, photographs taken, and locality and condition report form filled out. Date should be in the format of year-\#month\#day (e.g., 2020-0508).

Locality Number: A tracking number unique to AGFO, as initially assigned in the 2003 Locality Database Project and the 2014 update. In concurrence with the Paleontology Resources Management Plan (PRMP), each locality was assigned a unique identifying number that can be used to tie all fossils collected from the locality to that locality. Paleontological collections were made prior to the establishment of the Monument and thousands of specimens are housed in at least 24 non-NPS repositories. These specimens are marked with the locality number of the institution excavating the quarry at that particular time and each institution has its own unique identifying number assigned to the locality. In addition, many institutions have worked the same quarries. The extensive research required to locate and identify fossil material from AGFO and correlate the specimens to the localities was beyond the scope of this project. As specimens that are housed in other institutions are located and correlated, a separate, linked table within the Fossil Locality Database in MS Access would complete the information needed for each of these localities.

Investigator: Person that investigated the locality and filled out the form. Format is "Last name, First name."

Locality Name: In most cases established locality names were used. In those instances where a locality had another name given to them from the past excavations, such as some of the Carnegie Hill Quarries and North Ridge, the names used by the University of Nebraska were used due to their reference in recent publications. In the case of new localities, new names were chosen.

Type of Locality: Describes the locality types. There are two types of locality: geologic and paleontologic.

Closest Datum Point: The closest datum point to or within the locality.

NAD: North American Datum standard on USGS topographic maps. It is revised on maps published after 1983. The 1927 Agate map still needs to be adjusted. The NAD is already adjusted on the aerial map being used for the locality maps and it does not affect the GIS recordings. It is necessary that geographic coordinates include which datum was used for the projection, because there is a more than $60 \mathrm{~m}(200 \mathrm{ft})$ difference between the two most heavily used projections for North America, NAD 1927 and NAD 1983 (WGS84). USGS topographic maps produced before 2009 use NAD 1927. Users should be aware, however, that the use of the NAD 1927 datum can cause problems when transferring files to GIS. Also, be advised that GPS units are often factory preset to NAD 1983 (WGS84). 
UTM Zone: Universal Transverse Mercator plane coordinate system locations standard. The zone for western Nebraska is 13 .

Northing: Universal Transverse Mercator plane coordinate system location standard. The northing coordinates of each locality were recorded on the GPS GeoTracker III with a beacon on the belt for real-time corrections. Each coordinate was then differentially corrected through Jewel Cave National Monument, South Dakota.

Easting: Universal Transverse Mercator plane coordinate system location standard. The easting coordinates of each locality were recorded on the GPS GeoTracker III with a beacon on the belt for real-time corrections. Each coordinate was then differentially corrected through Jewel Cave National Monument, South Dakota.

Elevation: The elevations for each locality were recorded from topographical maps because GPS recordings can be inaccurate up to $90 \mathrm{~m}(300 \mathrm{ft})$.

Latitude: Universal coordinate system standard. Differentially corrected from GPS GeoTracker III with a beacon on a belt.

Longitude: Universal coordinate system standard. Differentially corrected from GPS GeoTracker III with a beacon on a belt.

Legal Description: The legal description to the $1 / 4,1 / 4,1 / 4$ section identified from the USGS quadrangle map on which the locality is found.

Quad Map: The name of the USGS quadrangle map on which the locality is found.

Description of Locality: Physical description of locality that includes general location and surrounding identifiable structures. In addition to exact geographic coordinates, it is useful to describe the locality in reference to geographic landmarks, particularly roads and gates which may be used to access the locality. Any sites within the locality should also be documented within this section.

Age: Standard division of geological/paleontological time.

Formation: Standard geological division of rock units.

NALMA: North American Land Mammal Age. Standard division of paleontological time based primarily on first appearance datums (FADs) and secondarily on index fossil range.

Lithology: Descriptions of the facies in which the paleontological material is found, including sediment type and color.

Estimated Thickness of Deposit: Measured in meters during field survey.

Taxa Observed: The species of specimens left in situ at locality. 
Taxa Collected: Genus and species of specimens recovered at locality. Information from various authors.

Specimens Located Offsite: Many specimens are located in collections offsite. Specimens from the locality that are housed in outside museums should be listed here. If specific specimens are not known, this space can still be used to record what museums have material from the locality.

Locality Photo Attached: Photos of the locality were taken from a distance as well as near the localities. They are attached to hardcopies of locality forms and also appear as hotlinks in GIS ArcView.

Comments: Optional additional comment section when needed. 
Date Locality Investigated:

Locality Number: AGFO-FL-

\section{AGFO FOSSIL LOCALITY FORM}

Investigator: Locality Name:

Type of Locality: Closest Datum Point:

Site Datum UTM Coordinates:

NAD:

Zone:

Northing:

Easting:

Elevation:

Latitude:

Longitude:

Legal Description:

Quad Map:

Description of Locality:

Age:

Formation:

NA Land Mammal Age:

Lithology:

Estimated Thickness of Deposit:

Taxa Observed: 
Taxa Collected:

Specimens Located Offsite:

Locality Photo Attached:

Comments: 



\section{Appendix C. AGFO Locality Condition Form}

All AGFO paleontology locality condition sheets (Appendix C) contain the following fields, which are detailed here from top to bottom and left to right. This version has been adapted for Word. A tabular version exists as well.

Date Locality Investigated: Date the locality's condition was assessed. Year-\#month\#day format (e.g., 2020-0508).

Locality Number: AGFO locality number, e.g., AGFO-FL-0001

Investigator: Person that assessed the locality and filled out the form. Format is "Last name, First name."

Locality Name: In most cases established locality names were used. In those instances where a locality had another name given to them from the past excavations, such as some of the Carnegie Hill Quarries and North Ridge, the names used by the University of Nebraska were used due to their reference in recent publications. In the case of new localities, new names were chosen.

Locality Significance: How important the locality is, and why. Includes factors such as past research history, fossil taxa found, diversity of taxa at locality, level of preservation quality, unusual taphonomy, etc.

Scoring Categories: Include Disturbance Rating, Disturbance Mitigation, Fragility Rating, Fragility Mitigation, Fossil Abundance Rating, Loss Rating, Loss Mitigation, Locality Access Rating, Locality Access Mitigation. Each category has descriptions of score levels, and a field to record the appropriate score.

Total Score For Locality Condition: Write the sum of the scoring categories into this field. This number determines the overall condition for the locality: Good, Fair, or Poor.

Recommendations: Any recommendations pertaining to management at this site can be written down here. 
Date Locality Investigated:

Locality Number: AGFO-FL-

\section{LOCALITY CONDITION FORM}

Investigator:

Locality Name:

Locality Significance:

Historical:

Research:

Museum Collections: Interpretive:

Other Land Management:

\section{LOCALITY RATING}

Disturbance Rating:

0: Poor: The fossils erode rapidly/High level of illegal removal

10: Moderate: Above normal erosion/Occasional illegal removal

20: Outstanding: Normal erosion/No illegal removal

Disturbance Mitigation:

0 : No action

15: Erosion stopped or illegal removal of fossils reduced

Fragility Rating:

0: High: Easily eroded

10: Moderate: Erodes 1-3 years

20: Low: Erodes slowly

Fragility Mitigation:

0 : No action

15: Fossils are collected and documented regularly

Fossil Abundance Rating:

0: High: Large number of fossils/easily spotted

10: Moderate: Fossils present over large area/must search to locate

20: Low: Occur sporadically/not easily recognized

Loss Rating:

0: High: Noticeable disappearance yearly

10: Moderate: Reduced by small amount yearly

20: Low: No significant change yearly

Loss Mitigation:

0 : No action

10: Monitored

20: Collected and documented 
Locality Access Rating:

0: High: Close to roads and trails

10: Moderate: Relatively inaccessible

20: Low: Difficult to locate

Locality Access Mitigation:

0 : No action

5: Monitored by staff

10: Actively patrolled, collected on occasion, protected by a barrier, or cyclic monitoring

20: Active law enforcement, surveillance, or ongoing collection by researchers

TOTAL SCORE FOR LOCALITY CONDITION:

Recommendations: 



\section{Appendix D. AGFO Visitor Site Report Form}

Visitor site reports, as used at parks such as BADL, are a way to encourage visitors to actively participate in effective management of paleontological resources, as well as alerting Monument staff to previously unreported fossil occurrences. A visitor site report consists of a simple questionnaire with fields for the description of the geographic location, the stratigraphy, the kind of fossil, and its condition. Paper copies of the form are provided at visitor facilities. AGFO does not currently have a visitor site report program implemented, but Ed Welsh (BADL) has provided a draft of such a form customized for AGFO. It has not yet received OMB approval. It is included below as images of the two sides of the digital document (Appendix D figures 1 and 2). Detailed instructions for the fields are included on the forms, to aid their use by visitors who have little experience recording scientific data. Text from the form is provided below. 


\section{Visitor Site Report}

\section{Paleontological Field Identification}

Date

Employee Name

Site Location

Please mark the location of the fossil on this map of the Agate Fossil Beds Area. You can also attach a copy of another map showing the fossil location.

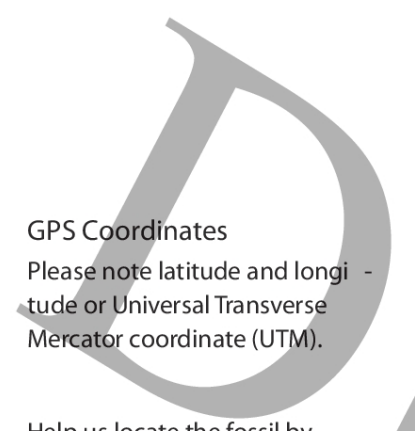

Help us locate the fossil by answering these questions about the site.

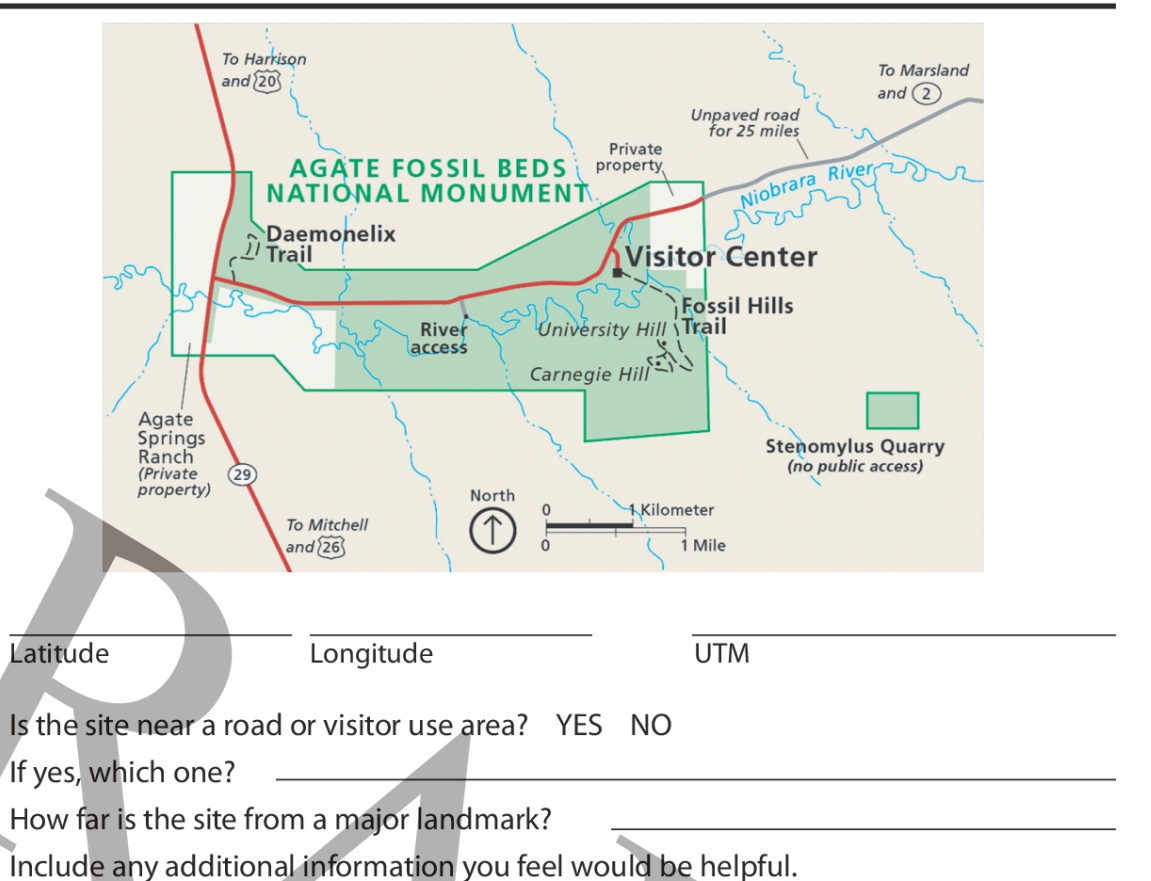

Include any additional information you feel would be helpful.

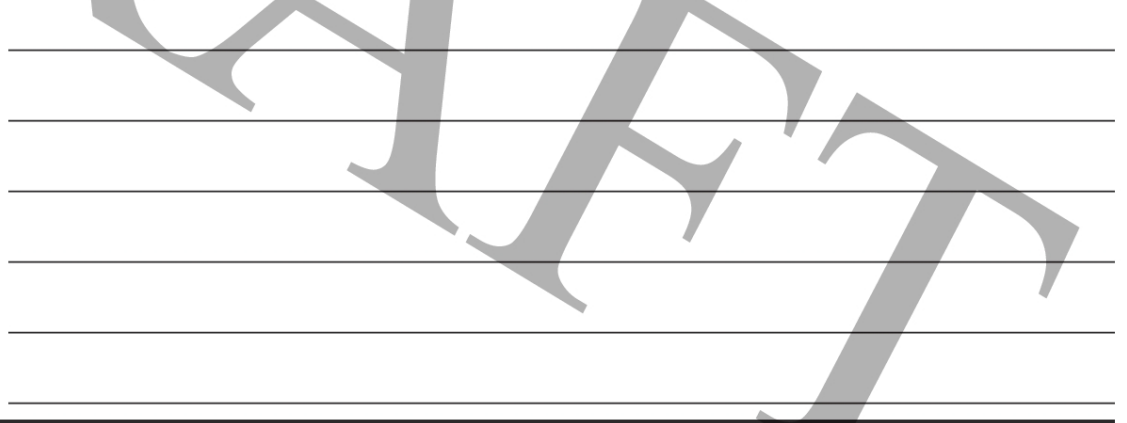

In what type of terrain was the fossil found?

Butte Wash Sod Table Flat Other

What is the color and texture of the surrounding rock?

Color: Brown Gray Green Other

Texture: Clay Popcorn/Rough and broken Sandy Nodule

Appendix D Figure 1. The front side of the proposed AGFO Visitor Site Report form (NPS/ED WELSH). Text of form provided below. 
Fossil Description The fossil is: Bone Tooth Both

Help us identify the fossil.

What is the color is the fossil?

Color: White Red Brown Black Other

On a scale of $1-5$, how weathered is the fossil? $1 \begin{array}{lllll}1 & 2 & 3 & 4 & 5\end{array}$

$1=$ no weathering, intact $5=$ broken bits of bone, scattered

What is the surface texture of the fossil?
Texture: Shiny Rough Splintered Other

What is the general shape of the fossil?

Does it resemble any of the parts on the skeleton drawing below? YES NO If yes, please circle it.

Visitor Contact Information

Thank you for filling out this

Visitor Site Report. We will write

to you if we collect the fossil.

Name

Address

Email

You can also visit our website at www.nps.gov/agfo and choose Contact Us.

Appendix D Figure 2. The reverse side of the proposed AGFO Visitor Site Report form (NPS/ED WELSH). Text of form provided below. 


\section{Text of Proposed AGFO Visitor Site Report Form}

Visitor Site Report

Paleontological Field Identification

National Park Service

U.S. Department of the Interior

Agate Fossil Beds National Monument

Nebraska

Date (text field)

Employee name (text field)

$\underline{\text { Site Location }}$

Please mark the location of the fossil on this map of the Agate Fossil Beds Area. You can also attach a copy of another map showing the fossil location.

[Map of Agate Fossil Beds National Monument]

\section{GPS Coordinates}

Please note latitude and longitude or Universal Transverse Mercator coordinate (UTM).

Latitude (text field)

Longitude (text field)

UTM (text field)

Help us locate the fossil by answering these questions about the site.

Is the site near a road or visitor use area? (choices below)

$\square$ Yes

$\square$ No

If yes, which one? (text field)

How far is the site from a major landmark? (text field)

Include any additional information you feel would be helpful. (text field)

Site Description

Help us locate the fossil by answering these questions about the terrain.

In what type of terrain was the fossil found? (choices below)

Butte

Wash

Sod

$\square$ Table

$\square$ Flat

$\square$ Other (text field) 
What is the color and texture of the surrounding rock? (choices below)

Color:

$\square$ Brown

$\square$ Gray

$\square$ Green

$\square$ Other (text field)

Texture:

Clay

$\square$ Popcorn/Rough and broken

Sandy Nodule

Fossil Description

Help us identify the fossil.

The fossil is: (choices below)

$\square$ Bone

$\square$ Tooth

$\square$ Both

What is the color is the fossil? (choices below)

Color:

White

$\square$ Red

$\square$ Brown

Black

$\square$ Other (text field)

On a scale of $1-5$, how weathered is the fossil? $1=$ no weathering, intact; $5=$ broken bits of bone, scattered. (choices below)

$\square \quad 1$
$\square \quad 2$
$\square \quad 3$
$\square \quad 4$
$\square \quad 5$


What is the surface texture of the fossil? (choices below)

Texture:

$\square$ Shiny

$\square$ Rough

$\square$ Splintered

$\square$ Other (text field)

What is the general shape of the fossil? (text field)

Does it resemble any of the parts on the skeleton drawing below? (choices below)

$\square$ Yes

$\square$ No

If yes, please circle it.

[Drawing of an animal skeleton]

Visitor Contact Information

Thank you for filling out this Visitor Site Report. We will write to you if we collect the fossil.

Name (text field)

Address (text field)

Email (text field)

You can also visit our website at www.nps.gov/agfo and choose Contact Us. 


\section{Appendix E. Monitoring Levels Description}

Identifying threats and existing conditions of all paleontology sites or features are a requirement as per NPS DO 77, Management Policies of 2006 and the Paleontological Resources Preservation Act. All fossil sites should be recorded using the paleontological locality information form and be entered into the paleontological database. Additionally, a paleontological site condition assessment form should be completed to collect a baseline assessment. A systematic inventory and field survey of AGFO is hypothetically possible given its small size; however, understanding the realities of budgets, time availability, and staffing, the higher priority is to reevaluate the currently known localities and attempt to schedule routine monitoring for them. At minimum, monitoring paleontological sites at any opportunistic time and at any logical monitoring level is better than no monitoring at all. All monitoring levels/plans will strive to include indicators and standards for unacceptable impact.

To keep the monitoring tasks manageable, and given the difficulties of a full inventory, the following three levels of monitoring are suggested.

\section{Level One Monitoring (least intensive)}

Because of long or difficult access, scattered sites over a large area, poor location data, and/or obscure, lower quality specimens, there is little likelihood of visitation or "re"-discovery by the general public. Academic interest in these areas is not likely in the near term. The areas will likely require an initial on-ground inventory (possibly requiring detailed searches) before systematic monitoring needs can be determined. Opportunistic repeat photography and site condition assessments are recommended. At AGFO, these are localities that have historically only produced small amounts of fragmentary float or where fossils are only hypothesized to be present.

\section{Level Two Monitoring (moderate intensity)}

Sites in this category include those with easier access, those containing specimens that are overall more recognizable, sites that are more broadly published, or sites that are threatened by natural or human destructive processes. If these sites have not been recognized and recorded in the Paleontological Database, a baseline inventory should be completed as soon as possible, using the Paleontological Locality Information Form and the Paleontological Locality Condition Assessment Form. Monitor once every 1-to-3 years, depending on site fragility and accessibility. The following evaluations are useful (similar to Level Three monitoring) and should be made when on site (on the ground):

1. Identify conditions by quick inspection and document by photo, text and drawing as appropriate.

2. Establish specimen or site disintegration by photo documenting and describing the condition of the specimen or site compositional material.

3. Photo-document and/or describe any approach routes, trails or outcrops that demonstrate possible route impacts to site. 


\section{Level Three Monitoring (most intensive)}

A) Site Monitoring: These are the most important localities at AGFO, such as the Fossil Hills and Stenomylus Quarry. Monitor such sites at least twice annually. Sites should be recorded in the Database, if they have not been already, and Condition Assessments should be completed for each. Develop a monitoring and photo-documentation plan to include indicators and standards for unacceptable impact. This plan should include documentation of:

1. Increased fracturing, including breakage or slow fracturing. Any fracturing obviously humancaused by attempts at removal or malicious destruction would be unacceptable. Natural weathering and fracturing should be documented and change rate monitored for possibility of taking protective measures.

2. Granular disintegration or change in smoothness of outcrop, e.g., sharp edges on digits or claws become less distinct in a footprint. Change in this category may be more subtle, and can differ from feature-to-feature or within same feature based on particle size and induration. In coarse sandstones, the effect might be crumbling loss, while in fine-grained mud or siltstones, especially harder textures, change may only be noticeable as a degree of smoothness.

3. Matrix loss and/or detachment of a fossil from bedrock outcrop. A feature may be eroding/weathering in a manner that separates it from the bedrock (i.e., it becomes a loose item), or otherwise compromises the context of the feature and surrounding bedrock.

4. Loose fossils require similar documentation. These may be larger footprint casts near or far from their original depositional location, or smaller debris, such as bone fragments or isolated teeth that are a component of a weathered talus pile at the source outcrop's foot.

Consistent camera positions and angles, close-up photo detail, and recognizable scale devices in the photos are critical to evaluate change. The monitoring data should be the basis for consideration of additional management actions if necessary.

B) Access (trail or route) Monitoring: Document points of fossil site access using photographs and descriptions of the route (e.g., how much human impact on the site or landscape is visible).

If any level of monitoring demonstrates unacceptable impact to the paleontological resources, such as fresh or smooth wear surfaces, crumbling, discoloration, loss of relief, cracked, chipped or gouged fossil specimens, or disturbance to the landscape from human visitation, then management should take protective actions. Actions could include posting warning signs (maintaining an approach distance), site closure, or "fencing" the features. A short-term closure is preferred if in summer season and evaluation/decision time is required. Monitoring will be adapted and continued in order to determine if management actions have achieved desired results. 


\section{Appendix F. Documentation for Research}

Researchers seeking to apply for a permit to undertake a study at AGFO must apply through the following RPRS website: https://irma.nps.gov/rprs/. This website also contains documents that help explain how to navigate and use its application system, as well as a park-specific page for AGFO detailing its park-specific research conditions, desired research, and records of prior research permit applications and approvals. Documents that will be helpful to researchers looking to submit an application through the RPRS are listed and briefly described below.

Becoming an Investigator in Research Permitting and Reporting System (RPRS)

https://irma.nps.gov/DataStore/DownloadFile/632382

Create an Investigator Account

https://irma.nps.gov/DataStore/DownloadFile/563572

These documents explain how to become an investigator in the RPRS system, which is a prerequisite for applying for permits. This first requires a researcher to be registered with Integrated Resource Management Applications (IRMA). NPS employees will already be registered. Non-NPS employees can see the second listed document for instructions on how to register with IRMA.

Frequently Asked Questions Concerning Collections

https://irma.nps.gov/DataStore/DownloadFile/627370

Answers common questions related to collecting on NPS lands and required curation standards. Includes: questions about funding for cataloging; reasons and legal basis for NPS retaining legal ownership of specimens collected; and information on what can and cannot be copyrighted by a researcher and fair use of the products of research by the NPS.

Frequently Asked Questions related to the Research Permit and Reporting System https://irma.nps.gov/DataStore/DownloadFile/494691

Answers common questions related to applying for a permit through RPRS. Includes how to apply, guidelines for proposals, questions related to applying to multiple parks or for long duration permits, how to learn why a permit was denied, how to follow up with a park once a permit application is approved, and questions related to Investigator's Annual Reports.

RPRS Workflows

https://irma.nps.gov/DataStore/DownloadFile/494693

Provides a broad overview of the entire RPRS website, permitting process, and investigator workflows.

How to log into your investigator account and submit an Investigator's Annual Report https://irma.nps.gov/DataStore/DownloadFile/601665

Detailed instructions about how to fill out and submit an IAR.

General Conditions for Scientific Research and Collecting Permit

https://irma.nps.gov/DataStore/DownloadFile/494569 
List of all general conditions for receiving and retaining a Scientific Research and Collecting Permit, which are applicable when working at all NPS units. These are also listed in Appendix G. AGFO has its own park-specific conditions as well; see Appendix G for current park-specific conditions at time of writing and "Paleontological Research and Collecting Permits" for recommended park-specific conditions. All park-specific conditions should also be listed at https://irma.nps.gov/RPRS/Park/AGFO.

10-741 a Research Application Form

https://irma.nps.gov/DataStore/DownloadFile/601661

Application form for a research and collecting permit.

Appendix A form: Proposed Repository Agreement

https://irma.nps.gov/DataStore/DownloadFile/601663

Application form for a repository agreement, needed if the collecting institution wants to house, prepare, and/or exhibit the specimens in their own facilities. This agreement sets up annual inventory reporting and reaffirms that specimens remain property of the federal government.

Investigator's Annual Report Form 10-226 (IAR)

https://irma.nps.gov/DataStore/DownloadFile/601662

Form used for Investigator's Annual Reports, which are submitted for each year in which research took place.

Application Procedures and Requirements

https://irma.nps.gov/DataStore/DownloadFile/494568

Explains why permits are required, possible need for additional permits, who/when/how/where to apply, review of proposals, advice for facilitating a favorable decision, park response, permittee response once approved, permit stipulations, expected research products and deliverables, and information and notices pertaining to the Privacy and Paperwork Reduction Act including estimation of total burden from reporting duties to investigators (approximately 1.25 to 2 hours per year).

Guidelines to Researchers for Study Proposals

https://irma.nps.gov/DataStore/DownloadFile/494570

Provides a template, with descriptions of desired content for individual sections, for study proposals.

Instructions for Researchers

https://irma.nps.gov/DataStore/DownloadFile/494571

Brief page explaining that permits are required to do research on NPS land and referring prospective researchers to the RPRS website.

Documentation for Researchers to Provide NPS

Researchers must document their work and provide these records for NPS archiving. At minimum, this includes the study proposal and Investigator's Annual Report. However, specific parks may have additional required documentation, including: copies of field notes; copies of datasets; copies of resulting presentations, posters, and/or publications; etc. 


\section{Appendix G. Conditions for Research Permits}

\section{General Conditions for Scientific Research and Collecting Permit}

1. Authority-The permittee is granted privileges covered under this permit subject to the supervision of the superintendent or a designee, and shall comply with all applicable laws and regulations of the National Park System area and other federal and state laws. A National Park Service (NPS) representative may accompany the permittee in the field to ensure compliance with regulations.

2. Responsibility-The permittee is responsible for ensuring that all persons working on the project adhere to permit conditions and applicable NPS regulations.

3. False information-The permittee is prohibited from giving false information that is used to issue this permit. To do so will be considered a breach of conditions and be grounds for revocation of this permit and other applicable penalties.

4. Assignment-This permit may not be transferred or assigned. Additional investigators and field assistants are to be coordinated by the person(s) named in the permit and should carry a copy of the permit while they are working in the park. The principal investigator shall notify the park's Research and Collecting Permit Office when there are desired changes in the approved study protocols or methods, changes in the affiliation or status of the principal investigator, or modification of the name of any project member.

5. Revocation-This permit may be terminated for breach of any condition. The permittee may consult with the appropriate NPS Regional Science Advisor to clarify issues resulting in a revoked permit and the potential for reinstatement by the park superintendent or a designee.

6. Collection of specimens (including materials) - No specimens (including materials) may be collected unless authorized on the Scientific Research and Collecting permit.

The general conditions for specimen collections are:

- Collection of archeological materials without a valid Federal Archeology Permit is prohibited.

- Collection of federally listed threatened or endangered species without a valid U.S. Fish and Wildlife Service endangered species permit is prohibited.

- Collection methods shall not attract undue attention or cause unapproved damage, depletion, or disturbance to the environment and other park resources, such as historic sites.

- New specimens must be reported to the NPS annually or more frequently if required by the park issuing the permit. Minimum information for annual reporting includes specimen classification, number of specimens collected, location collected, specimen status (e.g., herbarium sheet, preserved in alcohol/formalin, tanned and mounted, dried and boxed, etc.), and current location.

- Collected specimens that are not consumed in analysis or discarded after scientific analysis remain federal property. The NPS reserves the right to designate the repositories of all 
specimens removed from the park and to approve or restrict reassignment of specimens from one repository to another. Because specimens are Federal property, they shall not be destroyed or discarded without prior NPS authorization.

- Each specimen (or groups of specimens labeled as a group) that is retained permanently must bear NPS labels and must be accessioned and cataloged in the NPS National Catalog. Unless exempted by additional park-specific stipulations, the permittee will complete the labels and catalog records and will provide accession information. It is the permittee's responsibility to contact the park for cataloging instructions and specimen labels as well as instructions on repository designation for the specimens.

- Collected specimens may be used for scientific or educational purposes only, and shall be dedicated to public benefit and be accessible to the public in accordance with NPS policies and procedures.

- Any specimens collected under this permit, any components of any specimens (including but not limited to natural organisms, enzymes or other bioactive molecules, genetic materials, or seeds), and research results derived from collected specimens are to be used for scientific or educational purposes only, and may not be used for commercial or other revenue-generating purposes unless the permittee has entered into a Cooperative Research And Development Agreement (CRADA) or other approved benefit-sharing agreement with the NPS. The sale of collected research specimens or other unauthorized transfers to third parties is prohibited. Furthermore, if the permittee sells or otherwise transfers collected specimens, any components thereof, or any products or research results developed from such specimens or their components without a CRADA or other approved benefit-sharing agreement with NPS, permittee will pay the NPS a royalty rate of twenty percent $(20 \%)$ of gross revenue from such sales or other revenues. In addition to such royalty, the NPS may seek other damages to which the NPS may be entitled including but not limited to injunctive relief against the permittee.

7. Reports - The permittee is required to submit an Investigator's Annual Report and copies of final reports, publications, and other materials resulting from the study. Instructions for how and when to submit an annual report will be provided by NPS staff. Park research coordinators will analyze study proposals to determine whether copies of field notes, databases, maps, photos, and/or other materials may also be requested. The permittee is responsible for the content of reports and data provided to the National Park Service.

8. Confidentiality - The permittee agrees to keep the specific location of sensitive park resources confidential. Sensitive resources include threatened species, endangered species, and rare species, archeological sites, caves, fossil sites, minerals, commercially valuable resources, and sacred ceremonial sites. Permittee will sign a confidentiality agreement with the park for each scientific research and collecting permit, which will specify what resources/data are considered sensitive.

9. Methods of travel-Travel within the park is restricted to only those methods that are available to the general public unless otherwise specified in additional stipulations associated with this permit. 
10. Other permits - The permittee must obtain all other required permit(s) to conduct the specified project.

11. Insurance - If liability insurance is required by the NPS for this project, then documentation must be provided that it has been obtained and is current in all respects before this permit is considered valid.

12. Mechanized equipment-No use of mechanized equipment in designated, proposed, or potential wilderness areas is allowed unless authorized by the superintendent or a designee in additional specific conditions associated with this permit.

13. NPS participation - The permittee should not anticipate assistance from the NPS unless specific arrangements are made and documented in either an additional stipulation attached to this permit or in other separate written agreements.

14. Permanent markers and field equipment—-The permittee is required to remove all markers or equipment from the field after the completion of the study or prior to the expiration date of this permit. The superintendent or a designee may modify this requirement through additional park specific conditions that may be attached to this permit. Additional conditions regarding the positioning and identification of markers and field equipment may be issued by staff at individual parks.

15. Access to park and restricted areas-Approval for any activity is contingent on the park being open and staffed for required operations. No entry into restricted areas is allowed unless authorized in additional park specific stipulations attached to this permit. The permittee must abide by the rules set out in the park's site etiquette and site info disclosure documents at all times.

16. Notification - The permittee is required to contact the park's Research and Collecting Permit Office (or other offices if indicated in the stipulations associated with this permit) prior to initiating any fieldwork authorized by this permit. Ideally this contact should occur at least one week prior to the initial visit to the park.

17. Expiration date-Permits expire on the date listed. Nothing in this permit shall be construed as granting any exclusive research privileges or automatic right to continue, extend, or renew this or any other line of research under new permit(s).

18. Other stipulations - This permit includes by reference all stipulations listed in the application materials or in additional attachments to this permit provided by the superintendent or a designee. Breach of any of the terms of this permit will be grounds for revocation of this permit and denial of future permits.

\section{Park-Specific Conditions for Scientific Research/Collecting Permit}

Suggestions for park-specific permit conditions are listed in "Paleontological Research and Collecting Permits". Current park specific permit conditions, as listed on AGFO's RPRS webpage, are: 
- Researchers are asked to check in at the Visitor Center and Museum before initiating any fieldwork in the park, and generally keeping the front desk informed of their schedule and whereabouts.

- Vehicular travel within the park should be limited to established roads, and researchers should take a park-provided radio with them (available at the front desk).

- If using park guest housing, researchers are asked to wash kitchen dishes and utensils, and linens, and clean other facilities they used before leaving the park.

\section{Interdisciplinary Project Permits}

For a project involving archeological and/or cultural resources in addition to paleontological ones, an ARPA permit may be used to permit paleontological work in lieu of a Scientific Research and Collecting Permit. 


\section{Appendix H. Site Disclosure Policy/Leave No Trace Guideline}

16 U.S. Code $\S 470$ aaa-3c.3 stipulates that "specific locality data will not be released by the permittee or repository without...written permission.” 2006 NPS Management Policy Section 1.9.2.3 points to exemptions of disclosure of information under the Freedom of Information Act if the service "foresees that disclosure would be harmful to" "resources at risk of harm, theft, or destruction" because of said disclosure. As discussed in "Paleontological Resource Data Management", locality information is sensitive and its unauthorized disclosure may endanger the resources. By default, researchers, employees, volunteers, and visitors who become privy to detailed locality information or locations must not disclose that information.

2006 NPS Management Policy Section 1.9.2.3 also states to withhold information in the following other circumstances: "some types of personnel, financial, and law enforcement matters" and "when the park service has entered into written agreement to withhold data for a fixed period of time at time of acquisition of information." Also, "if information is withheld from one requesting party, it must be withheld from anyone else who requests it." Inversely, "if information is provided to one requesting party, it must be provided to anyone else who requests it" barring prior agreement or certain exemptions.

Furthermore, individuals or groups working at and/or leaving a paleontological site are responsible not just for keeping that information secret and leaving the site undisturbed, but they must also leave the surrounding area as undisturbed as possible. Leaving evidence of resource management work, research, or travel to localities (e.g., trample paths, flagging, scraps of Tyvek, stray jacketing materials, cairn construction) can reveal the presence of paleontological resources to the unauthorized. To avoid this, those traveling to and working at paleontological sites must adhere to the rules of "Leave No Trace" both at the site itself and along accessways to the site.

In particular, the following Leave No Trace principles are critical:

- Plan Ahead and Prepare

- Travel on Durable Surfaces

- Dispose of Waste Properly

- Leave What You Find (valid collection permits provide a partial exception)

- Be Considerate of Other Visitors

Those working or camping in remote locations for an extended period of time should also take the final two principles in mind:

- Minimize Campfire Impacts

- Respect Wildlife 



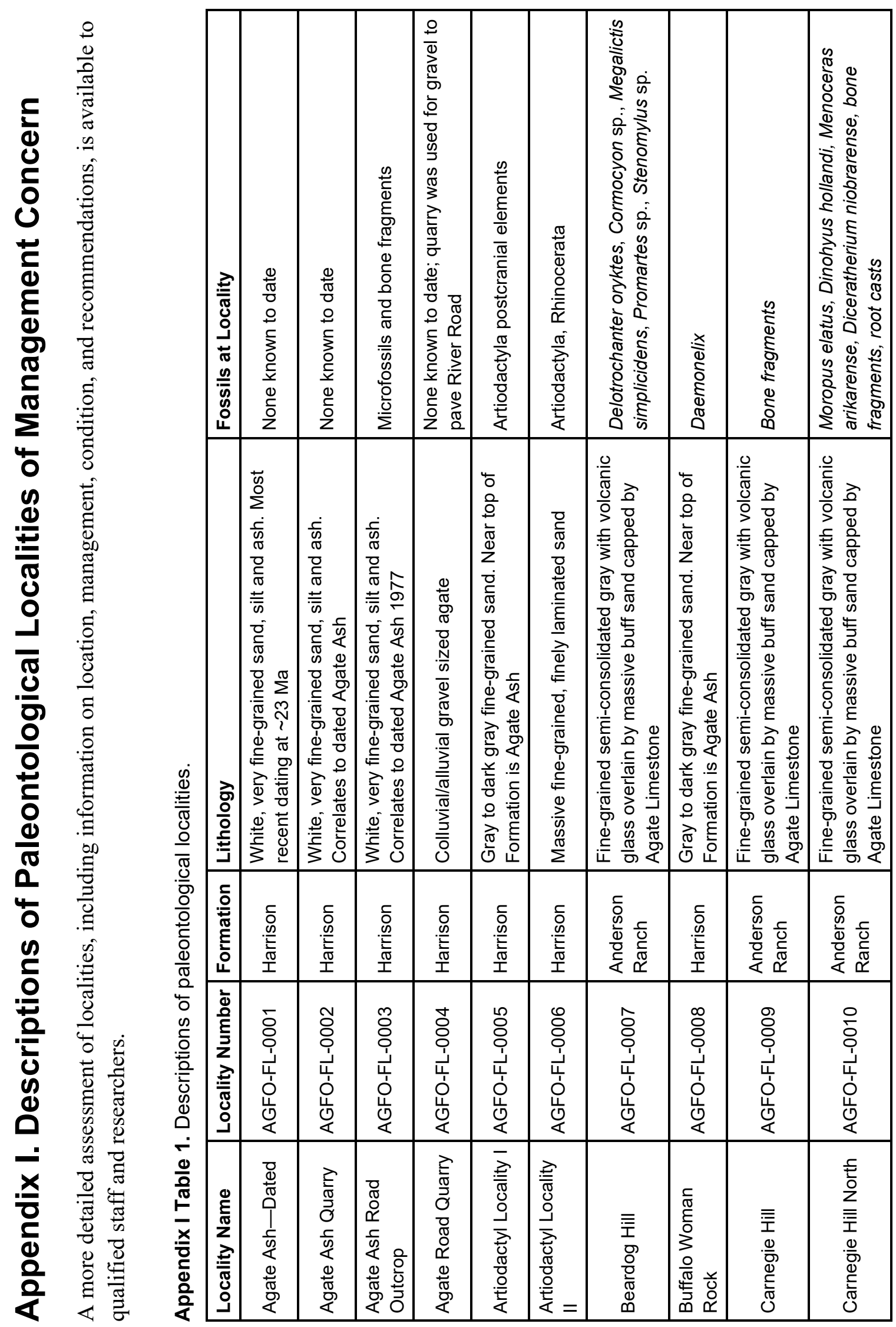




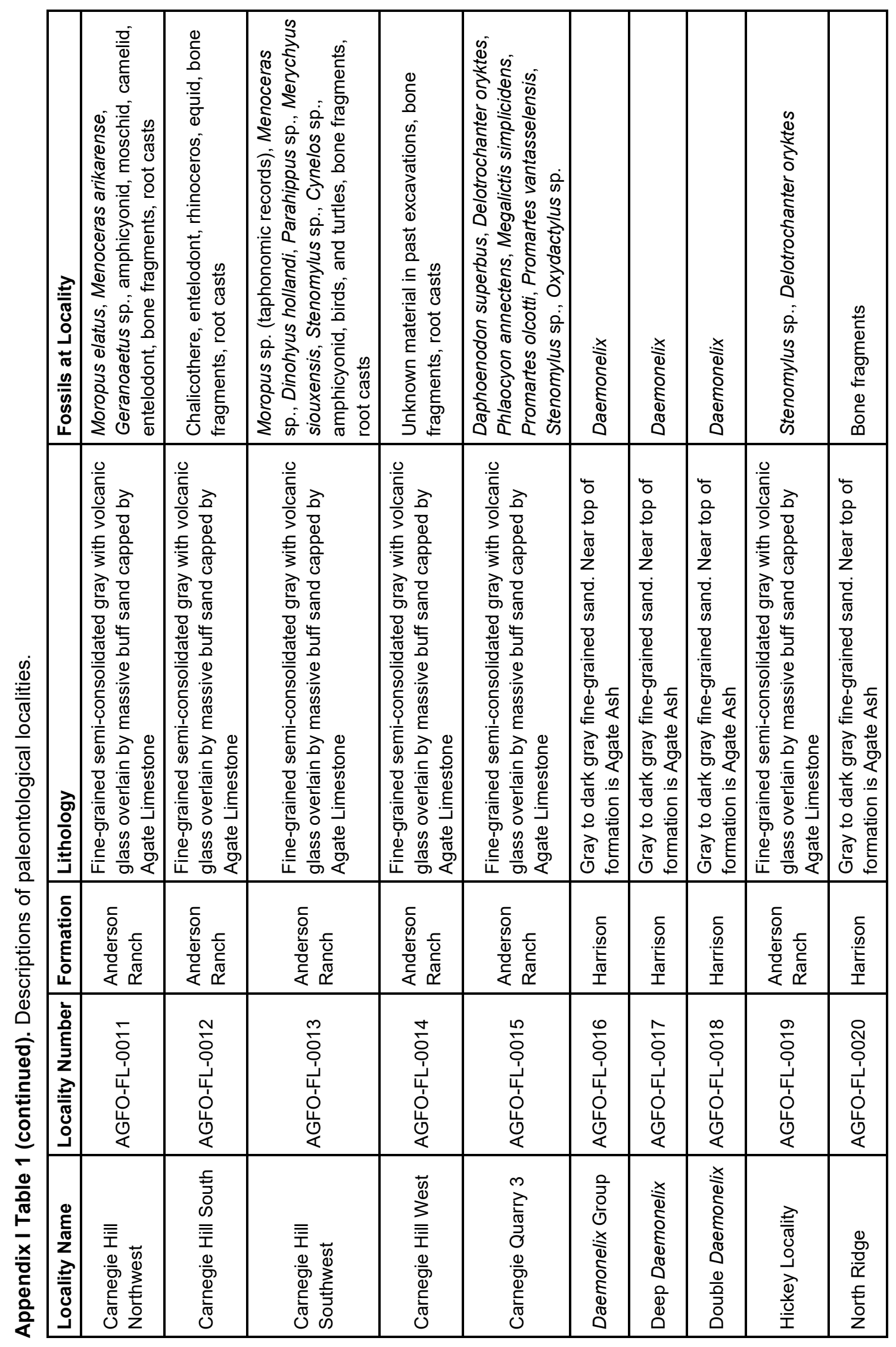




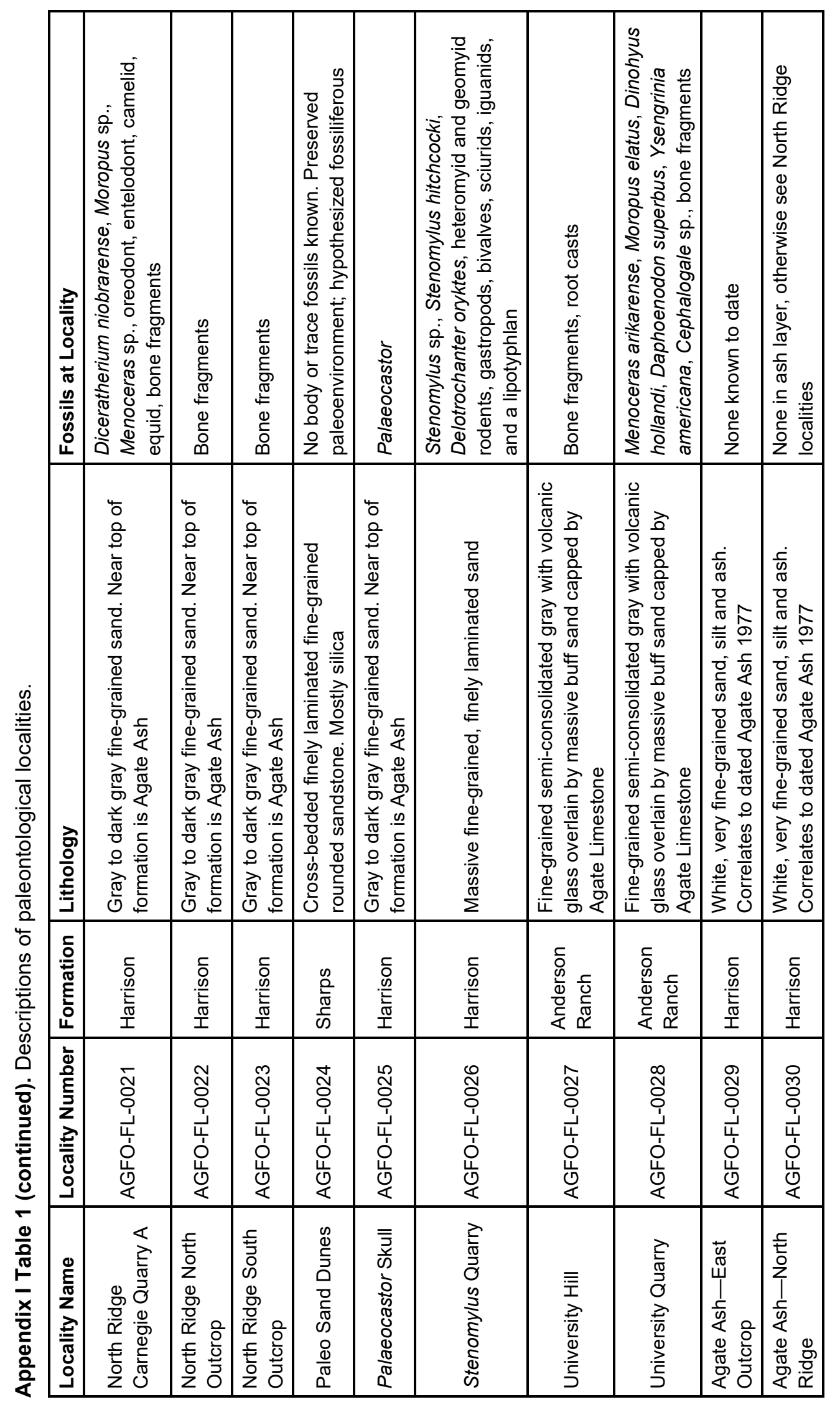





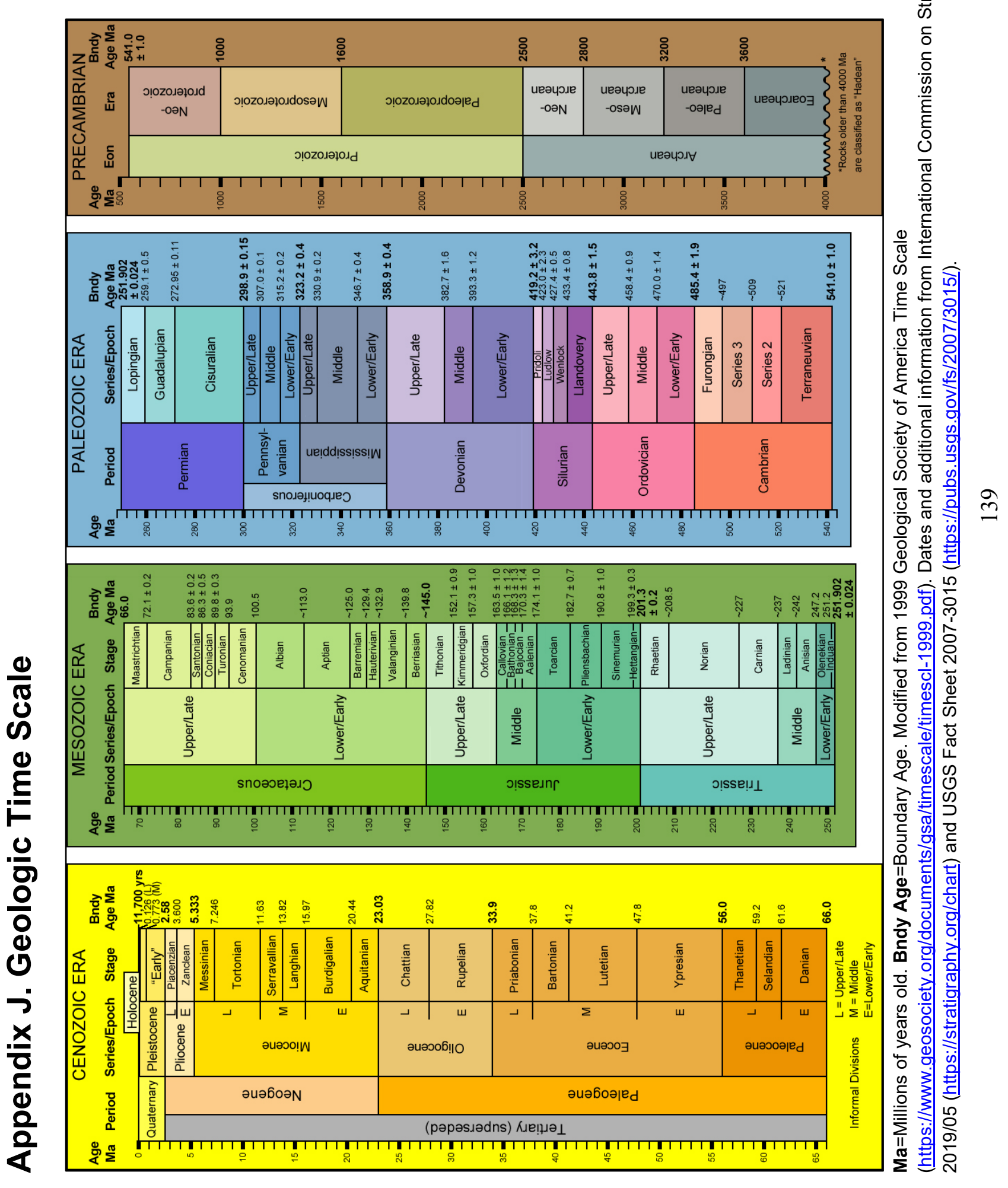



The Department of the Interior protects and manages the nation's natural resources and cultural heritage; provides scientific and other information about those resources; and honors its special responsibilities to American Indians, Alaska Natives, and affiliated Island Communities.

NPS 165/173719, September 2020 
National Park Service

U.S. Department of the Interior

Natural Resource Stewardship and Science

1201 Oakridge Drive, Suite 150

Fort Collins, CO 80525 